\title{
wiiw
}

\section{NOVEMBER 2021}

\section{Research Report 457}

\section{EU Employment Dynamics:}

\section{The Pandemic Years and Beyond}

Stefan Jestl and Robert Stehrer

The Vienna Institute for International Economic Studies

Wiener Institut für Internationale Wirtschaftsvergleiche

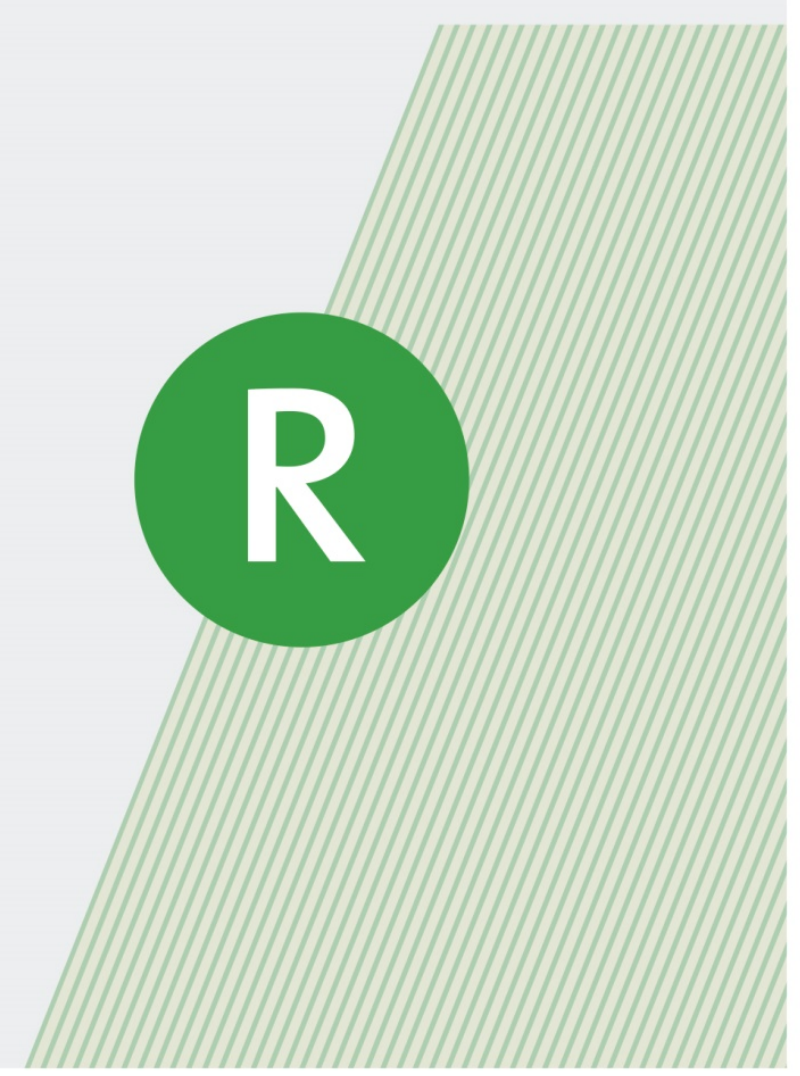





\title{
EU Employment Dynamics:
}

\section{The Pandemic Years and Beyond}

\author{
STEFAN JESTL
}

ROBERT STEHRER

Stefan Jestl is Economist at the Vienna Institute for International Economic Studies (wiiw). Robert Stehrer is Scientific Director at wiiw.

Support provided by ETUI for this research is gratefully acknowledged. This analysis has already been published as ETUI Working Paper 2021.09. 



\section{Executive summary}

The economic shock induced by the pandemic has plunged European economies into a recession. Lockdowns and social distancing measures have affected economic life in a substantial way, with industries and population groups facing varying difficulties. This study explores potential future employment dynamics across European industries and employment groups for the period up to 2026 by drawing on past sectoral trends and the latest macroeconomic forecast results from the International Monetary Fund (IMF) and the European Commission.

A scenario analysis is also carried out, taking into account the great uncertainty and risks that are related to the baseline forecasts. We consider four scenarios.

The 'baseline scenario' presumes a strong economic recovery in European countries from mid-2021 onwards. Some restrictions are expected to remain in place, but implemented only locally and seasonally. Vaccines will in general remain effective, including against mutants; however, a booster shot vaccine will be required every year. Therefore, although the virus will continue to exist in the longer run, it will be kept under control. The Recovery and Resilience Facility (RRF) is expected to trigger important economic impulses. Governments will not implement austerity policies (with harsh fiscal consolidation) in the years up to 2026, thus putting no pressure on the economic recovery.

The 'negative scenario' reflects the possible emergence of one or more mutations which will spread more quickly and have a higher death rate. Vaccines will remain somewhat effective against the mutants; however, vaccine hesitancy will limit the number of individuals being fully vaccinated. The tense epidemiological situation and the related pressure on healthcare systems will make it necessary to introduce various lockdowns, with significant repercussions for economic development. Moreover, this negative scenario implicitly presumes that the fiscal stimuli resulting from investments financed by the RRF will turn out to be less economically powerful.

The 'worst-case scenario' presumes the emergence of new, more infectious virus variants. In this scenario, however, these mutations will cause the virus to achieve an even higher death rate and spread even more quickly, partly by being resistant to current vaccines. Although over time new vaccines will be developed to work against the mutations, in the meantime many more people will die in Europe, and further harsh restrictions on economic life will be required. Right up until 2026, various 'lockdown' conditions will remain in place to try to prevent healthcare systems from being overwhelmed. The weak growth under this scenario also implies that the economic effects of the fiscal impulses will be only marginal. A strong focus on fiscal consolidation may further limit the fiscal space in European countries over time, hampering economic growth.

The 'more optimistic scenario' predicts an even stronger economic recovery in 2021 and 2022 compared to the baseline scenario, although with the same predicted growth for the 2023-2026 period. In this scenario, the pandemic is over, allowing for a strong rebound for the economy and businesses, with no significant future containment measures that could impact economic development. The spread of the 
Delta variant across European regions will not cause an increase in the hospitalisation rate and neither will it hinder economic recovery. The strong recovery will encourage confidence among private households, and they will significantly increase spending of their accumulated savings (even more than predicted in the baseline scenario).

The baseline scenario results indicate that in most countries employment is expected to reach its prepandemic level as early as 2021 or 2022, based on high projected gross domestic product (GDP) growth rates of up to $4 \%$ for those years, while hours worked will lag behind, catching up fully only in 2022 and 2023. Even though these predictions suggest a relatively quick recovery from the economic disturbance caused by the pandemic, these numbers are highly uncertain. Our scenario analysis indicates that the recovery of employment could in fact turn out to be rather sluggish. The more negative scenarios, moreover, predict only a limited recovery for persons employed and an incomplete recovery for hours worked, even by 2026.

The results further suggest that younger and low-skilled workers have been the hardest-hit population groups, with employment recovery expected to take longer for them as compared to other age and education groups. A more negative economic development, as suggested in certain scenarios, would put even more pressure on these employment groups.

These results hint at a number of valuable policy conclusions. First, in order for the labour market recovery to continue and strengthen, including in the most badly affected industries, overall economic growth needs to be strong. This means that fiscal and monetary policies need to be expansionary. It is vital that fiscal support be maintained in order to underpin a quick recovery to pre-crisis employment levels in conjunction with sustainable and strong growth. Fiscal support should not be indiscriminate but rather targeted at the most pressing short-term needs, as well as help to prepare EU economies for the most important future challenges, such as the climate crisis and digitalisation. A premature return to fiscal consolidation and harsh austerity - as happened after the global financial crisis in 2009 - would weaken the economic recovery. Our results suggest a pivotal role for RRF investments in the recovery of employment in many European economies.

Second, for the industries that have suffered the most from the pandemic and are still in danger should the Delta variant trigger a fourth wave of the virus, support schemes should remain in place or be quickly reactivated if necessary. This applies in particular to job retention programmes such as short-time work schemes.

Third, targeted policies are needed for segments of the labour market that have suffered the most and might also lag behind in the recovery phase. This includes, in particular, younger workers who have recently or are about to enter the labour market, and groups such as low-skilled workers and those who have lost jobs in heavily affected industries such as tourism. However, more help than just RRF spending will be needed, as failing to address these labour market challenges in the longer term is likely to fuel economic and social inequalities.

Finally, even though employment in terms of persons employed is generally currently recovering in EU countries (albeit less so in terms of hours worked), it might take a long time for it to reach its pre-crisis level. Policymakers need to pay particular attention to the long-term unemployed, as persistent unemployment often results in scarring effects that are harmful for economic development. Again, this 
will require a particular focus on certain age groups (e.g. older workers), regions (e.g. those most reliant on tourism), and workers lacking skills that are likely to be increasingly important in the post-pandemic world.

Keywords: EU employment dynamics, forecasts, pandemic, recovery

JEL classification: C53, J21 



\section{CONTENTS}

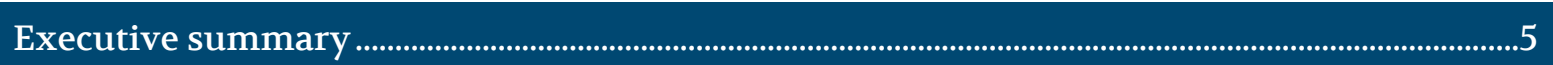

1. Introduction ......................................................................................................................................13

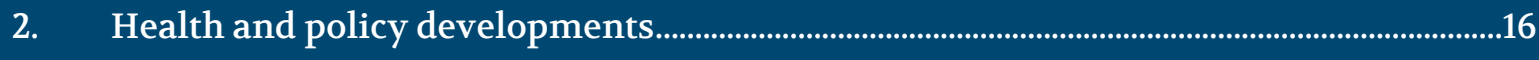

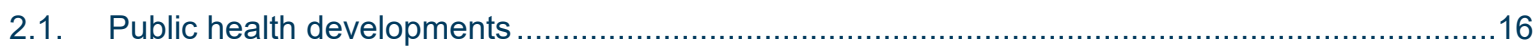

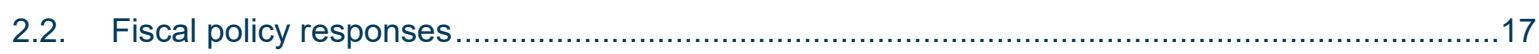

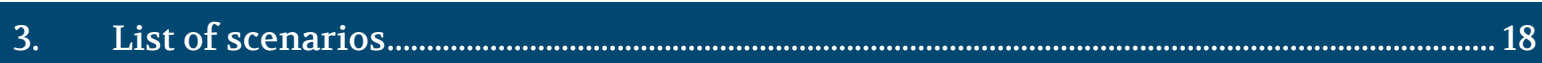

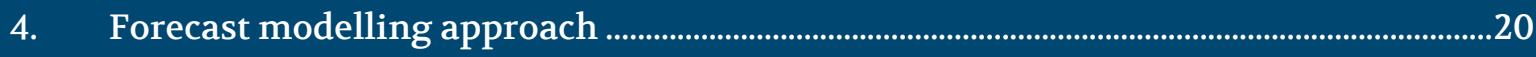

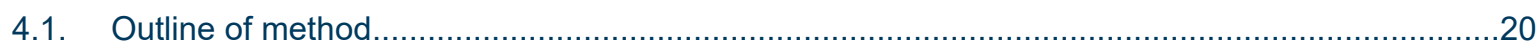

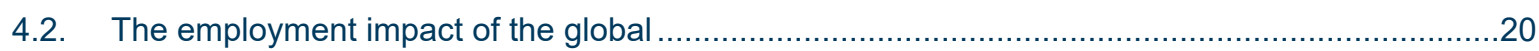

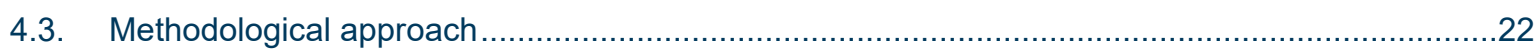

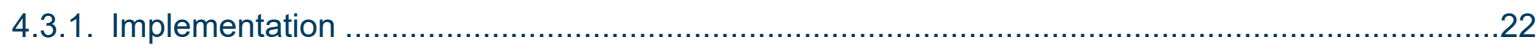

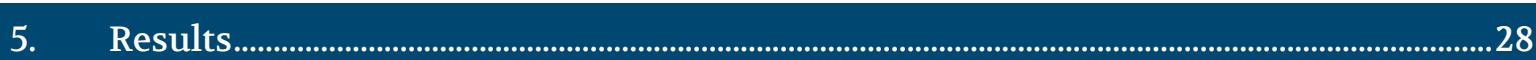

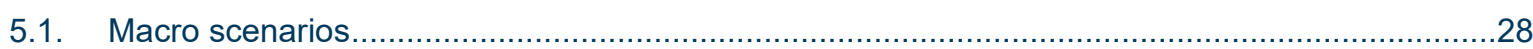

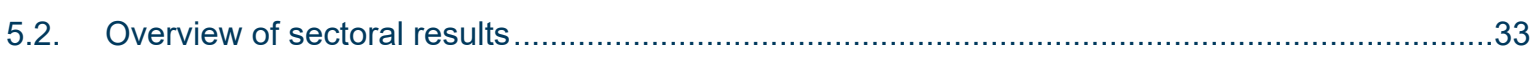

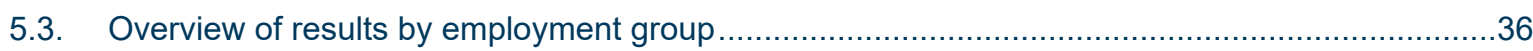

5.4. Special focus 1 : the impact of sluggish recovery in the tourism industry ....................................

5.5. Special focus 2: the role of fiscal measures and consolidation.................................................

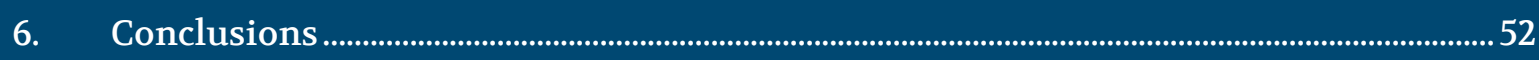

7. References............................................................................................................................................... 54

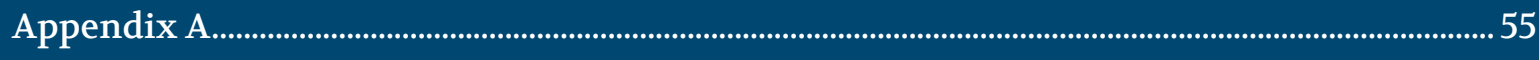

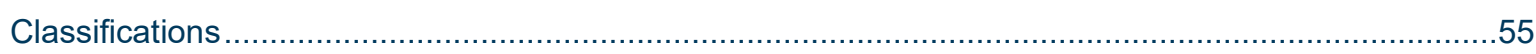

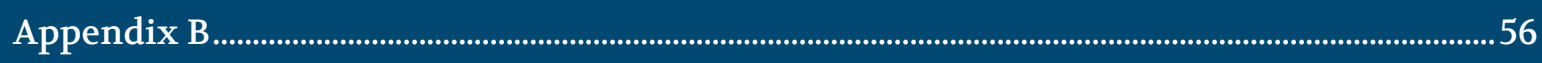

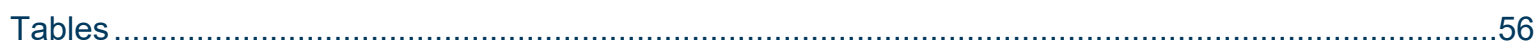




\section{TABLES AND FIGURES}

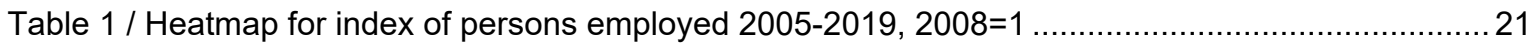

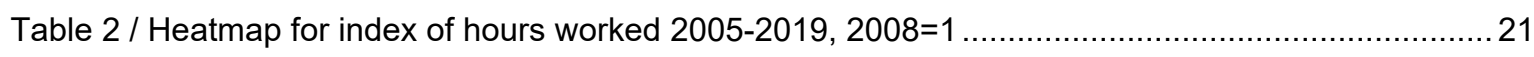

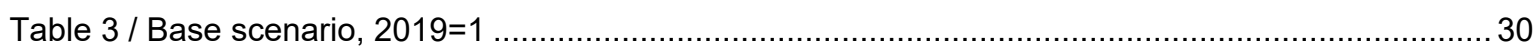

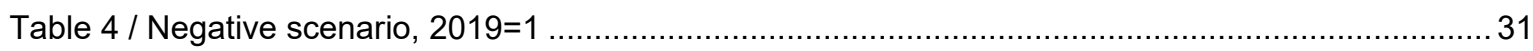

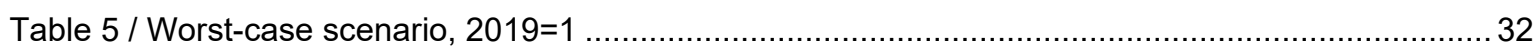

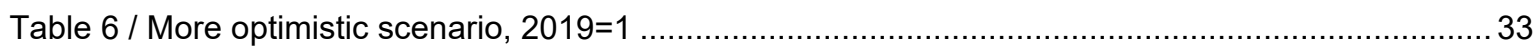

Table 7 / Employment dynamics by industry for EU27, 2019=1, baseline scenario ............................. 34

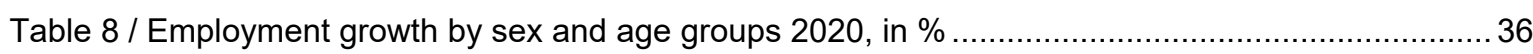

Table 9 / Employment growth by occupational groups 2020, in $\%$................................................ 37

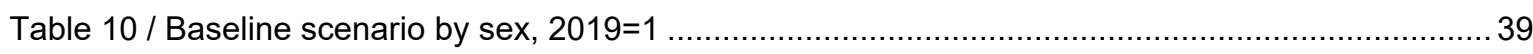

Table 11 / Baseline scenario by age groups, 2019=1 .......................................................... 41

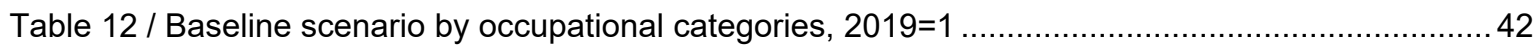

Table 13 / Employment growth by employment groups and scenarios for EU-27, 2019=1 ...............43

Table 14 / Employment growth and structures in tourism (industry I) ......................................... 44

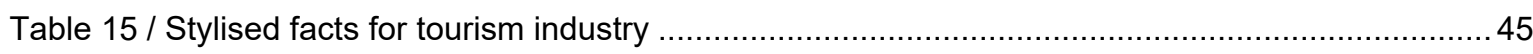

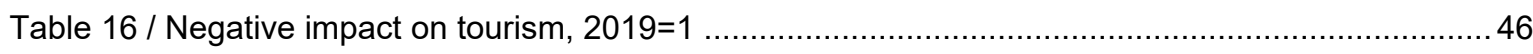

Table 17 / Impact of RFF on persons employed by industry ..................................................... 50

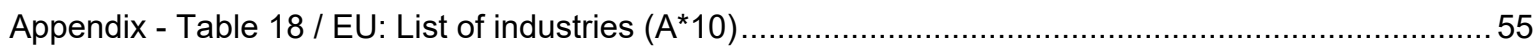

Appendix - Table 19 / EU Commission forecasts (Spring 2021, Summer 2021) ................................56

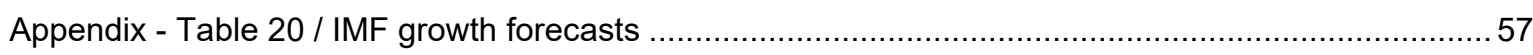

Appendix - Table 21 / Sectoral average annual value-added growth rates 2013-2019, in \% ................58

Appendix - Table 22 / Sectoral value-added shares 2019, in \% .....................................................59

Appendix - Table 23 / Average annual labour productivity growth rates based on persons employed 2013-2019, in \%.

Appendix - Table 24 / Average annual labour productivity growth rates based on hours worked 20132019 , in \%

Appendix - Table 25 / Average annual growth rates of persons employed 2013-2019, in \% ................62

Appendix - Table 26 / Average annual growth rates of hours worked 2013-2019, in \% .....................63

Appendix - Table 27 / Sectoral value-added growth rates 2020, in \% ...........................................6 64

Appendix - Table 28 / Sectoral nominal value-added shares 2020, in \%.........................................65

Appendix - Table 29 / Labour productivity growth rates (based on persons employed) in 2020, in \% ....66

Appendix - Table 30 / Labour productivity growth rates (based on hours worked) in 2020 ..................67

Appendix - Table 31 / Average annual growth rates of persons employed 2020, in \%.....................68

Appendix - Table 32 / Average annual growth rates of hours worked 2020, in \% ................................69

Appendix - Table 33 / Sectoral shares of persons employed 2019, in \%......................................... 70

Appendix - Table 34 / Sectoral shares of persons employed 2020, in \%....................................... 71

Appendix - Table 35 / Sectoral shares of hours worked 2019, in \% .............................................. 72

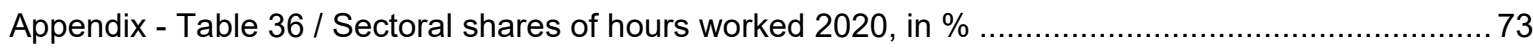


Figure 1 / Developments after the financial crisis in EU27 total economy.........................................20

Figure 2 / IMF and EU Commission GDP forecasts for EU27, in \% ............................................22

Figure 3 / Average annual value-added growth rates in EU27, 2013-2019 (in \%) ............................24

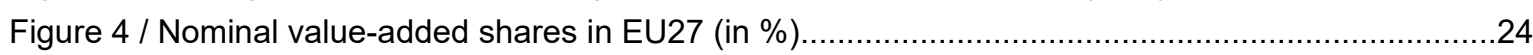

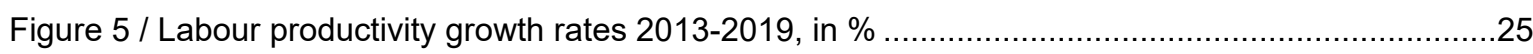

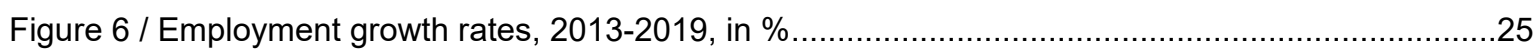

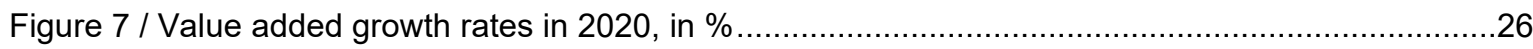

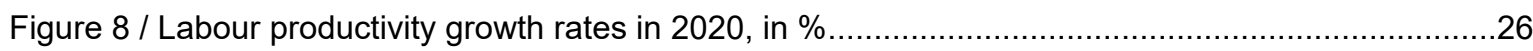

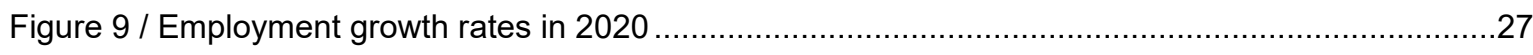

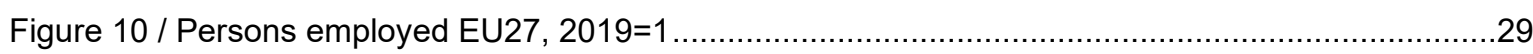

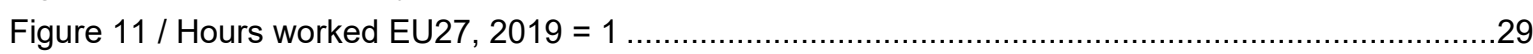

Figure 12 / Changes in persons employed 2026, deviation from index 2019=1, baseline scenario.........35

Figure 13 / Changes in hours worked 2026, deviation from index $2019=1$, baseline scenario ...............35

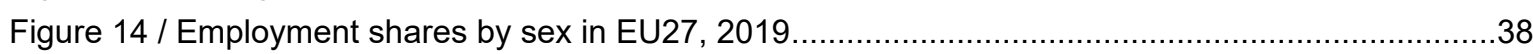

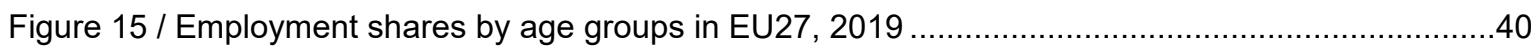

Figure 16 / Employment shares by occupational groups in EU27, 2019 .......................................40

Figure 17 / Effects of simultaneous change of government expenditure by $1 \%$ in all EU27 Member

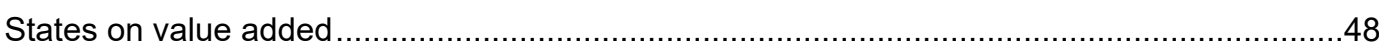

Figure 18 / Share of RFF spending (grants and loans) in \% of value added.....................................48

Figure 19 / Effects of RFF spending per year in all EU27 Member States on value added ...................49

Figure 20 / Effects of RFF spending per year in all EU27 Member States on employment ....................49

Figure 21 / Impact of RFF on persons employed by sex .......................................................... 51

Figure 22 / Impact of RFF on employment by age group ........................................................... 51

Figure 23 / Impact of RFF on employment by occupational group .............................................51 



\section{Introduction}

The Covid-19 pandemic has hit economies around the globe much harder than the global financial crisis did. According to the Organisation for Economic Co-operation and Development (OECD) (2021a), global GDP declined in 2020 by almost $5 \%$, whereas in 2009 the world economy 'only' (more or less) stagnated. The European Union (EU), in particular, experienced a severe economic contraction in 2020 of around 6\% (European Commission, 2021a); China, on the other hand, was the only large economy that experienced positive growth last year.

Since the outbreak of the pandemic, lockdowns and social distancing measures have forced employers to lay off their employees and/or to apply for short-time work schemes. Even though many European countries showed a boost in economic output in the third quarter of 2020, this rebound ran out of steam in the last months of the year. The resurgence of infections and the emergence of new variants of the virus forced national governments to introduce lockdown measures once again around the turn of the year. Problems and delays in the vaccine rollout programmes raised further concerns regarding the foreseeable end of the pandemic. These developments resulted in a downgrading of the economic outlook for the near term in the first European Economic Forecast of 2021 (European Commission, 2021a). However, stronger global growth and an accelerating vaccination campaign have helped to raise previously gloomy expectations in EU countries (European Commission, 2021b). Most recently, the reopening of advanced economies and the gradual easing of restrictions have resulted in a strong rebound in mobility and economic activity. As a result, the European Commission (2021c) and the IMF (2021b) revised up the economic growth numbers for 2021 and 2022 in their July 2021 forecasts. Nevertheless, these predictions are surrounded by great uncertainty and significant downside risks.

The negative consequences of the pandemic have been far from equal across countries, industries, and thus also different segments of the labour market. The total economy was affected at the onset of the pandemic, but industries have faced varying economic difficulties throughout the crisis. For example, while manufacturing industries experienced a solid recovery relatively quickly, service industries started to struggle again in the fourth quarter of 2020 (European Commission, 2021a), with the re-introduction of lockdown measures in October and November of that year causing the closure of many businesses. Tourism, meanwhile, which in some countries makes up a sizeable share of the economy, has been one of the most affected industries. Most European countries started to remove their stricter containment measures in April-May 2021. For this reason, economic activities (again, mostly in the service industries) experienced a boost in the second quarter of 2021. However, even though the tourism industry has started to recover somewhat, it is still lagging behind its pre-pandemic level (European Commission, 2021c).

A large number of empirical research indicates that the (short-term) labour market consequences of the pandemic have crucially hinged on the ability to work from home (e.g. Adams-Prassl et al., 2020; Dingel and Neimann, 2020). Individuals in industries and occupations with the possibility of teleworking tend to have a lower probability of facing job and earnings losses. Given the reduced ability to work remotely and the stronger exposure to social distancing measures, individuals in specific service industries (particularly contact-intensive services) have disproportionally been at risk of experiencing negative 
labour market effects. In contrast to the previous financial crisis, this particularly applies to women, due to their overrepresentation in these industries. Lockdowns and school closures also seem to have disproportionally affected the labour market outcomes of mothers (e.g. Heggeness, 2020), as women typically take over the major part of housework and childcare responsibilities. Empirical findings further point to severe pandemic-related labour market outcomes for vulnerable population groups, such as lower-educated and younger individuals, as well as individuals in precarious employment (e.g. OECD, 2021b; Eurofound, 2021). The strained labour market situation and the sluggish recovery until the second quarter of 2021 have put jobless individuals at risk of facing long-lasting scarring effects and of being trapped in unemployment for a longer time. The unequal labour market consequences threaten to persist in the post-pandemic period, which could eventually entrench existing inequalities within societies (OECD, 2021b).

The roll-out of unprecedented public support measures, however, has helped to dampen the negative economic and social effects of the pandemic. While the US has mostly focused on supporting incomes (via direct monetary transfers to households), European countries have put more emphasis on job retention (via transfers and support to companies). The centrepiece of the public support measures in Europe has been the launch of short-term work schemes. Throughout the pandemic, many companies have called on these programmes, which have helped to save many jobs and mitigate losses in household incomes. Even though the number of workers on furlough has dropped significantly since April 2020, a non-negligible number of workers still relies on short-time work schemes.

As a response to the crisis and to lend support to national government measures, the European Commission launched a large-scale recovery plan in January 2021. Together, the Multiannual Financial Framework for the period 2021-2027 and the newly introduced recovery fund Next Generation EU aim to provide large stimulus packages to foster an economic rebound and to support long-term prosperity. The Recovery and Resilience Facility (RRF), as the major instrument of the recovery fund, will provide financial resources for investment projects in the EU Member States. The green and digital transition in European countries will play a key role in investment projects as part of the recovery and resilience plans. Of the total expenditures, $37 \%$ must be devoted to green investments and reforms, and $20 \%$ to investments in the digital transition. This strong focus on the green and digital transitions conforms with the EU's long-term strategy, of which the European Green Deal (EGD) has been a key element since its presentation in 2019 (European Commission, 2019).

The level of government financial support during the pandemic has also already begun to fuel debates about the fiscal stance of European countries in the post-pandemic era. Some deem it necessary to pay more attention to fiscal consolidation in the years to come, despite its potential negative impact on economic recovery (Heimberger, 2017).

Given these various processes in play, it is of great importance for policymakers to be well-informed about the potential longer-term employment outcomes of the pandemic. In light of the great economic uncertainty and downside risks, the crafting of different scenarios can provide valuable insights into the range of possible employment outcomes. Possible heterogenous outcomes across employment groups over the course of the economic recovery can present further relevant information for defining targeted policy measures. What is clear is that a failure to address unequal labour market consequences is likely to fuel economic and social inequalities in the longer term (OECD, 2021b). Persistent unemployment often results in scarring effects that are harmful for economic development. 
This study explores the development of potential employment dynamics across European industries (in terms of persons employed and hours worked) and employment groups (in terms of persons employed) for the period up to 2026. We draw on past sectoral trends and use the latest macroeconomic forecast results taken from the IMF and the European Commission as our baseline. The calculations are based on a simple model framework. We model the recovery based on long-term value added and productivity growth patterns aligned to the macroeconomic forecasts. We then conduct a sensitivity analysis introducing both pessimistic and optimistic macroeconomic scenarios, which allows us to take into account the great uncertainty and risks that are related to the baseline forecasts. The crisis impact and the results of the scenarios are further split by employment group (sex, age and occupational category) to explore the heterogenous effects of the pandemic and the recovery patterns. The tourism industry, which has been hard hit by the crisis, is analysed in a separate section. Furthermore, the importance of fiscal policy measures and, specifically, the importance of RFF spending for employment is highlighted through the use of a global input-output analysis.

The study is structured as follows: Section 2 discusses our assumptions regarding health and fiscal policy developments; Section 3 presents our scenarios; Section 4 explains the applied modelling approach; Section 5 presents the results of the analysis; and, finally, Section 6 concludes. 


\section{Health and policy developments}

We will first discuss our main assumptions regarding developments in the pandemic and the fiscal policy response. An initial qualitative assessment will provide the basis for the quantitative investigation of employment dynamics via our modelling approach. Based on these assumptions, we then define four different scenarios, which are discussed in detail in Section 3.

\subsection{PUBLIC HEALTH DEVELOPMENTS}

The re-emergence of the virus by the end of 2020 forced national governments to once again impose lockdown measures. Problems in the vaccine rollout programmes and the possible resistance of the virus to vaccines have further spurred expectations of a prolonged 'non-normal' situation. However, vaccine programmes have accelerated over the past year and the obstacles at the beginning of the campaigns have since been effectively removed.

For the major global economies and the developed world in general it seems that the worst is now over, even if a full return to normal will not happen in 2021. A ramping up of vaccination efforts, along with better weather in the northern hemisphere, allowed a substantial easing of restrictions by late spring 2021. In the developed world, a large proportion of the adult population has now been vaccinated. The EU did not tackle the initial phase of the vaccine rollout well, but now seems to be getting its act together. Mass vaccination alone does not mean normal life, but it does mean something much closer to it. At least once a year, a required booster shot vaccine can be expected (similarly as with influenza) which might have to be adapted in the face of new mutations. Proof of vaccination and/or testing may continue to be necessary for access to indoor public spaces (and conceivably also on public transport) for some years, along with mask-wearing in certain contexts. Overall, containment measures are expected to remain but only at a marginal level. In the longer term, it is assumed that the pandemic will become like influenza, i.e. it will continue to exist but will be managed with updated vaccines each year.

The easing of restrictions and the reopening of European economies in the second quarter of 2021 have resulted in an economic boost that is expected to initiate the recovery phase, as reflected in the most recent European Economic Forecasts (European Commission, 2021c) and the last IMF World Economic Outlook Update (IMF, 2021b). Nevertheless, this prediction carries a high degree of uncertainty. It is actually unclear how the pandemic will develop in the next months and years. Even though the epidemiological situation was steadily improving, and the numbers of cases and hospitalisations had remained low for a while, European countries have more recently experienced the spread of the Delta variant. This highly contagious mutant has raised concerns about new outbreaks of the virus. As predicted (European Commission, 2021c), the Delta variant has become the dominant mutant. Its epidemiological repercussions crucially depend on the speed of full vaccination rollouts across European countries in the coming months, as only one dose of vaccine appears to be less effective against this variant. Vaccine hesitancy will remain a real problem, potentially hindering the objective of a high rate of full vaccination. The emergence of other variants, against which the effectiveness of available vaccines remains uncertain, represents a further serious downside risk. 


\subsection{FISCAL POLICY RESPONSES}

The suspension of EU fiscal rules (which ostensibly require a 'structural' fiscal deficit not exceeding $0.5 \%$ of GDP and public debt to be below $60 \%$ of GDP) in response to the pandemic has facilitated the rollout of unprecedented public measures to support businesses, protect jobs and provide household income replacement. The cornerstone of these measures has been the subsidised short-time work (STW) schemes. Such schemes have been implemented in all EU Member States (albeit with various degrees of subsidisation), facilitated in some cases by allocations from the EU Recovery Assistance for Cohesion and the Territories of Europe (REACT-EU) facility, worth EUR 47.5 billion (bn).

REACT-EU is part of the established Next Generation EU (NGEU) recovery fund, which is financed via debt creation at the EU level. The NGEU has a total of EUR 750 bn to be distributed in 2021-2023 and is also aimed at fostering structural reforms, above all by financing green and digital investments. Within the NGEU, of central importance is the Recovery and Resilience Facility (RRF), through which a total of EUR 672.5 bn are set to flow throughout the EU, including EUR 312.5 bn in the form of grants and EUR 360 bn in loans. Of total expenditures, 37\% must be devoted to green investments and reforms and $20 \%$ to investments in the digital transition. The RRF stipulates fixed allocations per Member State but requires them to submit national 'recovery and resilience plans', which should state the reform plans and public investment projects that are to be implemented by 2026 as well as address the country-specific recommendations of the European Commission. National recovery and resilience plans have already been submitted and assessed by the Commission; following approval by the European Council, the EU will start to pay out financial support. ${ }^{1}$

The European Economic Forecast factors in a considerable positive economic impulse generated by the RRF through private and public investments. The European Commission (2021b, 2021c) predicts a total economic growth of around 1.2\% of 2019 EU real GDP over the period 2021 and 2022. The IMF's World Economic Outlook (IMF, 2021a, 2021b) also incorporates the expected economic effects of the RRF between now and 2026. The IMF additionally accounts for large fiscal support in the US, which is expected to have important economic spillovers for EU economies. Against the backdrop of the activation of the RRF and the prolonged suspension of the fiscal rules until $2023^{2}$, the European Commission and the IMF expect the fiscal stance in European countries to remain supportive in 2021 and 2022, and thus no harsh austerity impact in later years. ${ }^{3}$

However, there have also been calls for a gradual reduction of government support measures as well as debates on the possibility of paying back public debt. Even though the RRF will support national public investment programmes, fiscal consolidation at the national level might re-emerge, which would eventually limit fiscal support in the post-pandemic years. The IMF (2021b) also sees the downside risk that the effects of the fiscal impulses may be weaker than predicted.

\footnotetext{
https://ec.europa.eu/info/business-economy-euro/recovery-coronavirus/recovery-and-resilience-facility en

https://ec.europa.eu/commission/presscorner/detail/en/qanda 21885

3 There have been intense discussions about reforming the EU fiscal rules (e.g. Blanchard et al., 2021; Martin et al., 2021), which, accordingly, may never resume their pre-pandemic form and may allow more fiscal space in their adapted version.
} 


\section{List of scenarios}

This study aims to present detailed insights into employment dynamics across industries and population subgroups in European countries up until 2026. As there is a considerable degree of uncertainty and risk at the moment, it is important to analyse possible heterogenous employment outcomes. We consider a set of four different scenarios for our predictions: first the baseline scenario; and then, in order to provide a sensitivity analysis of the results, a negative scenario, a worst-case scenario and a more optimistic scenario.

\section{Baseline scenario}

We take our baseline projections for growth in countries from the IMF World Economic Outlook of July 2021, which has projections up until 2026, and also from the European Economic Forecast of April 2021. Accordingly, the baseline scenario presumes a strong economic recovery in European countries from mid-2021 onwards. Some restrictions are expected to remain in place, but implemented only locally and seasonally. Vaccines will in general remain effective, including against mutants; however, a booster shot vaccine will be required every year. Therefore, although the virus will continue to exist in the longer run, it will be kept under control.

The RRF is expected to trigger important economic impulses. Governments will not implement austerity policies (with harsh fiscal consolidation) in the years up to 2026, thus putting no pressure on the economic recovery.

\section{Negative scenario}

The projections in the baseline scenario come with uncertainty and downside risks (IMF, 2021b; European Commission, 2021b, 2021c). Chatterjee and Nowak (2016) analysed the structure of forecast errors in IMF World Economic Forecasts over time and point to a considerable size of pessimistic forecast errors. In order to explore the potential employment effects of the large downside risks, we assume GDP growth in European countries to be 1 percentage point (pp) lower in 2021 and 2022, 0.75 pp lower in 2023, and 0.50 pp lower in 2024, compared to the baseline. These downward adjustments principally correspond to the negative forecast scenario provided by the OECD (2021a) for global growth and are also in line with the downside scenario presented by the IMF (2021b).

The negative scenario reflects the possible emergence of one or more mutations which will spread more quickly and have a higher death rate. Vaccines will remain somewhat effective against the mutants; however, vaccine hesitancy will limit the number of individuals being fully vaccinated. The tense epidemiological situation and the related pressure on healthcare systems will make it necessary to introduce various lockdowns, with significant repercussions for economic development. Moreover, this negative scenario implicitly presumes that the fiscal stimuli resulting from investments financed by the RRF will turn out to be less economically powerful. A detailed discussion on fiscal policy and the effects of the RRF is presented in Section 5.5. 


\section{Worst-case scenario}

In order to shed more light on the downside risks, we implement a further negative scenario that considers an even worse economic situation. In this scenario, GDP growth in European countries is expected to be 2 pp lower in 2021 and 2022, 1.5 pp lower in 2023, and 1 pp lower in 2024 compared to the baseline. This tremendous economic damage can be considered the worst-case scenario.

As in the first negative scenario, this scenario presumes the emergence of new, more infectious virus variants. In this scenario, however, these mutations will cause the virus to achieve an even higher death rate and spread even more quickly, partly by being resistant to current vaccines. Although over time new vaccines will be developed to work against the mutations, in the meantime many more people will die in Europe, and further harsh restrictions on economic life will be required. Right up until 2026, various 'lockdown' conditions will remain in place to try to prevent healthcare systems from being overwhelmed. The weak growth under this scenario also implies that the economic effects of the fiscal impulses will be only marginal. A strong focus on fiscal consolidation may further limit the fiscal space in European countries over time, hampering economic growth.

\section{More optimistic scenario}

The reopening of EU economies, due to the lifting of containment measures, has caused an economic boost that has been stronger than previously expected (European Commission, 2021c). This has resulted in an upward revision of growth predictions (in particular for 2021) for EU economies in the most recent European Economic Forecast. As these numbers represent the upper bound of projected growth for European economies, we consider a more optimistic scenario which reflects the numbers of the latest European Economic Forecast (Summer 2021) for 2021 and 2022.

This scenario predicts an even stronger economic recovery in 2021 and 2022 compared to the baseline scenario, although with the same predicted growth for the 2023-2026 period. In this scenario, the pandemic is over, allowing for a strong rebound for the economy and businesses, with no significant future containment measures that could impact economic development. The spread of the Delta variant across European regions will not cause an increase in the hospitalisation rate and neither will it hinder economic recovery. The strong recovery will encourage confidence among private households, and they will significantly increase spending of their accumulated savings (even more than predicted in the baseline scenario). 


\section{Forecast modelling approach}

\subsection{OUTLINE OF METHOD}

Given the high degree of uncertainty regarding the potential outcomes of the most severe crisis in Europe since the Second World War, it is difficult to foresee how employment dynamics will play out over the next years. In fact, even the current macroeconomic forecasts can be better described as a scenario. Standard economic models are not particularly suitable for providing scenarios at the detailed levels of industry or employment group, or for the impact of various policy actions. Therefore, we opt for a simple approach. We take macroeconomic forecasts (i.e. GDP growth rate forecasts) or scenarios as provided by various institutions, such as the European Commission or the IMF, and calculate potential sectoral outcomes based on historic trends. Specifically, we assume that after the pandemic shock, the industry-level growth dynamics that emerged following the global financial crisis will return. This is technically explained in Section 4.3.

\subsection{THE EMPLOYMENT IMPACT OF THE GLOBAL}

Although the pandemic has induced an economic crisis that has distinct characteristics, it is informative to look at the employment dynamics following the global financial crisis of 2009. The developments in the EU27 regarding 'value added', 'persons employed', and 'hours worked' (as a proxy for overall labour demand) are presented in Figure 1 over the period 2005-2019. As can be seen, although value added recovered around 2014 to the level of 2008, it took much longer for persons employed (around 2016) and hours worked (around 2018) to reach the levels of 2008. ${ }^{4}$ Tables 1 and 2 provide corresponding information by EU Member State.

Figure 1 / Developments after the financial crisis in EU27 total economy

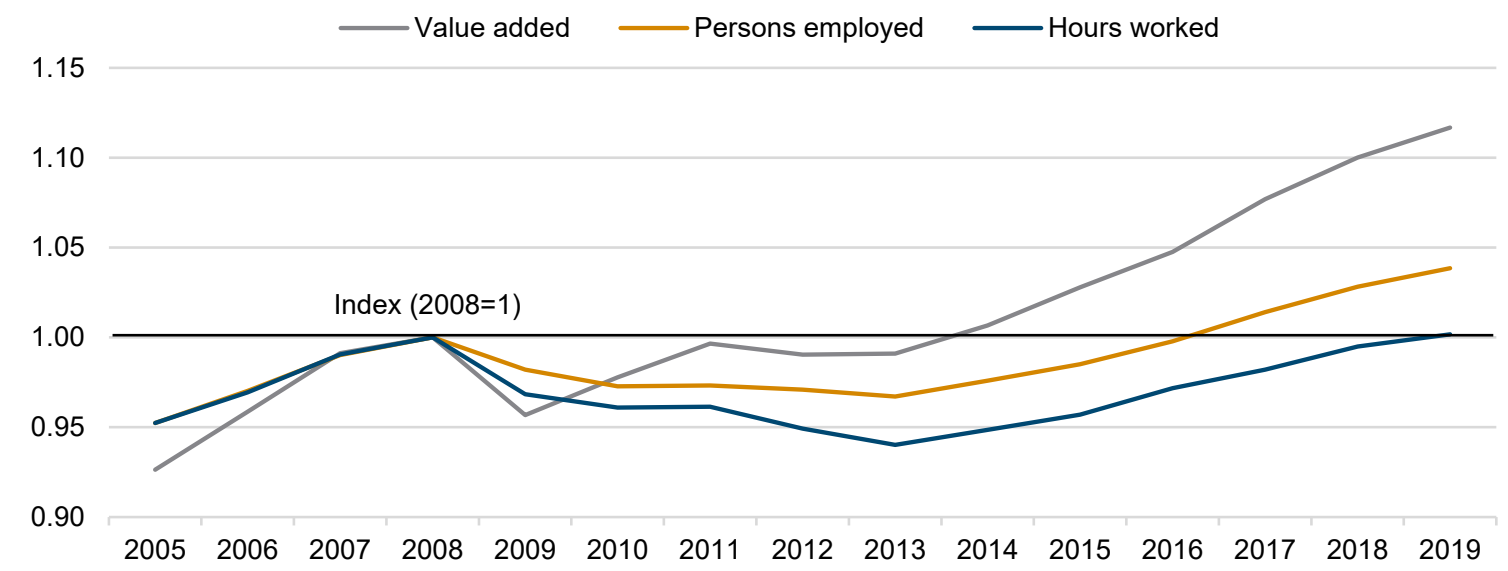

Source: Eurostat, own calculations.

4 Similar patterns are found at the industry level, though of course with differentiated dynamics. 
Table 1 / Heatmap for index of persons employed 2005-2019, 2008=1

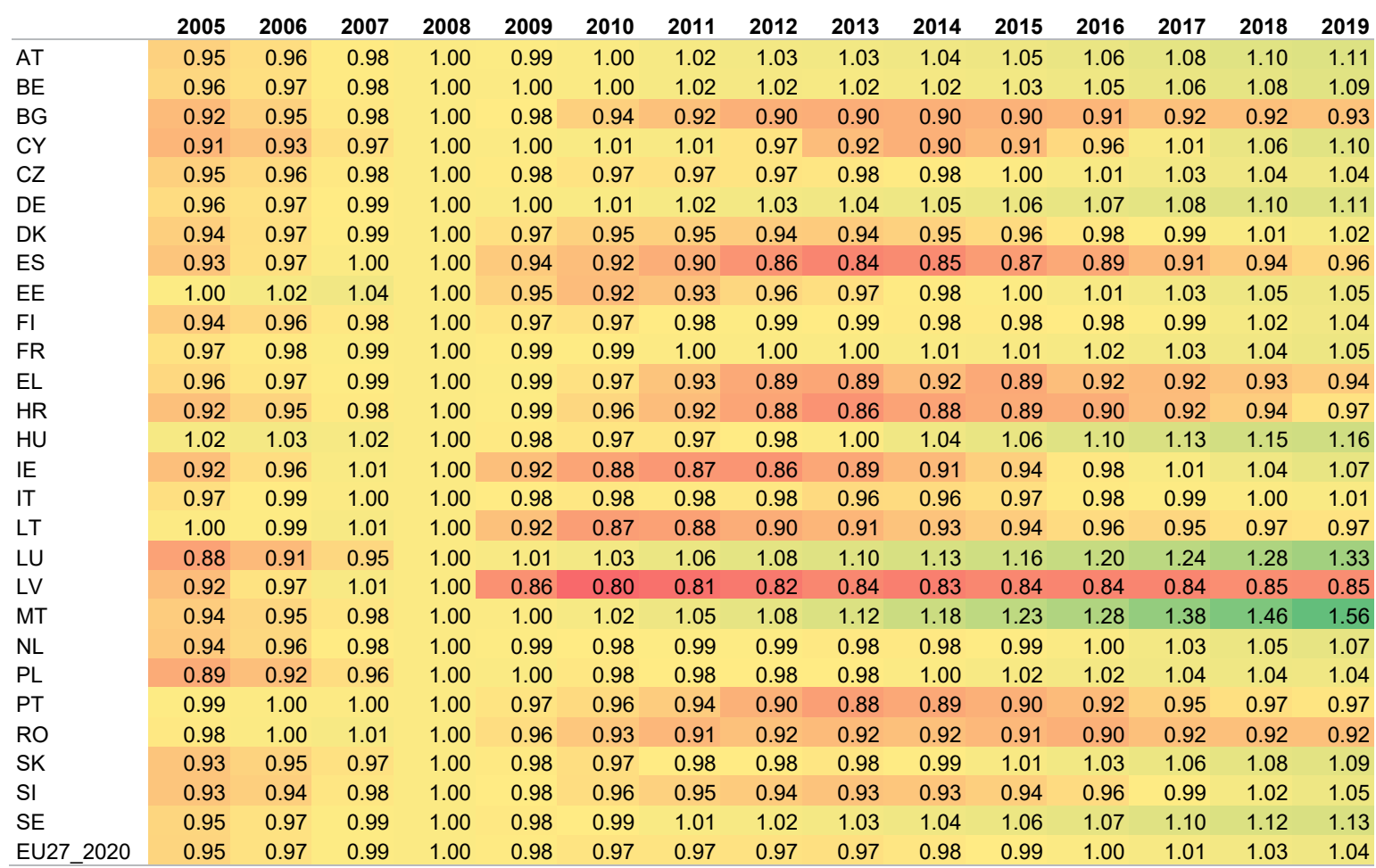

Source: Eurostat, own calculations.

Table 2 / Heatmap for index of hours worked 2005-2019, 2008=1

\begin{tabular}{|c|c|c|c|c|c|c|c|c|c|c|c|c|c|c|c|}
\hline & 2005 & 2006 & 2007 & 2008 & 2009 & 2010 & 2011 & 2012 & 2013 & 2014 & 2015 & 2016 & 2017 & 2018 & 2019 \\
\hline BG & 0.90 & 0.92 & 0.95 & 1.00 & 0.96 & 0.92 & 0.90 & 0.87 & 0.87 & 0.87 & 0.88 & 0.88 & 0.90 & 0.90 & 0.90 \\
\hline$C Z$ & 0.95 & 0.96 & 0.97 & 1.00 & 0.98 & 0.98 & 0.98 & 0.97 & 0.96 & 0.97 & 0.97 & 1.00 & 1.02 & 1.04 & 1.04 \\
\hline DE & 0.95 & 0.97 & 0.99 & 1.00 & 0.97 & 0.99 & 1.00 & 1.00 & 1.00 & 1.01 & 1.02 & 1.03 & 1.04 & 1.05 & 1.06 \\
\hline DK & 0.96 & 0.98 & 0.99 & 1.00 & 0.96 & 0.94 & 0.95 & 0.93 & 0.94 & 0.94 & 0.94 & 0.96 & 0.97 & 0.97 & 0.98 \\
\hline $\mathrm{FI}$ & 0.95 & 0.96 & 0.98 & 1.00 & 0.96 & 0.96 & 0.97 & 0.97 & 0.96 & 0.95 & 0.95 & 0.96 & 0.96 & 0.99 & 1.00 \\
\hline FR & 0.96 & 0.96 & 0.99 & 1.00 & 0.98 & 0.99 & 1.00 & 1.00 & 0.99 & 0.99 & 0.99 & 1.00 & 1.00 & 1.02 & 1.03 \\
\hline EL & 0.97 & 0.98 & 0.99 & 1.00 & 0.98 & 0.94 & 0.91 & 0.89 & 0.89 & 0.90 & 0.86 & 0.90 & 0.89 & 0.91 & 0.90 \\
\hline HR & 0.92 & 0.95 & 0.98 & 1.00 & 0.99 & 0.96 & 0.92 & 0.88 & 0.85 & 0.86 & 0.85 & 0.85 & 0.87 & 0.88 & 0.92 \\
\hline HU & 1.04 & 1.04 & 1.02 & 1.00 & 0.96 & 0.96 & 0.95 & 0.95 & 0.96 & 1.02 & 1.04 & 1.08 & 1.10 & 1.11 & 1.12 \\
\hline LV & 0.87 & 0.93 & 0.95 & 1.00 & 0.84 & 0.77 & 0.79 & 0.80 & 0.81 & 0.80 & 0.80 & 0.80 & 0.79 & 0.81 & 0.79 \\
\hline MT & 0.93 & 0.95 & 0.97 & 1.00 & 1.00 & 0.99 & 0.99 & 1.00 & 1.03 & 1.06 & 1.10 & 1.19 & 1.24 & 1.33 & 1.44 \\
\hline NL & 0.94 & 0.96 & 0.98 & 1.00 & 0.99 & 0.98 & 0.99 & 0.98 & 0.97 & 0.98 & 0.99 & 1.01 & 1.03 & 1.06 & 1.08 \\
\hline$P L$ & 0.90 & 0.93 & 0.97 & 1.00 & 1.00 & 0.97 & 0.97 & 0.97 & 0.97 & 0.99 & 1.01 & 1.01 & 1.02 & 1.01 & 1.00 \\
\hline PT & 1.00 & 0.99 & 1.00 & 1.00 & 0.97 & 0.96 & 0.93 & 0.88 & 0.86 & 0.88 & 0.90 & 0.91 & 0.94 & 0.96 & 0.98 \\
\hline RO & 1.00 & 1.00 & 1.02 & 1.00 & 0.95 & 0.94 & 0.92 & 0.91 & 0.90 & 0.90 & 0.89 & 0.89 & 0.90 & 0.90 & 0.90 \\
\hline SK & 0.92 & 0.94 & 0.97 & 1.00 & 0.97 & 0.97 & 0.98 & 0.98 & 0.96 & 0.97 & 0.99 & 1.00 & 1.01 & 1.02 & 1.03 \\
\hline SI & 0.94 & 0.94 & 0.96 & 1.00 & 0.99 & 0.97 & 0.94 & 0.92 & 0.92 & 0.94 & 0.95 & 0.95 & 0.96 & 0.98 & 1.00 \\
\hline SE & 0.94 & 0.96 & 0.99 & 1.00 & 0.97 & 0.99 & 1.02 & 1.02 & 1.02 & 1.03 & 1.05 & 1.08 & 1.10 & 1.11 & 1.11 \\
\hline EU27_2020 & 0.95 & 0.97 & 0.99 & 1.00 & 0.97 & 0.96 & 0.96 & 0.95 & 0.94 & 0.95 & 0.96 & 0.97 & 0.98 & 0.99 & 1.00 \\
\hline
\end{tabular}

Source: Eurostat, own calculations. 
Focusing on employment, Tables 1 and 2 present the index of persons employed and hours worked (2008=1) for each EU Member State. Interestingly, in 2019 almost a third of EU economies had still not reached the employment levels of 2008. In contrast, other EU countries show significantly higher employment levels than before the global financial crisis.

\subsection{METHODOLOGICAL APPROACH}

The employment developments described above are largely driven by overall macroeconomic growth performance in conjunction with sectoral growth and labour productivity dynamics. These dynamics are used to model the impact of the pandemic. In this section we introduce the methodology and the underlying assumptions. We show these at the EU27 level and provide country-specific information in the Appendix.

\subsubsection{Implementation}

\section{Macroeconomic growth rates}

Our approach, as explained in the technical outline, is implemented in the following way. First, we take GDP growth rates for the crisis year 2020 and the following years up to 2022. Appendix Table 18 reports the growth rates for EU27 Member States (and others) from the European Commission Spring Forecast (European Commission, 2021b) ${ }^{5}$, including growth rates from the pre-pandemic period. Since GDP predictions in the European Economic Forecast are only available for 2021 and 2022, we draw on predictions from the IMF for the period 2023-2026. Appendix Table 19 displays information from the World Economic Forecast (IMF, 2021a) for the EU Member States. For illustrative purposes, Figure 2 shows the annual (predicated) GDP growth rates for the EU27. Accordingly, the deep recession in 2020 is followed by high growth rates of above $4 \%$ which, however, come down to around $2 \%$ and below from 2023 onwards.

\section{Figure 2 / IMF and EU Commission GDP forecasts for EU27, in \%}

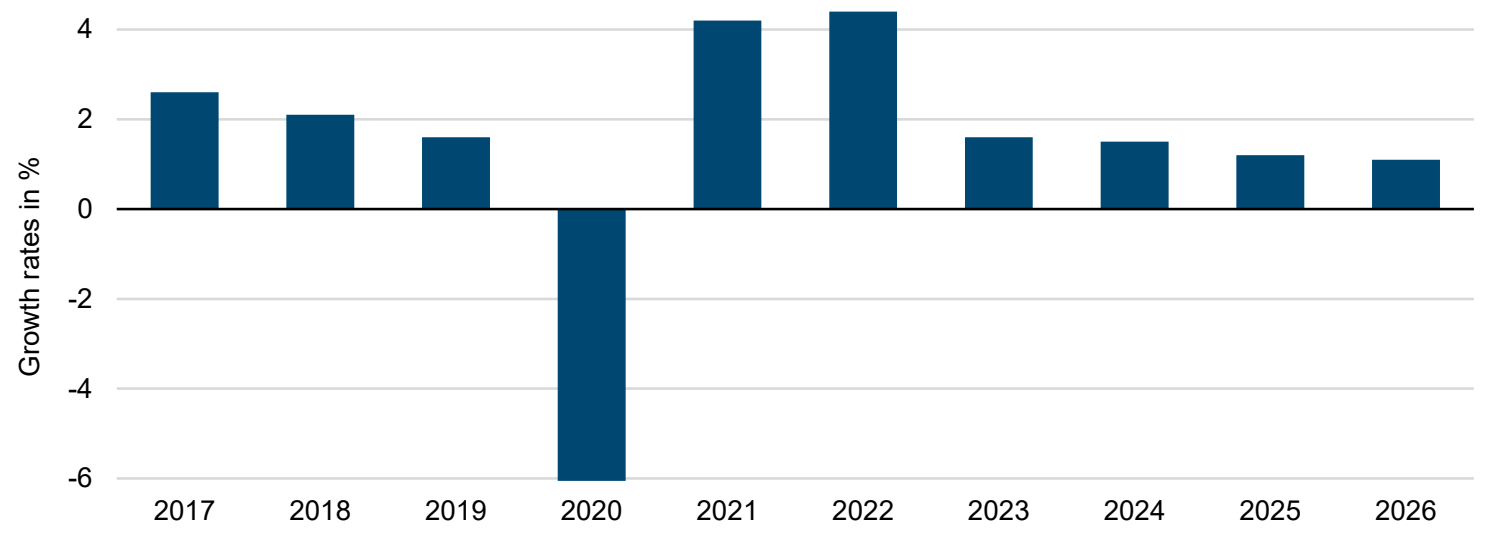

Source: EC (2021); IMF (2021) for years 2023-2026; own calculations. 


\section{TECHNICAL OUTLINE}

The starting point of the calculations are the GDP forecasts provided by the European Commission and the IMF. Unfortunately, these forecasts do not provide a sectoral breakdown. Furthermore, while they are already quite uncertain, the sectoral forecasts would be even more so. We therefore opt for an approach in which our baseline scenario assumes that the sectoral growth pattern from the period before 2020 will re-emerge in the years after the crisis, and thus adapt sectoral growth rates in such a way that these correspond to the GDP growth forecasts. Consequently, we implicitly assume that there will be no significant shifts in sectoral growth rates and productivity performance in the upcoming years. We discuss sector-specific developments for the tourism industry in Section 5.4. Formally, we denote the forecasted GDP growth rate by $g_{G D P, t}$. From historic data, we obtain sectoral value-added growth rates (e.g. averages over a certain period), as captured by $\bar{g}_{i}$ (for industry I), and (nominal) sectoral shares, denoted by $\bar{s}_{i}$ (also averaged over the specified period). The overall growth rate is then denoted by:

$$
\bar{g}=\sum_{i} \bar{s}_{i} \bar{g}_{i}
$$

To derive the growth rates for a specific year (t), with the growth forecast given by $g_{G D P, t}$, we rescale the growth rates $\bar{g}_{i}$ by ratio $g_{G D P, t} / \bar{g}$ which results in:

$$
g_{G D P, t}=\sum_{i} \bar{s}_{i} \widehat{g}_{\mathrm{tt}}
$$

Where $\widehat{g}_{1}$ is the rescaled industry-level value-added growth rate. ${ }^{*}$

Furthermore, using long-term growth rates on labour productivity by industry (either in terms of persons employed or hours worked) - denoted by $\bar{\varphi}_{i}$ - allows us to calculate the associated employment growth rates (in terms of persons employed or hours worked) for the coming years, denoted by:

$$
\widehat{e_{1 \mathrm{t}}}=\widehat{g_{\mathrm{lt}}}-\bar{\varphi}_{i}
$$

Using these growth rates one can translate them into the evolvement of numbers of persons employed or hours worked.

The different dynamics of persons employed and hours worked reflect changes in working-time arrangements (e.g. the share of part-time employed, temporary contracts, short-time working arrangements, etc.). When considering the different dynamics of persons employed and hours worked, it is implicitly assumed that working-time arrangements (e.g. short-time working scheme arrangements) that prevailed in the crisis year 2020 also persist in the post-pandemic period. Therefore, growth rates in terms of persons employed for the period after the crisis might be too optimistic, as changes in workingtime arrangements (e.g. a withdrawal of short-time working scheme arrangements) are expected to lower the numbers of persons employed.

* In cases where the signs of $\bar{g}$ and $\bar{g}_{i}$ differ, further assumptions are made. 
Wiiw Research Report 457

Industry-level information on long-run trends before the crisis (2012-2019)

As further outlined in Section 4.3.1, the macro-growth rates need to be broken down into industry-level growth rates. For this, we need data on sectoral growth rates in real terms (i.e. chain-linked volumes) and (nominal) value-added shares. Data on longer-term developments for EU Member States (and some other European countries) are available from National Accounts, allowing us to calculate valueadded growth rates at the level of the A10 industry classification (see Annex I). For the longer run, data for the period 2012-2019 are used, from which average annual growth rates are calculated for value added and productivity (for persons employed and hours worked). The value-added growth rates for the EU27 are presented in Figure 3 and range from $4.5 \%$ in industry $\mathrm{J}$ (information and communication) to less than $0.5 \%$ in industries $\mathrm{F}$ (construction) and $\mathrm{K}$ (financial and insurance activities). Nominal value added shares for 2019 and 2020 are reported in Figure 4. Similarly, labour productivity growth rates (on a value-added basis) are calculated as long-run averages (2012-2019) both for persons employed and hours worked, as presented in Figure 5. Finally, the corresponding labour demand growth rates are presented in Figure 6. Country- and industry-specific results are presented in Appendix B.

Figure 3 / Average annual value-added growth rates in EU27, 2013-2019 (in \%)

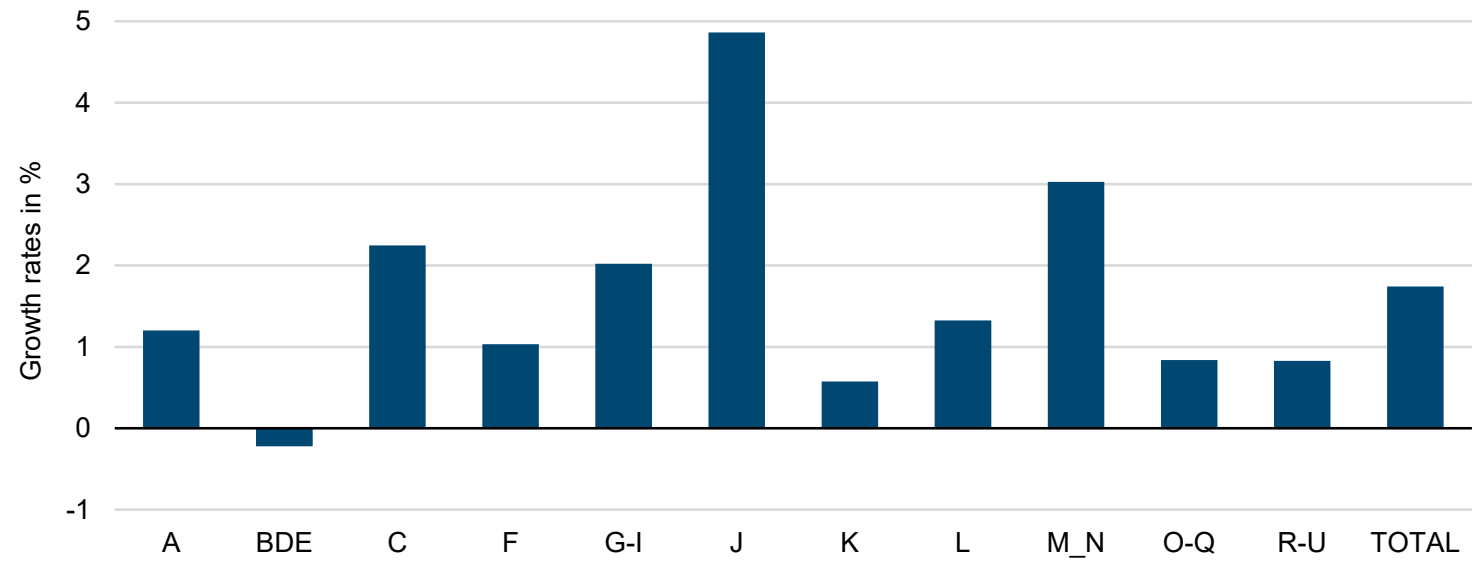

Source: Eurostat, own calculations.

Figure 4 / Nominal value-added shares in EU27 (in \%)

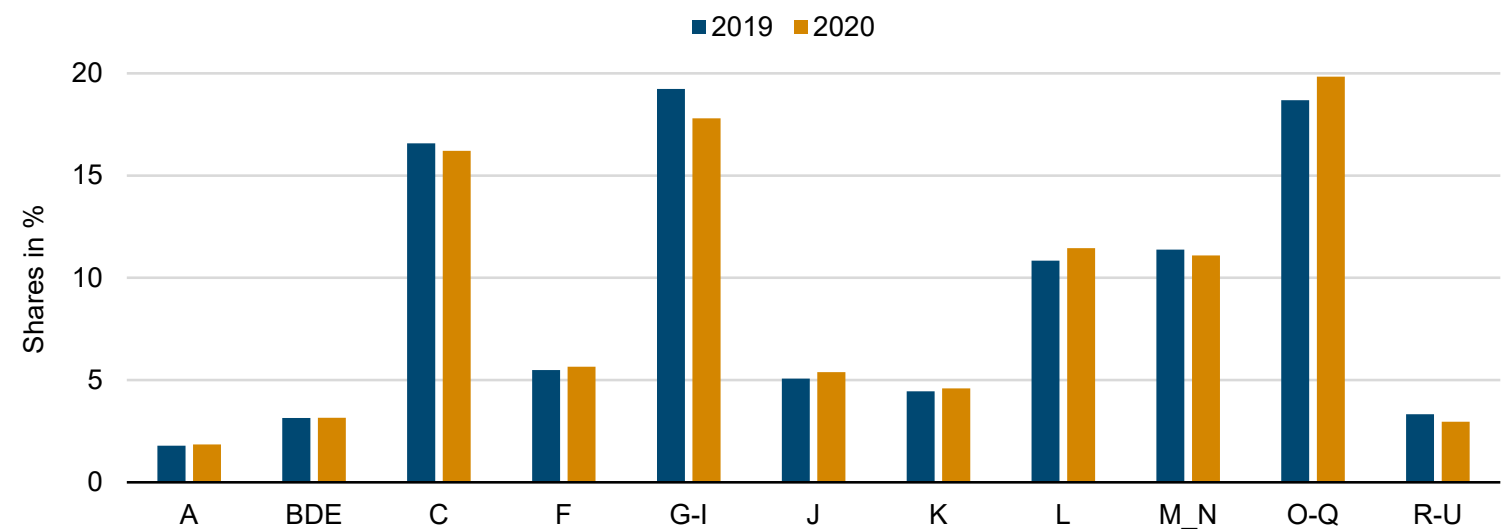

Source: Eurostat, own calculations 
Figure 5 / Labour productivity growth rates 2013-2019, in \%

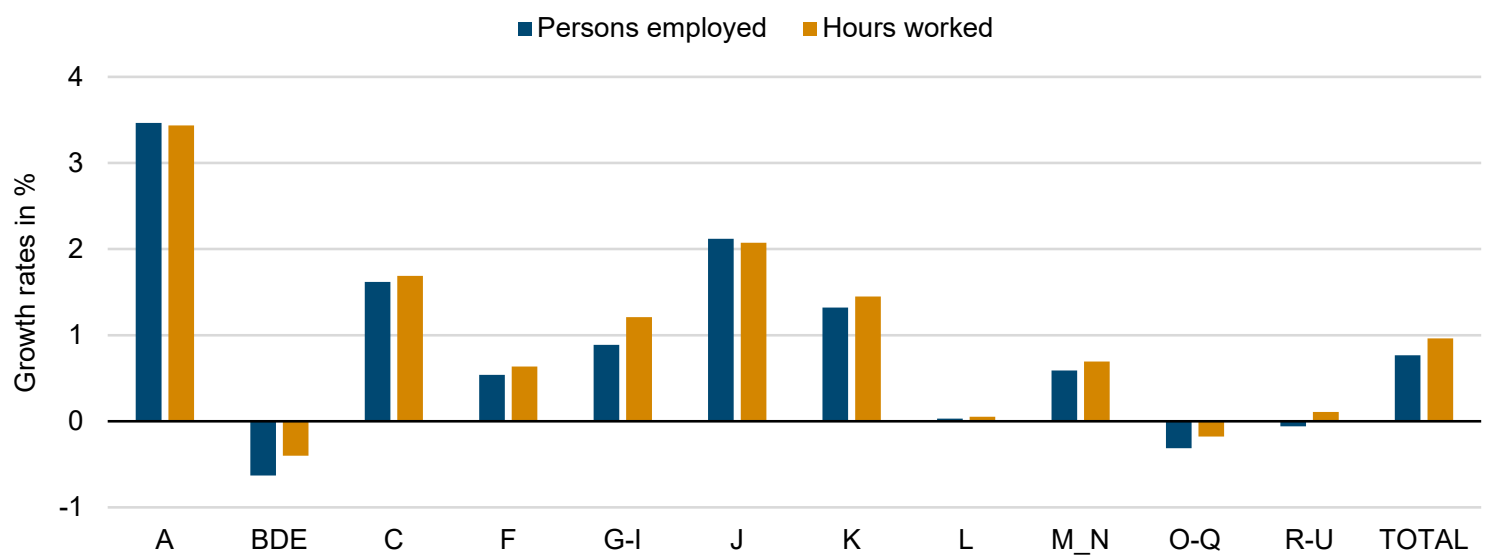

Source: Eurostat, own calculations.

Figure 6 / Employment growth rates, 2013-2019, in \%

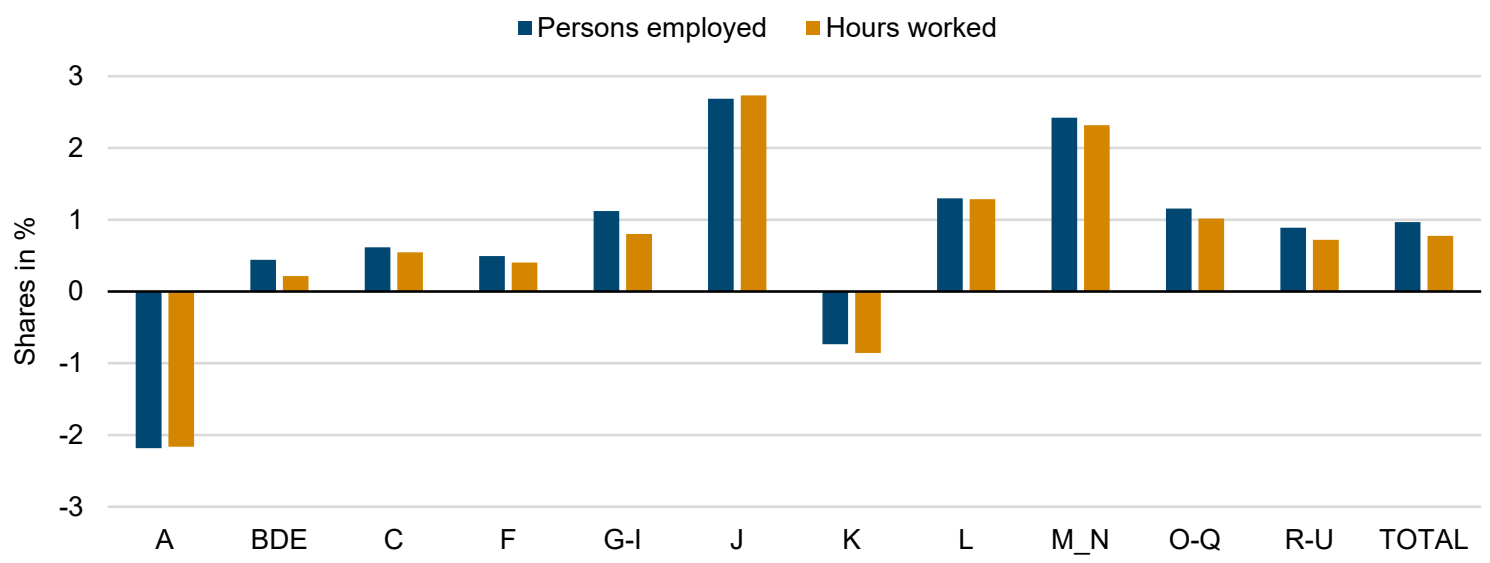

Source: Eurostat, own calculations.

Industry-level growth rates in the crisis year 2020

For the crisis year 2020, data at the A10 industry level are also available from Eurostat. Figure 7 presents the value-added growth rates by industry in 2020 . The crisis has unequally affected industries in European economies. Strong declines are reported for other services (R-U), as well as for wholesale and retail trade, transportation and storage $\left(G_{-} H\right)$, and accommodation and food service activities (I). Declines of value added in manufacturing $(C)$ and professional, scientific, technical, administration and support service activities (M_N) have been slightly more affected than the overall economy, while mining, quarrying and other industry (BDE) and construction ( $F$ ) slightly less. Agriculture (A), financial and insurance activities $(K)$, and real estate activities $(L)$ faced relatively small declines, whereas in the information and communication industry $(\mathrm{J})$, value added even slightly increased. 
Figure 7 / Value added growth rates in 2020 , in $\%$

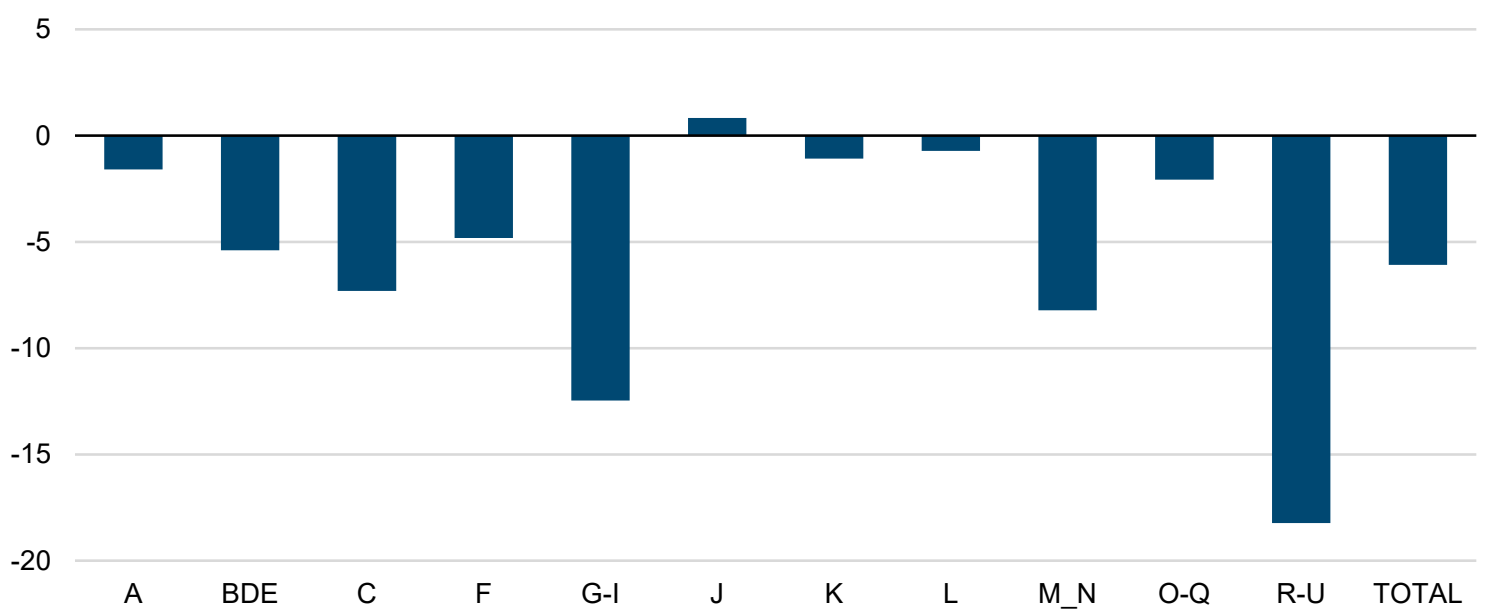

Source: Eurostat, own calculations.

Figure 8 illustrates labour productivity growth rates in 2020, differentiating between persons employed and hours worked. As can be seen, productivity declined much more sharply in terms of persons employed (particularly in G_H and I where it dropped by almost $10 \%$, and in R-U with a decline of around $18 \%$ ) than based on hours worked. For industries $\mathrm{A}, \mathrm{J}, \mathrm{K}$ and $\mathrm{L}$, increases in labour productivity were even reported. Finally, Figure 9 presents employment growth rates in the year 2020. Interestingly, the total employment level dropped by $1.5 \%$, slightly less than in the wake of the global financial crisis in 2009. This is remarkable when we consider that economic activity in the EU in 2020 declined by about $6 \%$ from the previous year, compared to a decline of 4.3\% in 2009 (European Commission, 2021a). Strong employment effects have been circumvented by government support schemes, furlough schemes and short-term working arrangements, together with labour hoarding. This is also clearly indicated by the more negative outcomes for hours worked compared to persons employed.

Figure 8 / Labour productivity growth rates in 2020 , in $\%$

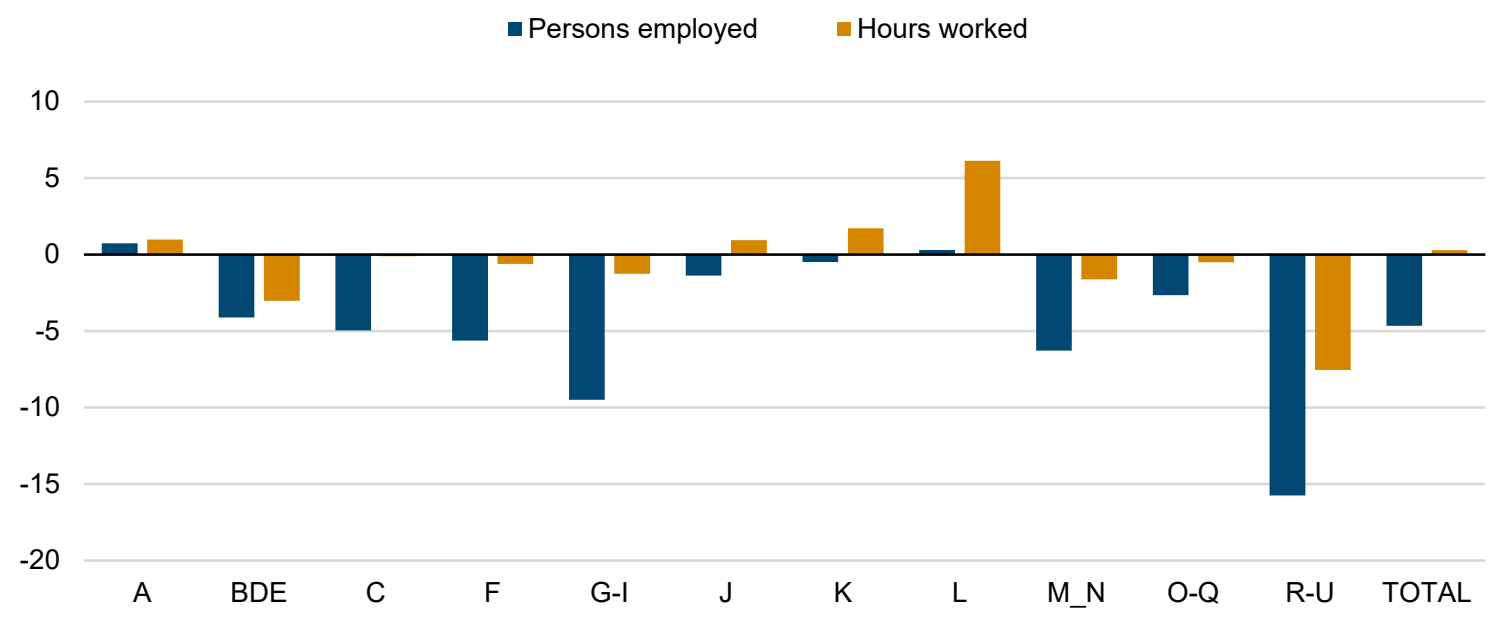

Source: Eurostat, own calculations. 
Figure 9 / Employment growth rates in 2020

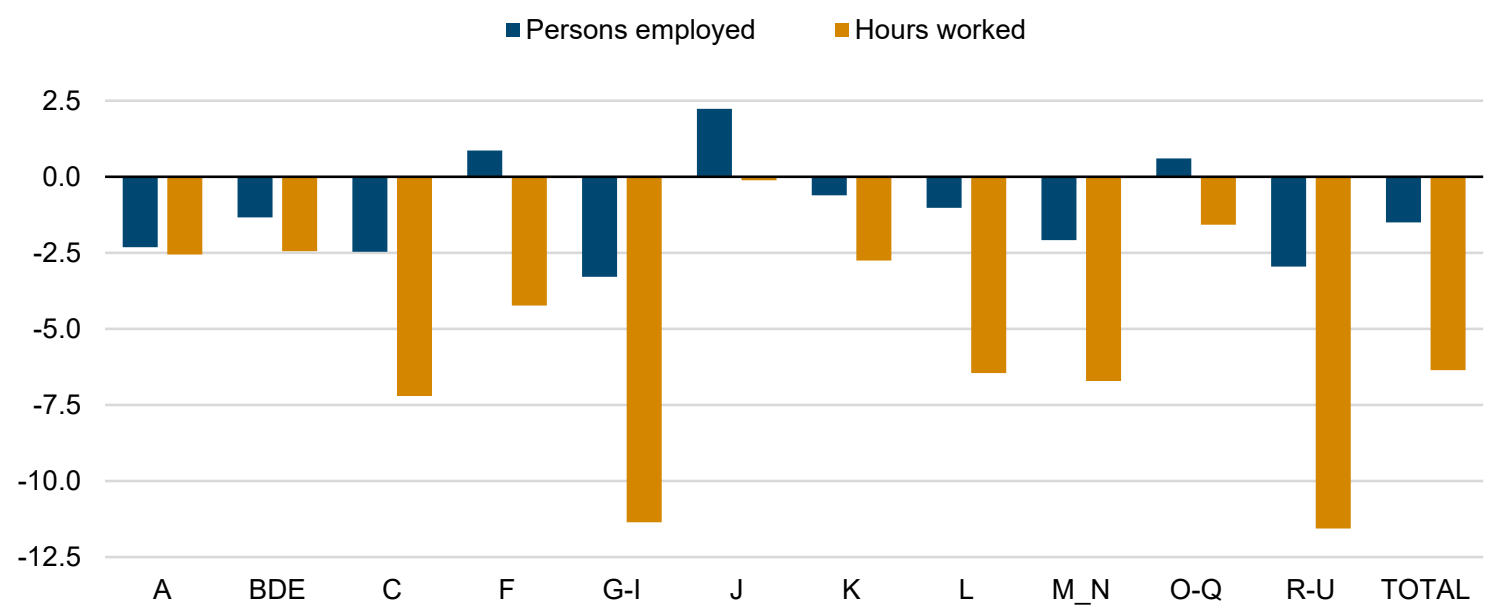

Source: Eurostat, own calculations. 


\section{Results}

\subsection{MACRO SCENARIOS}

Following our assumptions discussed in Section 4, we now calculate growth rates of employment (in terms of person employed and hours worked) for the period 2021-2026. These outcomes crucially depend on the validity of the macroeconomic growth forecasts applied, which might, however, be prone to substantial downward risks (see Section 2). For some industries (e.g. manufacturing) one might expect - given the macro forecasts - that recovery will happen even faster if the 'return to normality' sets in quickly. For other industries - like accommodation and food service activities (I) - this return might be a slower one and therefore a longer recovery period might be expected (see, for instance, the discussion in Section 5.3 on tourism).

As discussed in Section 3, we introduce a set of different scenarios in order to provide a sensitivity analysis and account for the large uncertainty and downside risks that surround the baseline scenario. The additional scenarios are implemented in the following way:

> Scenario 1: In the negative scenario, we model lower overall growth rates by subtracting $1 \mathrm{pp}$ of growth in 2021 and 2022, 0.75 pp in 2023 and 0.5 pp in 2024.

> Scenario 2: In the worst-case scenario, we reduce the macroeconomic growth rates by 2 pp in 2021 and 2022, 1.5 pp in 2023, and 1 pp in 2024.

> Scenario 3: In the more optimistic scenario, we account for a quicker recovery than expected in spring 2021. Specifically, we apply the upwardly revised growth rates for 2021 and 2022 from the most recent European Economic Forecast (European Commission, 2021c).

Figures 10 and 11 contrast the forecast results by scenario in the EU27 for persons employed and hours worked, respectively. According to the baseline scenario, the number of persons employed is expected to already recover in 2021 and might even surpass its 2019 level. This is, however, not the case when considering hours worked: the level in 2021 is still about $3 \%$ below its 2019 level. The pre-crisis level of 2019 is not expected to be reached before 2022. In both negative scenarios, employment levels in terms of persons employed are around $1 \mathrm{pp}$ (negative scenario) and $2 \mathrm{pp}$ (worst-case scenario) lower compared to the baseline in 2021 and by 2 pp and 4 pp, respectively, in 2022. As can be seen, these differences then translate into lower employment levels in the longer run. The differences are similar when looking at the results for hours worked in Figure 11. Importantly, in neither of the negative scenarios are the levels of 2019 reached, even by 2026. Finally, the more optimistic scenario predicts a slightly higher level both for persons employed and hours worked compared to the baseline. 
Figure 10 / Persons employed EU27, 2019=1

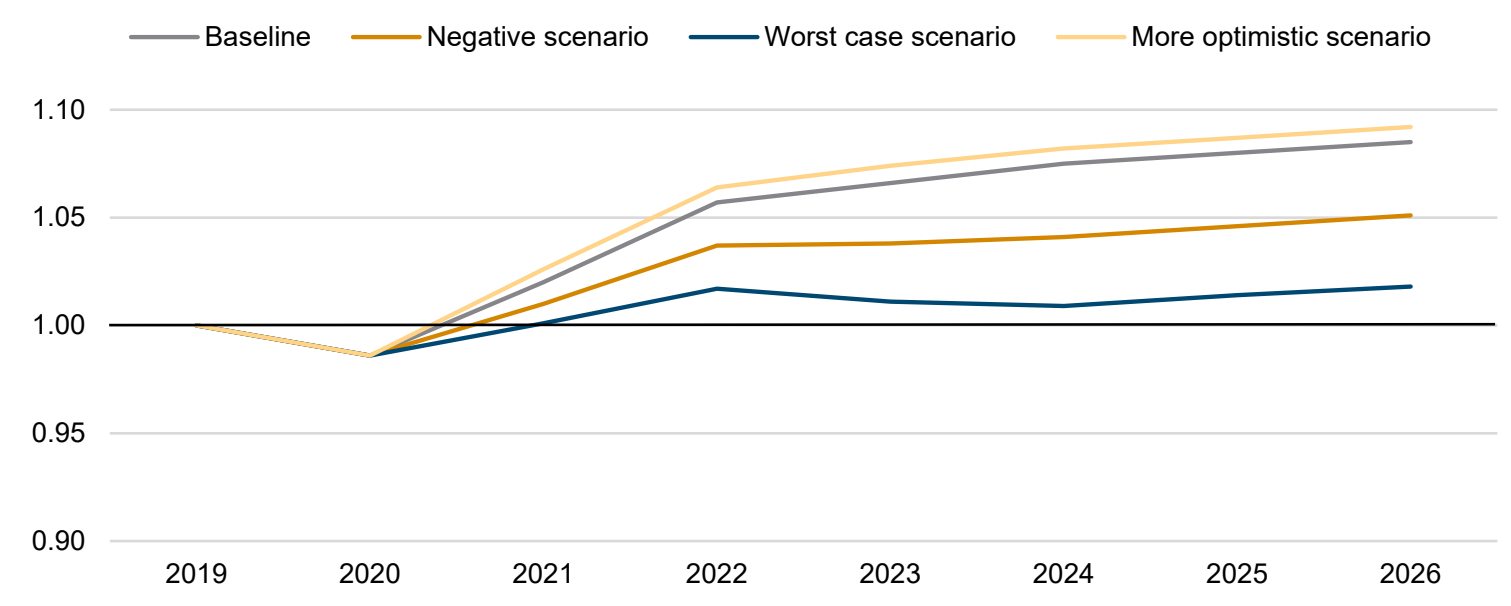

Source: Own calculations.

\section{Figure 11 / Hours worked EU27, $2019=1$}

- Baseline $\quad$ Negative scenario —Worst case scenario —— More optimistic scenario

1.10

1.05

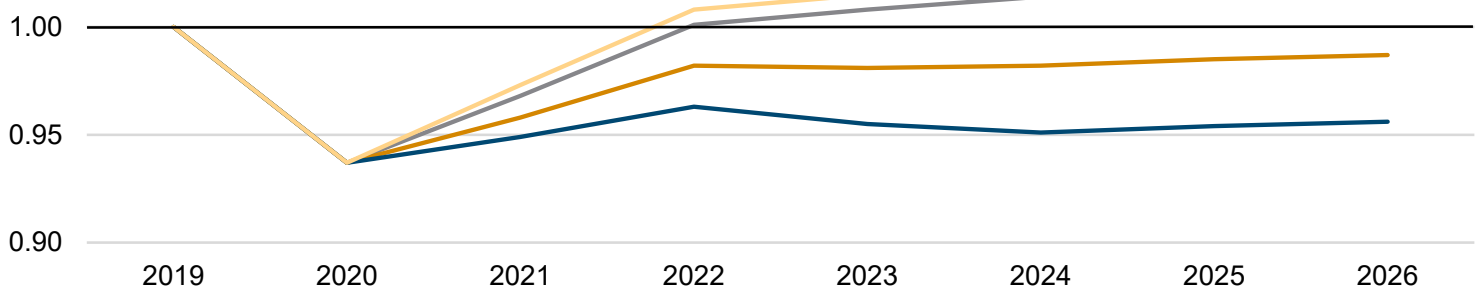

Source: Own calculations.

These results imply that strong and sustained growth in the recovery phase is an important prerequisite to reach decent employment levels. Furthermore, one has to bear in mind that the calculations implicitly assume that working-time arrangements (e.g. short-time working scheme arrangements), as introduced in the crisis year 2020, will persist in the post-pandemic period. A change in such arrangements is likely to lower employment levels in terms of persons employed, although hours worked could remain unaffected.

Country-specific results are reported in Table 3 for the baseline scenario and in Tables 4 to 6 for the additional scenarios. Results are broadly in line with the patterns described above. Only in some countries (such as Ireland and Romania) is the recovery in employment levels subdued, as a result of high labour productivity growth rates. 
WiiW Research Report 457

Table 3 / Base scenario, 2019=1

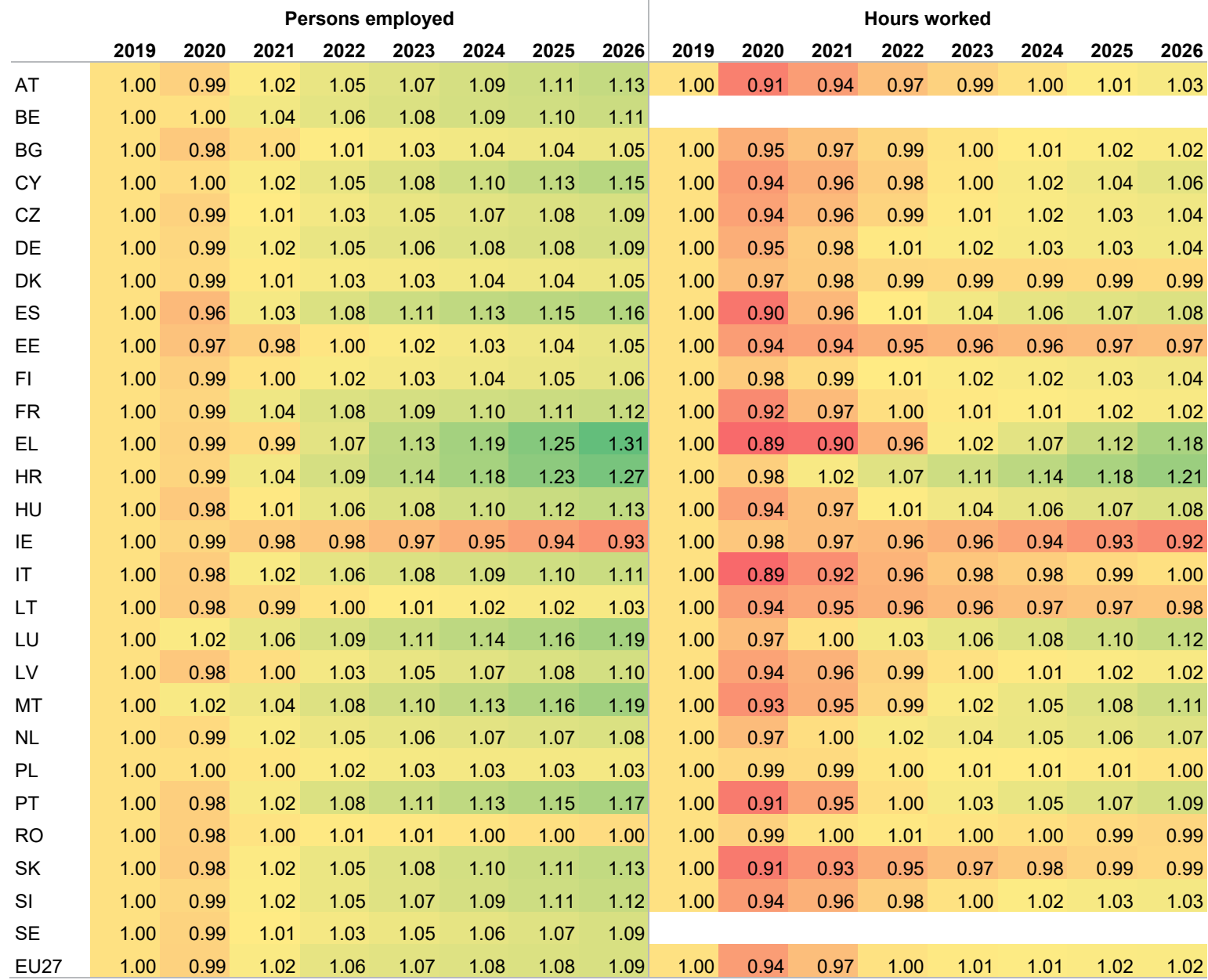

Note: For Malta results calculated at total economy level are presented. Information on hours worked not available for BEL and SWE. IRL introduced a methodological change in the GDP calculation, and is characterised, next to ROU, by a relatively high historic labour productivity growth rate (see Table 23 and 24).

Source: Own calculations. 
Table 4 / Negative scenario, 2019=1

\begin{tabular}{|c|c|c|c|c|c|c|c|c|c|c|c|c|c|c|c|c|}
\hline & & & & sons & iploye & & & & & & & Hours & orked & & & \\
\hline & 2019 & 2020 & 2021 & 2022 & 2023 & 2024 & 2025 & 2026 & 2019 & 2020 & 2021 & 2022 & 2023 & 2024 & 2025 & 2026 \\
\hline AT & 1.00 & 0.99 & 1.01 & 1.03 & 1.05 & 1.06 & 1.07 & 1.09 & 1.00 & 0.91 & 0.93 & 0.95 & 0.96 & 0.97 & 0.98 & 0.99 \\
\hline$B G$ & 1.00 & 0.98 & 0.99 & 1.00 & 1.00 & 1.00 & 1.01 & 1.01 & 1.00 & 0.95 & 0.96 & 0.97 & 0.98 & 0.98 & 0.98 & 0.99 \\
\hline $\mathrm{CY}$ & 1.00 & 1.00 & 1.01 & 1.03 & 1.05 & 1.07 & 1.09 & 1.11 & 1.00 & 0.94 & 0.95 & 0.96 & 0.98 & 0.99 & 1.01 & 1.03 \\
\hline DK & 1.00 & 0.99 & 1.00 & 1.01 & 1.00 & 1.00 & 1.01 & 1.01 & 1.00 & 0.97 & 0.97 & 0.97 & 0.96 & 0.96 & 0.96 & 0.96 \\
\hline ES & 1.00 & 0.96 & 1.02 & 1.06 & 1.08 & 1.09 & 1.10 & 1.11 & 1.00 & 0.90 & 0.95 & 0.99 & 1.00 & 1.02 & 1.03 & 1.04 \\
\hline EE & 1.00 & 0.97 & 0.98 & 0.99 & 0.99 & 1.00 & 1.01 & 1.02 & 1.00 & 0.94 & 0.93 & 0.94 & 0.94 & 0.93 & 0.94 & 0.94 \\
\hline $\mathrm{FI}$ & 1.00 & 0.99 & 0.99 & 1.00 & 1.01 & 1.01 & 1.02 & 1.03 & 1.00 & 0.98 & 0.99 & 0.99 & 0.99 & 1.00 & 1.00 & 1.01 \\
\hline $\mathrm{HU}$ & 1.00 & 0.98 & 1.00 & 1.03 & 1.05 & 1.06 & 1.08 & 1.09 & 1.00 & 0.94 & 0.96 & 0.99 & 1.01 & 1.02 & 1.03 & 1.05 \\
\hline $\mathrm{IE}$ & 1.00 & 0.99 & 0.98 & 0.97 & 0.95 & 0.94 & 0.92 & 0.91 & 1.00 & 0.98 & 0.96 & 0.95 & 0.94 & 0.92 & 0.91 & 0.90 \\
\hline IT & 1.00 & 0.98 & 1.01 & 1.04 & 1.05 & 1.05 & 1.06 & 1.07 & 1.00 & 0.89 & 0.92 & 0.94 & 0.95 & 0.95 & 0.96 & 0.96 \\
\hline LT & 1.00 & 0.98 & 0.98 & 0.98 & 0.99 & 0.99 & 0.99 & 1.00 & 1.00 & 0.94 & 0.94 & 0.94 & 0.94 & 0.94 & 0.94 & 0.95 \\
\hline LU & 1.00 & 1.02 & 1.05 & 1.07 & 1.09 & 1.10 & 1.13 & 1.15 & 1.00 & 0.97 & 0.99 & 1.01 & 1.03 & 1.05 & 1.07 & 1.09 \\
\hline LV & 1.00 & 0.98 & 0.99 & 1.01 & 1.02 & 1.03 & 1.05 & 1.06 & 1.00 & 0.94 & 0.95 & 0.96 & 0.97 & 0.97 & 0.98 & 0.99 \\
\hline MT & 1.00 & 1.02 & 1.04 & 1.06 & 1.08 & 1.10 & 1.13 & 1.16 & 1.00 & 0.93 & 0.94 & 0.97 & 0.99 & 1.02 & 1.04 & 1.07 \\
\hline $\mathrm{NL}$ & 1.00 & 0.99 & 1.01 & 1.02 & 1.03 & 1.03 & 1.04 & 1.05 & 1.00 & 0.97 & 0.99 & 1.00 & 1.01 & 1.01 & 1.02 & 1.04 \\
\hline PL & 1.00 & 1.00 & 1.00 & 1.00 & 1.01 & 1.00 & 1.00 & 1.00 & 1.00 & 0.99 & 0.99 & 0.99 & 0.99 & 0.98 & 0.98 & 0.98 \\
\hline
\end{tabular}

Note: For Malta results calculated at total economy level are presented. Information on hours worked not available for BEL and SWE. IRL introduced a methodological change in the GDP calculation, and is characterised, next to ROU, by a relatively high historic labour productivity growth rate (see Table 23 and 24).

Source: Own calculations. 
Wiiw Research Report 457

Table 5 / Worst-case scenario, 2019=1

Persons employed

Hours worked

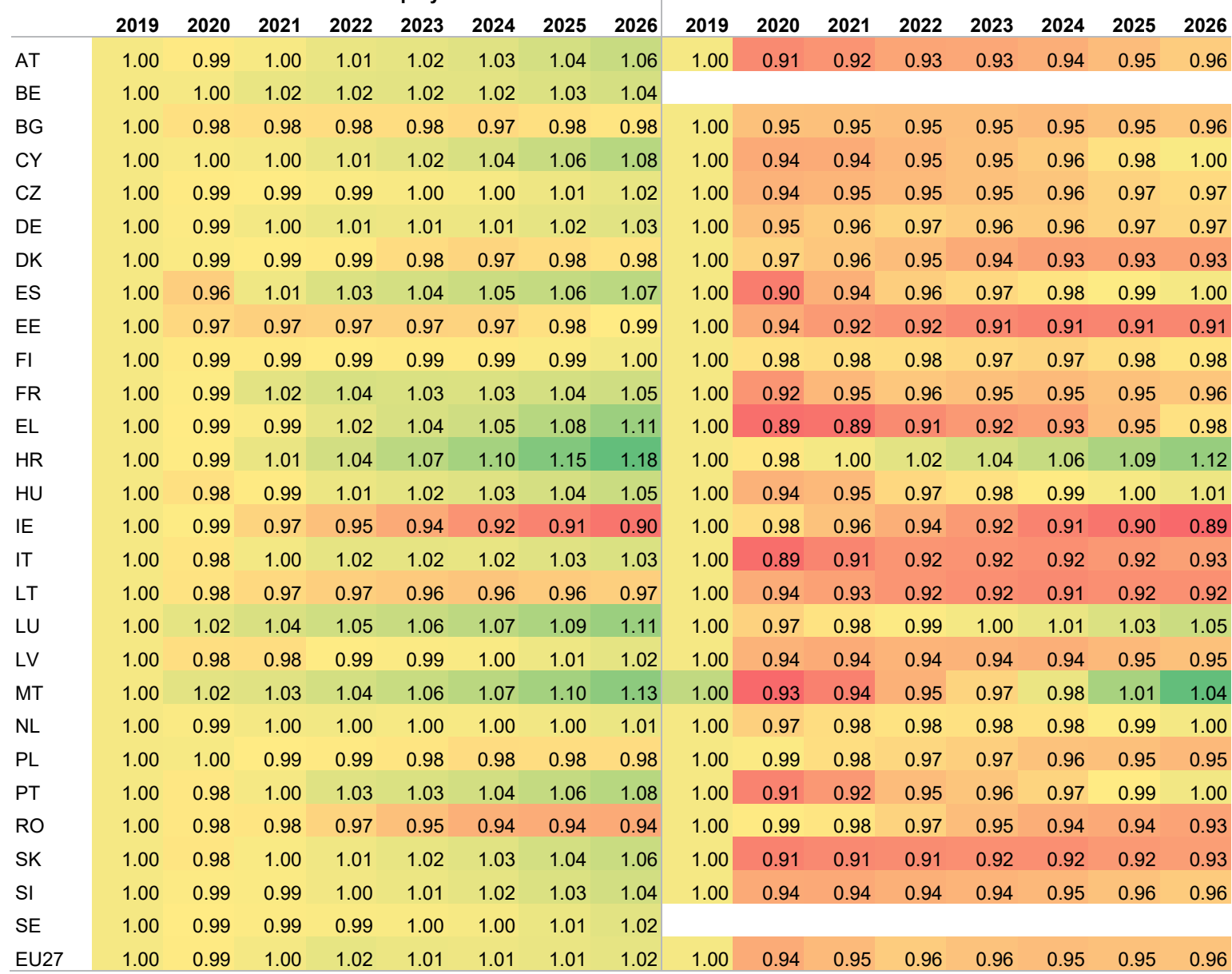

Note: For Malta results calculated at total economy level are presented. Information on hours worked not available for BEL and SWE. IRL introduced a methodological change in the GDP calculation, and is characterised, next to ROU, by a relatively high historic labour productivity growth rate (see Table 23 and 24).

Source: Own calculations. 
Table 6 / More optimistic scenario, 2019=1

\begin{tabular}{|c|c|c|c|c|c|c|c|c|c|c|c|c|c|c|c|c|}
\hline & & & & & & & & & & & & & orked & & & \\
\hline & 2019 & 2020 & 2021 & 2022 & 2023 & 2024 & 2025 & 2026 & 2019 & 2020 & 2021 & 2022 & 2023 & 2024 & 2025 & 2026 \\
\hline AT & 1.00 & 0.99 & 1.02 & 1.06 & 1.08 & 1.10 & 1.12 & 1.13 & 1.00 & 0.91 & 0.94 & 0.98 & 0.99 & 1.01 & 1.02 & 1.03 \\
\hline BE & 1.00 & 1.00 & 1.05 & 1.08 & 1.10 & 1.12 & 1.13 & 1.14 & & & & & & & & \\
\hline BG & 1.00 & 0.98 & 1.00 & 1.01 & 1.03 & 1.04 & 1.04 & 1.04 & 1.00 & 0.95 & 0.97 & 0.99 & 1.00 & 1.01 & 1.01 & 1.02 \\
\hline YY & 1.00 & 1.00 & 1.03 & 1.06 & 1.09 & 1.12 & 1.14 & 1.16 & 1.00 & 0.94 & 0.97 & 0.99 & 1.02 & 1.04 & 1.05 & 1.07 \\
\hline ZZ & 1.00 & 0.99 & 1.01 & 1.03 & 1.05 & 1.07 & 1.08 & 1.08 & 1.00 & 0.94 & 0.96 & 0.99 & 1.01 & 1.02 & 1.03 & 1.04 \\
\hline DE & 1.00 & 0.99 & 1.02 & 1.06 & 1.08 & 1.09 & 1.10 & 1.10 & 1.00 & 0.95 & 0.98 & 1.02 & 1.03 & 1.04 & 1.04 & 1.05 \\
\hline K & 1.00 & 0.99 & 1.01 & 1.03 & 1.04 & 1.04 & 1.05 & 1.05 & 1.00 & 0.97 & 0.98 & 1.00 & 1.00 & 1.00 & 1.00 & 1.00 \\
\hline ES & 1.00 & 0.96 & 1.03 & 1.10 & 1.13 & 1.15 & 1.16 & 1.18 & 1.00 & 0.90 & 0.96 & 1.03 & 1.05 & 1.08 & 1.09 & 1.10 \\
\hline$E E$ & 1.00 & 0.97 & 1.00 & 1.01 & 1.03 & 1.04 & 1.05 & 1.06 & 1.00 & 0.94 & 0.96 & 0.96 & 0.97 & 0.97 & 0.98 & 0.98 \\
\hline$F$ & 1.00 & 0.99 & 1.01 & 1.03 & 1.04 & 1.05 & 1.06 & 1.07 & 1.00 & 0.98 & 1.00 & 1.02 & 1.03 & 1.03 & 1.04 & 1.05 \\
\hline$R$ & 1.00 & 0.99 & 1.04 & 1.08 & 1.09 & 1.10 & 1.11 & 1.12 & 1.00 & 0.92 & 0.97 & 1.00 & 1.01 & 1.02 & 1.02 & 1.03 \\
\hline$L$ & 1.00 & 0.99 & 0.99 & 1.09 & 1.17 & 1.23 & 1.30 & 1.37 & 1.00 & 0.89 & 0.90 & 0.98 & 1.05 & 1.10 & 1.17 & 1.23 \\
\hline $\mathrm{IR}$ & 1.00 & 0.99 & 1.04 & 1.11 & 1.16 & 1.20 & 1.25 & 1.30 & 1.00 & 0.98 & 1.03 & 1.09 & 1.13 & 1.16 & 1.20 & 1.23 \\
\hline HU & 1.00 & 0.98 & 1.03 & 1.07 & 1.09 & 1.11 & 1.13 & 1.14 & 1.00 & 0.94 & 0.99 & 1.03 & 1.05 & 1.07 & 1.08 & 1.10 \\
\hline $\mathrm{E}$ & 1.00 & 0.99 & 1.00 & 1.00 & 0.99 & 0.97 & 0.96 & 0.94 & 1.00 & 0.98 & 0.99 & 0.99 & 0.98 & 0.96 & 0.95 & 0.94 \\
\hline & 1.00 & 0.98 & 1.03 & 1.08 & 1.10 & 1.11 & 1.12 & 1.13 & 1.00 & 0.89 & 0.93 & 0.97 & 0.99 & 1.00 & 1.01 & 1.02 \\
\hline LT & 1.00 & 0.98 & 1.00 & 1.01 & 1.02 & 1.03 & 1.04 & 1.04 & 1.00 & 0.94 & 0.95 & 0.97 & 0.98 & 0.98 & 0.99 & 0.99 \\
\hline _U & 1.00 & 1.02 & 1.06 & 1.09 & 1.12 & 1.14 & 1.17 & 1.19 & 1.00 & 0.97 & 1.01 & 1.04 & 1.06 & 1.08 & 1.10 & 1.13 \\
\hline & 1.00 & 0.98 & 1.00 & 1.04 & 1.06 & 1.08 & 1.09 & 1.10 & 1.00 & 0.94 & 0.96 & 0.99 & 1.01 & 1.02 & 1.03 & 1.03 \\
\hline MT & 1.00 & 1.02 & 1.05 & 1.09 & 1.11 & 1.14 & 1.17 & 1.20 & 1.00 & 0.93 & 0.96 & 1.00 & 1.03 & 1.06 & 1.09 & 1.12 \\
\hline $\mathrm{N}$ & 1.00 & 0.99 & 1.02 & 1.05 & 1.06 & 1.07 & 1.08 & 1.08 & 1.00 & 0.97 & 1.00 & 1.02 & 1.04 & 1.05 & 1.06 & 1.07 \\
\hline PL & 1.00 & 1.00 & 1.02 & 1.04 & 1.05 & 1.05 & 1.05 & 1.05 & 1.00 & 0.99 & 1.01 & 1.02 & 1.03 & 1.03 & 1.03 & 1.02 \\
\hline r & 1.00 & 0.98 & 1.02 & 1.08 & 1.1 & 1.14 & 1.16 & 1.18 & 1.00 & 0.91 & 0.95 & 1.00 & 1.03 & 1.06 & 1.08 & 1.10 \\
\hline RO & 1.00 & 0.98 & 1.02 & 1.02 & 1.02 & 1.02 & 1.01 & 1.01 & 1.00 & 0.99 & 1.02 & 1.02 & 1.02 & 1.01 & 1.01 & 1.00 \\
\hline SK & 1.00 & 0.98 & 1.02 & 1.06 & 1.09 & 1.11 & 1.13 & 1.14 & 1.00 & 0.91 & 0.93 & 0.96 & 0.98 & 0.99 & 1.00 & 1.00 \\
\hline SI & 1.00 & 0.99 & 1.04 & 1.08 & 1.10 & 1.12 & 1.14 & 1.15 & 1.00 & 0.94 & 0.98 & 1.01 & 1.03 & 1.04 & 1.05 & 1.06 \\
\hline SE & 1.00 & 0.99 & 1.02 & 1.05 & 1.07 & 1.08 & 1.09 & 1.11 & & & & & & & & \\
\hline EU27 & 1.00 & 0.99 & 1.03 & 1.06 & 1.07 & 1.08 & 1.09 & 1.09 & 1.00 & 0.94 & 0.97 & 1.01 & 1.02 & 1.02 & 1.02 & 1.03 \\
\hline
\end{tabular}

Note: For Malta results calculated at total economy level are presented. Information on hours worked not available for BEL and SWE. IRL introduced a methodological change in the GDP calculation, and is characterised, next to ROU, by a relatively high historic labour productivity growth rate (see Table 23 and 24).

Source: Own calculations.

\subsection{OVERVIEW OF SECTORAL RESULTS}

Even though the baseline results in Section 5.1 suggest a quick recovery for employment, the pace of the recovery is likely to be divergent across industries. It generally depends on the initial impact of the crisis and the assumed longer-term growth rates of value added and labour productivity. The initial impact of the pandemic crisis at the industry level has already been shown in Figures 7 and 9. Taking into account the baseline scenario, Table 7 details the employment dynamics in the EU27 by industry. The results suggest that persons employed recovers in almost all industries; the exceptions are agriculture $(A)$ and financial and insurance services $(K)$. These industries were, however, already characterised by negative employment growth rates in the pre-pandemic period (see Figure 6). Importantly, this reflects the underlying assumption that long-run pre-pandemic growth patterns will set in once again in the post-pandemic period. Again, a different pattern emerges for hours worked. Specifically, labour demand does not recover in industries BDE (mining, quarrying and other industries), 
Wiiv Research Report 457

G-I (wholesale and retail trade; transportation and storage; accommodation and food service activities) ${ }^{6}$, and R-U (other services). The latter two industries were strongly hit by the economic crisis in 2020 , with declines in hours worked of more than $10 \%$. The industries escaping the crisis rather quickly are $\mathrm{J}$ (information and communication technology) and $\mathrm{M}_{-} \mathrm{N}$ (professional, scientific, technical, administration and support service activities), following the longer-term trends.

Table 7 / Employment dynamics by industry for EU27, 2019=1, baseline scenario

Persons employed

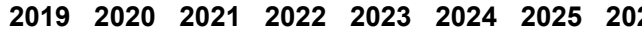

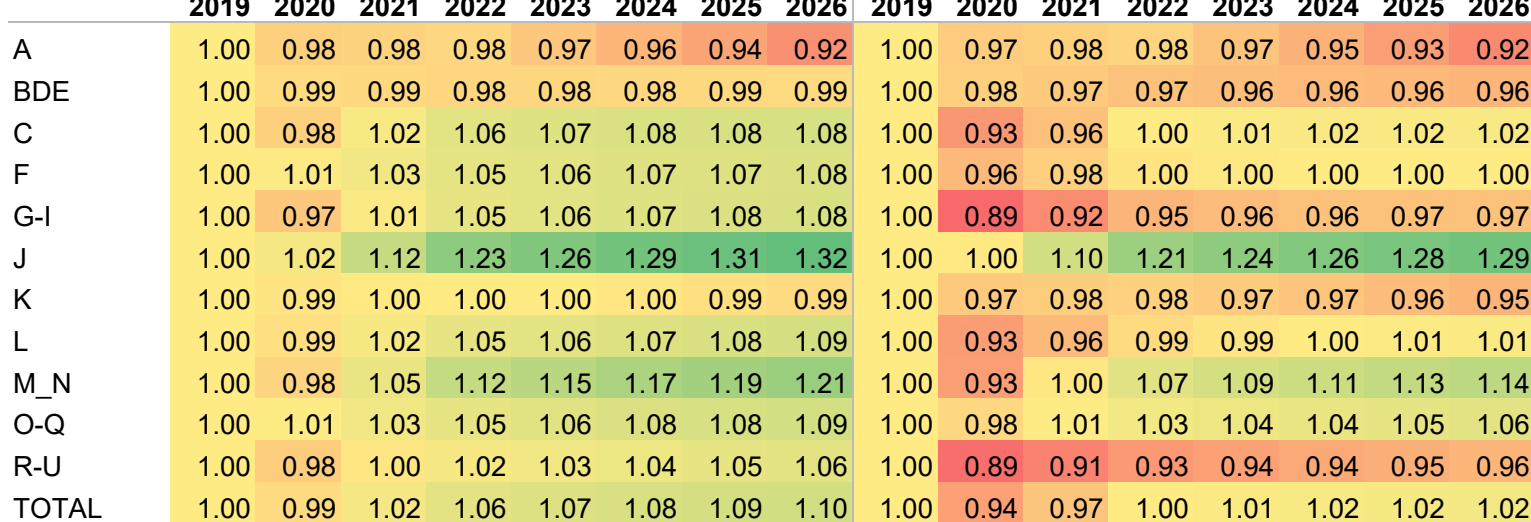

Note: Information on hours worked not available for BEL and SWE. Source: Own calculations.

These industry-specific patterns are also broadly observed at the country level for the baseline scenario, as presented in Figure 12 for persons employed and Figure 13 for hours worked. Specifically, these figures show the deviations of the employment index in 2026 from its 2019 level of one.

The results for the alternative scenarios principally reveal the same structure across industries, but at different levels. Importantly, under more pessimistic scenarios, the industries G-I and R-U face more difficulties in recovering from the pandemic. 
Figure 12 / Changes in persons employed 2026, deviation from index 2019=1, baseline scenario

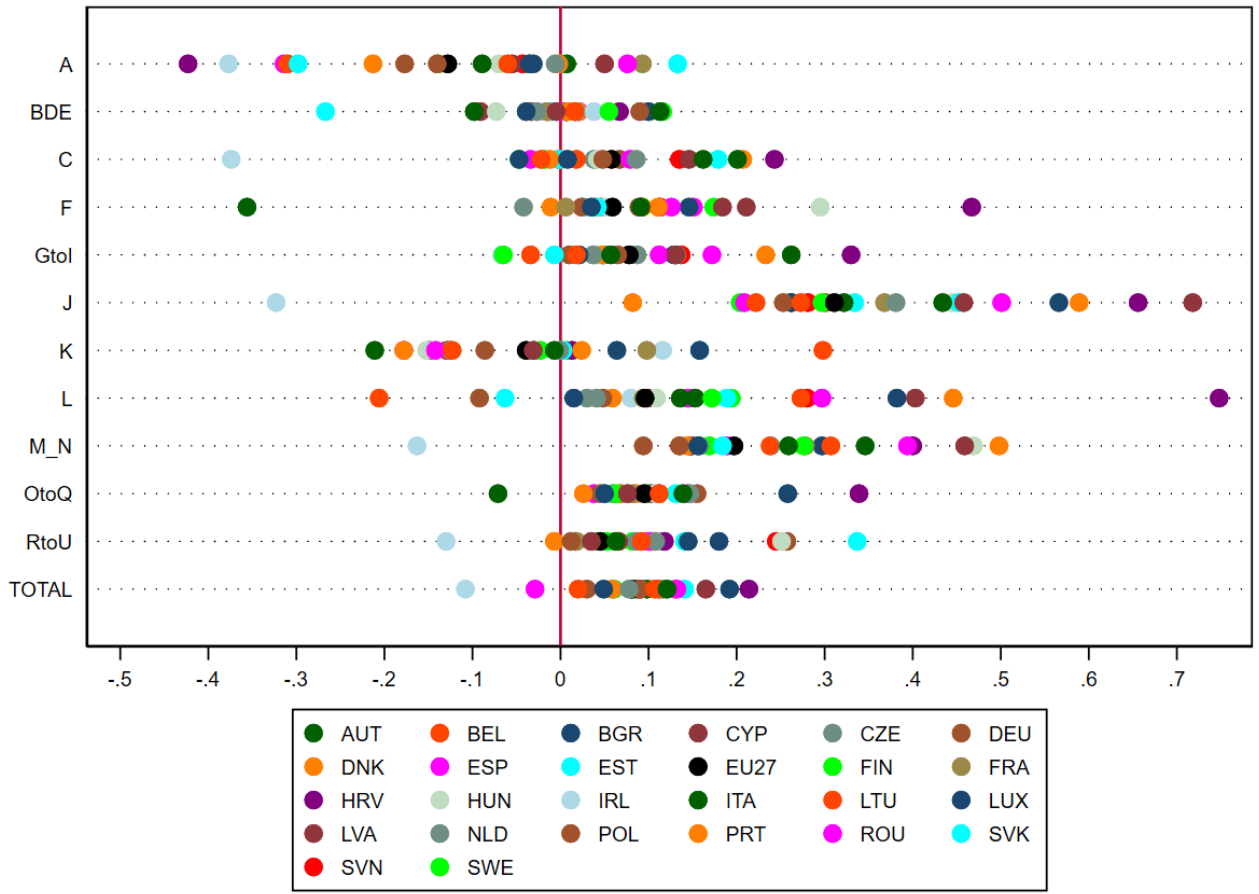

Note: Malta and Greece dropped due to unreliable data. Source: Eurostat, own calculations.

Figure 13 / Changes in hours worked 2026, deviation from index 2019=1, baseline scenario

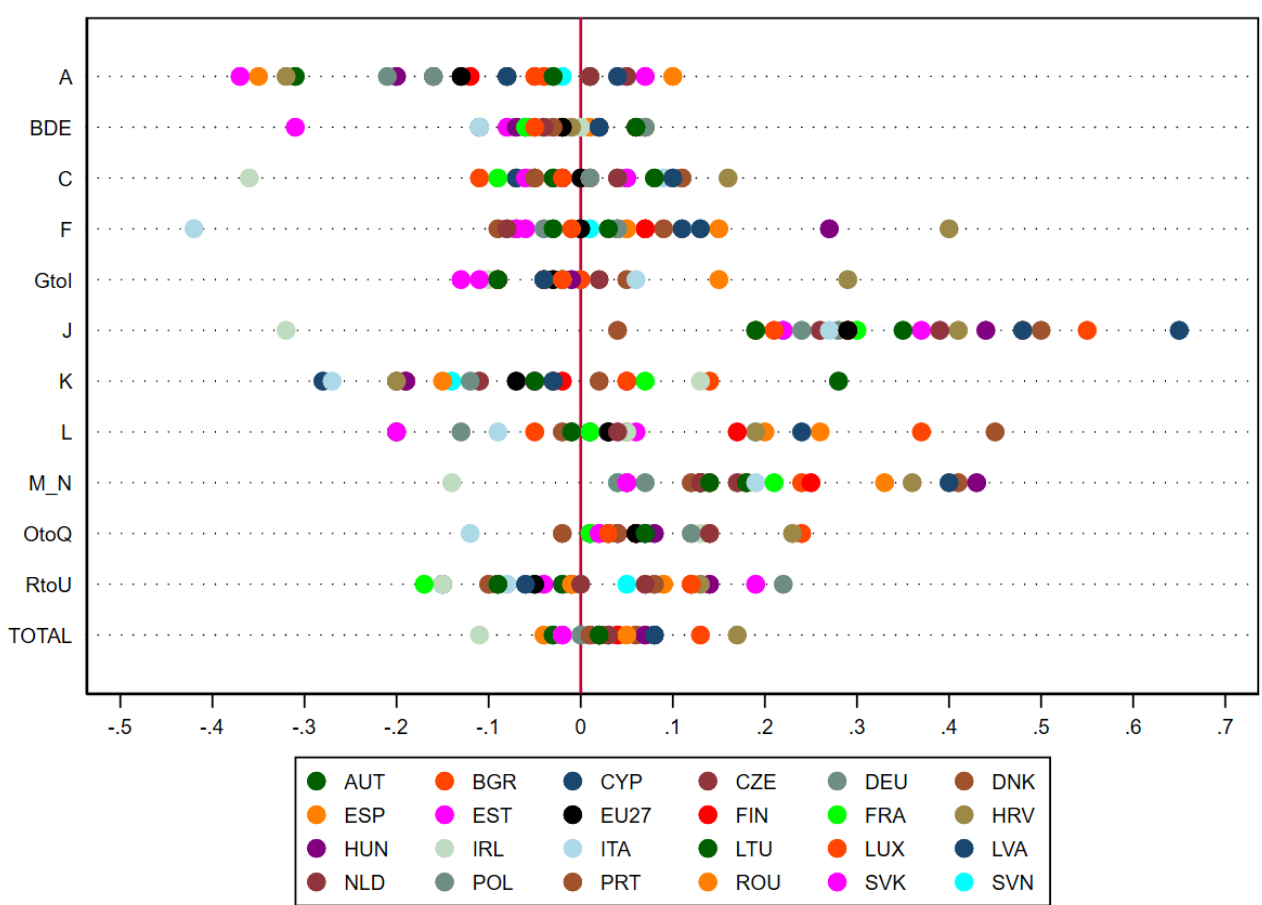

Note: Information on hours worked not available for BEL and SWE. Malta and Greece dropped due to unreliable data. Source: Eurostat, own calculations. 
Wiiw Research Report 457

\subsection{OVERVIEW OF RESULTS BY EMPLOYMENT GROUP}

Employment dynamics can be broken down by various labour market groups. In this section, we explore the effects for the dimensions of sex (male and female), age (15-24, 25-49, 50-64, and over 64), and occupation (according to the ISCO-08 1-digit categories), aggregated into four groups (low-skilled blue collar, high-skilled blue collar, low-skilled white collar, and high-skilled white collar). To present employment dynamics for population subgroups, we draw on detailed information from the EU Labour Force Survey (EU-LFS) for 2020 and integrate it into our forecasts. Due to limited data availability, it is only possible to present predictions for persons employed, and not for hours worked.

Table 8 presents the employment growth rates by sex and age groups in 2020. At the EU27 level, women have been slightly more affected by the crisis than men, though patterns across countries are quite different. However, there is a striking pattern revealing that the pandemic resulted in a poor labour market performance of younger age groups (15-24 and 25-49). Interestingly, this is a rather consistent pattern across countries (although they of course differ in magnitude). Please note that the absolute number of employed individuals above 65 is relatively low compared to other age groups.

Table 8 / Employment growth by sex and age groups 2020, in \%

\begin{tabular}{|c|c|c|c|c|c|c|c|}
\hline & & & & & & & \\
\hline & Total & Male & Female & $15-24$ & $25-49$ & $50-64$ & $>=65$ \\
\hline AT & -1.3 & -1.1 & -1.5 & -3.9 & -1.9 & 0.7 & -2.4 \\
\hline $\mathrm{BE}$ & -0.6 & -0.8 & -0.4 & -8.9 & -0.6 & 1.3 & 1.8 \\
\hline BG & -3.4 & -3.7 & -3.2 & -14.6 & -4.5 & -0.2 & 0.6 \\
\hline CY & 0.2 & 0.1 & 0.4 & -5.0 & 1.2 & -0.4 & -3.1 \\
\hline$C Z$ & -1.3 & -1.9 & -0.8 & -10.3 & -1.4 & 0.8 & -2.5 \\
\hline $\mathrm{DE}$ & -1.3 & -0.1 & -2.3 & -0.2 & -1.2 & -1.5 & -3.9 \\
\hline DK & -0.9 & -0.8 & -1.0 & -4.4 & -0.8 & 0.3 & 1.1 \\
\hline ES & -2.9 & -2.9 & -2.9 & -14.9 & -4.7 & 2.3 & 15.8 \\
\hline EE & -2.2 & -2.0 & -2.4 & -11.0 & -2.1 & -0.1 & -2.2 \\
\hline $\mathrm{FI}$ & -1.5 & -2.0 & -0.9 & -9.0 & -0.5 & -0.6 & -1.0 \\
\hline FR & -0.5 & -0.4 & -0.6 & -3.0 & -1.2 & 1.4 & 2.5 \\
\hline EL & -0.9 & -0.2 & -1.4 & -5.2 & -3.0 & 3.2 & 10.2 \\
\hline HR & -1.3 & -1.8 & -0.9 & -9.1 & -1.4 & 1.5 & -7.7 \\
\hline $\mathrm{HU}$ & -1.1 & -1.6 & -0.8 & -5.9 & -2.6 & 2.7 & 11.3 \\
\hline IE & -1.2 & -1.6 & -0.9 & -8.7 & -1.8 & 2.2 & 7.6 \\
\hline IT & -2.0 & -2.5 & -1.5 & -8.9 & -3.5 & 1.3 & 1.2 \\
\hline LT & -1.5 & -2.8 & -0.1 & -12.8 & -1.1 & -1.4 & 12.0 \\
\hline LU & 1.1 & 2.6 & -0.3 & -12.4 & 0.6 & 6.0 & 21.1 \\
\hline LV & -1.9 & -1.9 & -1.8 & -7.2 & -3.3 & 1.1 & 2.8 \\
\hline MT & 2.6 & 4.2 & 1.5 & -6.6 & 4.0 & 3.4 & 0.0 \\
\hline NL & 0.0 & 0.2 & -0.2 & -3.8 & -0.3 & 2.2 & 2.4 \\
\hline PL & -0.1 & -0.2 & 0.0 & -12.6 & 0.3 & 1.5 & 7.0 \\
\hline PT & -2.0 & -1.4 & -2.6 & -16.1 & -2.4 & 1.7 & -1.3 \\
\hline RO & -1.8 & -2.5 & -1.3 & -1.5 & -3.4 & 2.9 & -8.7 \\
\hline SK & -2.0 & -1.9 & -2.1 & -10.8 & -2.0 & -0.5 & 1.5 \\
\hline SI & -0.5 & -0.6 & -0.3 & -18.3 & -0.6 & 4.0 & 3.9 \\
\hline SE & -1.3 & -2.0 & -0.7 & -10.0 & -1.0 & 0.3 & 4.5 \\
\hline EU27 & -1.3 & -1.2 & -1.4 & -5.7 & -1.9 & 0.8 & 0.8 \\
\hline
\end{tabular}

Source: Eurostat, own calculations. 
Similarly, Table 9 documents employment dynamics by occupational category in 2020. We distinguish between low-skilled blue collar, high-skilled blue collar, low-skilled white collar, and high-skilled white collar. On average, the negative impact of the crisis on labour demand has been more pronounced for low-skilled blue collar workers (LSBC) and low-skilled white collar workers (LSWC) - and especially so for service workers - but also for high-skilled blue collar workers.

Table 9 / Employment growth by occupational groups 2020, in \%

\begin{tabular}{|c|c|c|c|c|c|c|c|c|c|}
\hline & Managers & Professionals & Technicians & Clerks & $\begin{array}{l}\text { WC } \\
\text { Service } \\
\text { workers }\end{array}$ & $\begin{array}{r}\text { HSBC } \\
\text { Skilled } \\
\text { agr. workers }\end{array}$ & $\begin{array}{r}\text { Craft } \\
\text { workers }\end{array}$ & $\begin{array}{l}\text { LSE } \\
\text { Operators \& } \\
\text { assemblers }\end{array}$ & $\begin{array}{l}\text { BC } \\
\text { Elementary }\end{array}$ \\
\hline AT & 5.6 & 0.9 & 3.4 & -3.6 & -5.2 & 1.7 & -4.1 & -4.8 & -4.5 \\
\hline $\mathrm{BE}$ & 1.0 & 4.3 & 2.0 & 0.6 & -5.9 & 1.6 & -2.4 & -5.3 & -7.7 \\
\hline$B G$ & -3.3 & 4.3 & -1.8 & -7.3 & -8.2 & 0.0 & -3.2 & -1.3 & -8.5 \\
\hline CY & -1.7 & 2.5 & 1.4 & 3.5 & -7.5 & 8.7 & 8.1 & 5.3 & -2.1 \\
\hline$C Z$ & -5.6 & 3.8 & 0.8 & -4.4 & -3.9 & -6.6 & -1.6 & -3.4 & -2.1 \\
\hline DE & -20.7 & 9.8 & -15.1 & 5.9 & -9.1 & 2.0 & -10.7 & -9.5 & -10.9 \\
\hline DK & -13.5 & 2.1 & 0.1 & -0.6 & -3.6 & -7.8 & 0.3 & 0.0 & -2.3 \\
\hline ES & -2.5 & 1.0 & 1.6 & -1.0 & -7.2 & -4.0 & -2.1 & -3.6 & -7.4 \\
\hline EE & -2.7 & 1.3 & 3.0 & -1.6 & -7.6 & -3.8 & -3.9 & -8.7 & -1.4 \\
\hline $\mathrm{FI}$ & -15.3 & 8.9 & -0.7 & -2.9 & -7.4 & -7.0 & -2.7 & -8.0 & -8.7 \\
\hline FR & 4.0 & 5.9 & -1.2 & -0.9 & -3.6 & -4.3 & -3.7 & -2.1 & -4.2 \\
\hline EL & 6.2 & 3.8 & 6.0 & 0.8 & -1.5 & -8.6 & -3.8 & -2.8 & -8.7 \\
\hline HR & 0.6 & 1.4 & 0.5 & -3.8 & -8.0 & 4.7 & 4.7 & 4.0 & -12.1 \\
\hline $\mathrm{HU}$ & -3.0 & 11.4 & -1.1 & -4.6 & -4.6 & 1.6 & 1.6 & -8.5 & -9.0 \\
\hline IE & 0.4 & 5.6 & 1.2 & 6.3 & -7.2 & -4.2 & -4.5 & -6.7 & -9.2 \\
\hline IT & -1.4 & 0.7 & -1.4 & 0.0 & -6.9 & -3.1 & -0.9 & -0.9 & -2.8 \\
\hline LT & -1.5 & 2.4 & 1.7 & 3.5 & -5.6 & -12.3 & -3.0 & -2.3 & -2.7 \\
\hline LU & -5.6 & 4.0 & 4.5 & 0.0 & -5.4 & 2.6 & 1.3 & -8.8 & 0.5 \\
\hline LV & 4.2 & 8.2 & -4.3 & -8.7 & -3.6 & -5.3 & -7.2 & -4.2 & -4.8 \\
\hline MT & 8.7 & 12.8 & -4.5 & 1.1 & 1.8 & 0.0 & -2.4 & 3.0 & -7.2 \\
\hline NL & -4.1 & 5.2 & 1.3 & -1.3 & -4.5 & -0.7 & -2.3 & -7.5 & -3.0 \\
\hline PL & 0.1 & 0.7 & 2.8 & 3.7 & -3.1 & 4.8 & -1.7 & -2.3 & -5.3 \\
\hline PT & -4.7 & 11.9 & -2.4 & -0.8 & -4.5 & -2.1 & -5.9 & -9.3 & -12.6 \\
\hline RO & 4.5 & -2.0 & 0.3 & 5.0 & 0.9 & -4.2 & -4.0 & -1.8 & -3.8 \\
\hline SK & 7.1 & 5.5 & -0.7 & 0.1 & -5.8 & -26.5 & -7.0 & -0.5 & -6.3 \\
\hline SI & 7.0 & 5.8 & 3.4 & -6.1 & -10.1 & -5.2 & -2.8 & -2.5 & -1.0 \\
\hline SE & -0.2 & 2.0 & 1.7 & -4.2 & -6.2 & 9.4 & -4.2 & -5.1 & -7.3 \\
\hline EU27 & -4.0 & 4.7 & -4.3 & 1.3 & -5.8 & -1.7 & -4.2 & -4.2 & -6.4 \\
\hline
\end{tabular}

Source: Eurostat, own calculations.

Next, we look at shares of each labour market group by industry and the employment recovery broken down by labour market group in the pre-pandemic year 2019: Figure 14 looks at gender, Figure 15 at age group and Figure 16 at occupational group.

As discussed above, the economic shock induced by the pandemic hit population subgroups rather differently in 2020. For the forecast period 2021-2026, we assume that the employment shares will gradually converge back to the shares of 2019. Specifically, we assume that the shares are a weighted average of the shares in 2019 and 2020. The respective weights are 0.3 and 0.7 for $2021,0.5$ and 0.5 for 2022, 0.7 and 0.3 for 2023, and 0.9 and 0.1 for 2024 . 
By 2025 the shares are thus assumed to have converged to the 2019 levels. ${ }^{7}$ For the interpretation of the results, one has to keep in mind that changes in the number of persons employed were less severe than for hours worked in 2020 (see Figure 9). It is therefore likely that the impact on hours worked has also been much more pronounced for population subgroups. Unfortunately, as already discussed, we cannot explore the effects on hours worked by population subgroup due to limited data availability.

By conducting the forecasts for the baseline scenario, we obtain the results for gender (see Table 10), age group (see Table 11) and occupational group (see Table 12). Though female and male shares differ quite strikingly across industries, the impact and recovery in terms of persons employed at the total economy level is rather balanced across these groups. Concerning age groups, it is revealed that younger workers (15-24) have been hit the hardest in the labour market (see Table 8). Importantly, this is also the age group for which employment recovery takes a particularly long time. In some countries, older workers $\left(65^{+}\right)$have also been strongly affected (though this accounts for only a small share and could have been driven by a transition into retirement). Finally, among occupational categories, changes in employment dynamics have been especially pronounced for low-skilled workers (both white and blue collar). Not surprisingly, as can be seen in Table 11, recovery also takes a longer time for those groups. Nevertheless, the baseline simulations suggest that the number of persons employed could reach the 2019 level as early as 2022 in most cases. The alternative scenarios show similar patterns across employment groups, but at different levels. Accordingly, younger and lower-skilled individuals could face even more severe problems in the labour market when general economic development turns out to be less favourable over the next period (see Table 13).

\section{Figure 14 / Employment shares by sex in EU27, 2019}

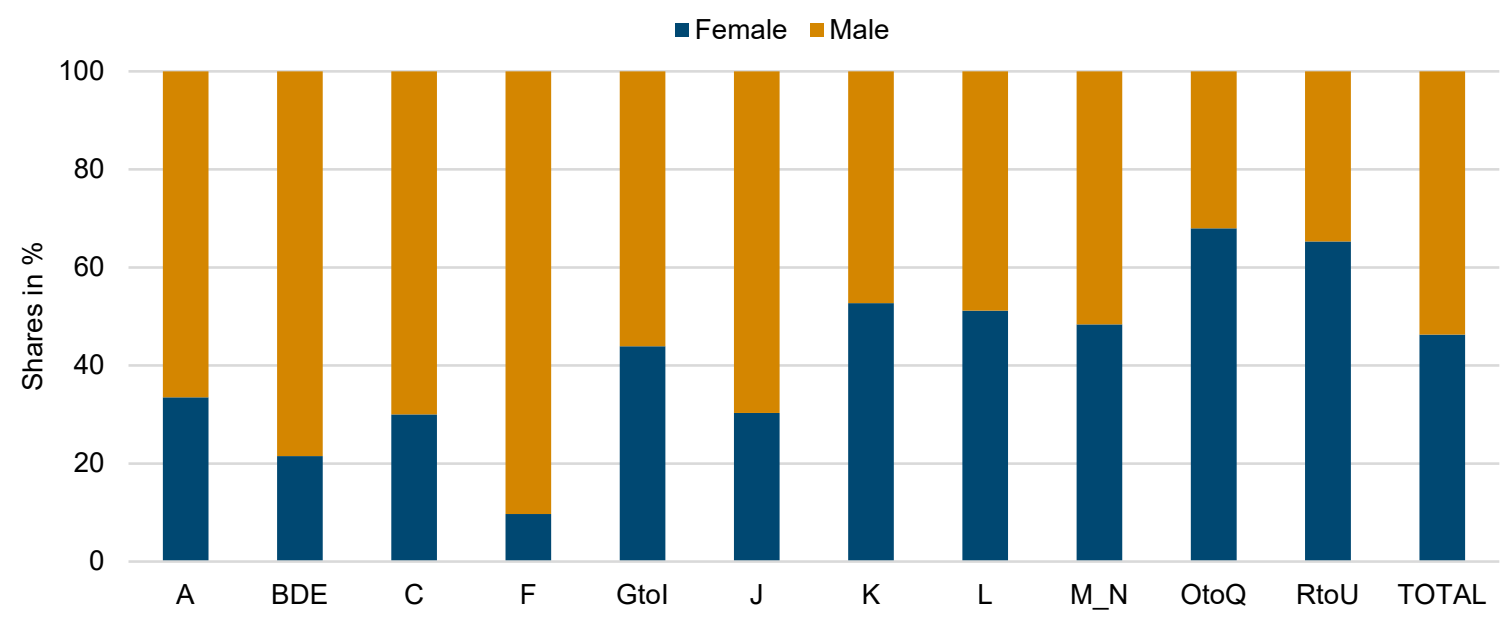

Source: Eurostat; own calculations.

$7 \quad$ Results are robust to small changes in the weights. 
Table 10 / Baseline scenario by sex, 2019=1

\begin{tabular}{|c|c|c|c|c|c|c|c|c|c|c|c|c|c|c|c|c|}
\hline & \multicolumn{8}{|c|}{ Female } & \multicolumn{8}{|c|}{ Male } \\
\hline & 019 & 2020 & 2021 & 2022 & 2023 & 2024 & 2025 & 2026 & 2019 & 2020 & 2021 & 2022 & 2023 & 2024 & 2025 & 2026 \\
\hline AT & 1.00 & 0.99 & 1.02 & 105 & 1.07 & 1.09 & 1.11 & 1.12 & 1.00 & 0.98 & 1.02 & 1.05 & 1.08 & 1.09 & 1.11 & 1.13 \\
\hline & & 99 & 03 & & & & & & & 1.01 & 1.04 & & 1.08 & 1.09 & 1.09 & 1.10 \\
\hline & & .98 & 1.00 & & & 1.04 & & 1.05 & 1.00 & 0.98 & 0.99 & 1.01 & 1.03 & 1.03 & 1.04 & 1.04 \\
\hline & & & & & & & & & & 0.99 & 02 & & 08 & & & 1.15 \\
\hline & & .98 & 1.01 & & & 1.08 & 1.09 & 1.10 & 1.00 & 0.99 & 1.01 & 1.03 & 1.05 & 1.06 & 1.07 & 1.07 \\
\hline & & & & & & & & 10 & & 0.98 & .01 & & 1.06 & & 08 & 1.08 \\
\hline & & 00 & 1.01 & 02 & 3 & 1.03 & 1.04 & 1.04 & 1.00 & 0.99 & 1.01 & 1.03 & 1.03 & 1.04 & 1.05 & 1.05 \\
\hline & & 97 & & & & 1.14 & & & 1.00 & 0.96 & 1.03 & & 1.11 & 1.13 & 14 & 1.15 \\
\hline$E$ & 1.00 & 0.97 & 0.99 & 1.01 & 1.02 & 1.04 & 1.05 & 1.06 & 1.00 & 0.97 & 0.98 & 1.00 & 1.01 & 1.02 & 1.03 & 1.04 \\
\hline & & 98 & .00 & & 03 & 1.04 & 1.05 & 1.06 & 1.00 & 0.99 & 1.00 & 1.02 & 1.03 & 1.04 & 05 & 1.06 \\
\hline & 1.00 & 0.99 & 1.04 & 1.08 & 1.09 & 1.10 & 1.11 & 1.12 & 1.00 & 0.99 & 1.04 & 1.08 & 1.09 & 1.10 & 1.11 & 1.12 \\
\hline & .00 & 0.99 & 1.02 & .11 & 1.18 & 1.24 & 1.31 & 1.38 & 1.00 & 0.98 & 0.97 & 1.04 & 1.10 & 1.15 & 1.20 & 1.26 \\
\hline & 1.00 & 0.98 & 1.03 & 1.09 & 1.14 & 1.19 & 1.24 & 1.28 & 1.00 & 1.00 & 1.04 & 1.09 & 1.14 & 1.18 & 1.23 & 1.27 \\
\hline & .00 & 0.96 & 0.99 & 1.04 & 1.07 & 1.09 & 1.11 & 1.12 & 1.00 & 0.99 & 1.02 & 1.07 & 1.09 & 1.11 & 1.12 & 1.13 \\
\hline & & 0 & & & & 0.98 & & 0.9 & & & 0.98 & & 0.95 & & 0.91 & 0.89 \\
\hline$[7$ & 1.00 & 0.98 & 1.01 & 1.05 & 1.07 & 1.09 & 1.10 & 1.11 & 1.00 & 0.99 & 1.03 & 1.07 & 1.08 & 1.09 & 1.10 & 1.11 \\
\hline & & 0.97 & 0.98 & & & 1.03 & & 1.04 & 1.00 & 1.00 & 1.00 & 1.00 & 1.01 & 1.01 & 1.01 & 1.01 \\
\hline 0 & חم & 1.04 & 1.07 & 1.10 & 1.13 & 1.16 & 1.18 & 1.21 & 1.00 & 1.01 & 1.04 & 1.08 & 1.10 & 1.13 & 1.15 & 1.17 \\
\hline & & 0.96 & & & & 1.06 & & 1.09 & 1.00 & 0.99 & 1.01 & 1.04 & 1.06 & 1.07 & 1.09 & 1.10 \\
\hline & & 1.02 & 1.05 & 1.09 & & 1.16 & 1.19 & 1.23 & 1.00 & 1.03 & 1.04 & 1.07 & 1.09 & 1.11 & 1.14 & 1.17 \\
\hline & & .99 & & & & 1.06 & & & & 0.99 & 02 & 1.05 & 06 & .07 & 07 & 1.08 \\
\hline & & 1.00 & & & & 1.03 & & 1.03 & 1.00 & 1.00 & 1.00 & 1.02 & 1.03 & 1.03 & 1.03 & 1.03 \\
\hline PT & & & & & & & & & & & 02 & & 10 & & & 1.17 \\
\hline & & 0.98 & 0.99 & 1.00 & & 1.00 & & 0.99 & 1.00 & 0.99 & 1.01 & 1.01 & 1.01 & 1.01 & 1.00 & 1.00 \\
\hline SK & & 0.98 & & & & 1.10 & 1.12 & 1.13 & 1.00 & 0.98 & 1.02 & 1.05 & 1.07 & 1.09 & 1.11 & 1.12 \\
\hline SI & & 1.00 & 1.02 & 1.05 & & 1.09 & 1.11 & 1.12 & 1.00 & 0.98 & 1.01 & 1.05 & 1.07 & 1.09 & 1.11 & 1.12 \\
\hline SE & 1.00 & 0.98 & 1.00 & 1.03 & 1.04 & 1.06 & 1.08 & 1.09 & 1.00 & 0.99 & 1.01 & 1.03 & 1.05 & 1.06 & 1.07 & 1.08 \\
\hline EU27 & 1.00 & 0.99 & 1.02 & 1.06 & 1.07 & 1.08 & 1.08 & 1.09 & 1.00 & 0.99 & 1.02 & 1.06 & 1.07 & 1.07 & 1.08 & 1.08 \\
\hline
\end{tabular}

Notes: IRL introduced a methodological change in the GDP calculation, and is characterised, next to ROU, by a relatively high historic labour productivity growth rate (see Table 23 and 24).

Source: Own calculations. 
Figure 15 / Employment shares by age groups in EU27, 2019

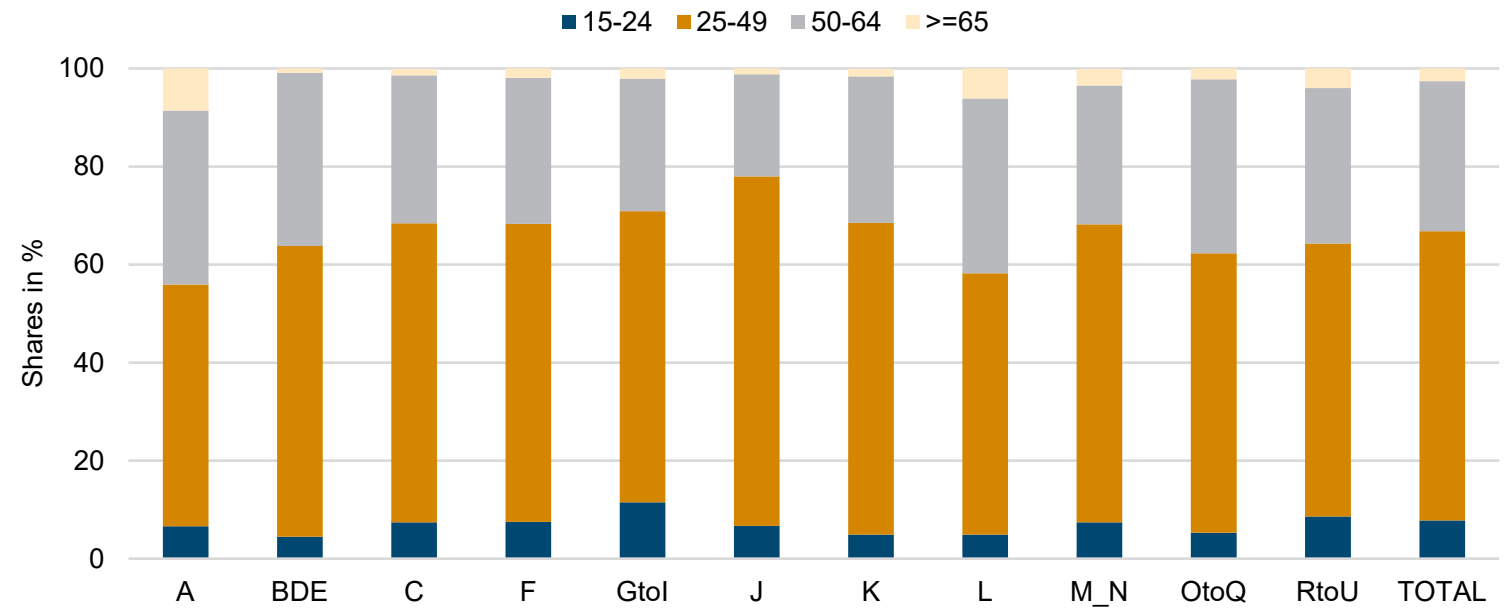

Source: Eurostat; own calculations

Figure 16 / Employment shares by occupational groups in EU27, 2019

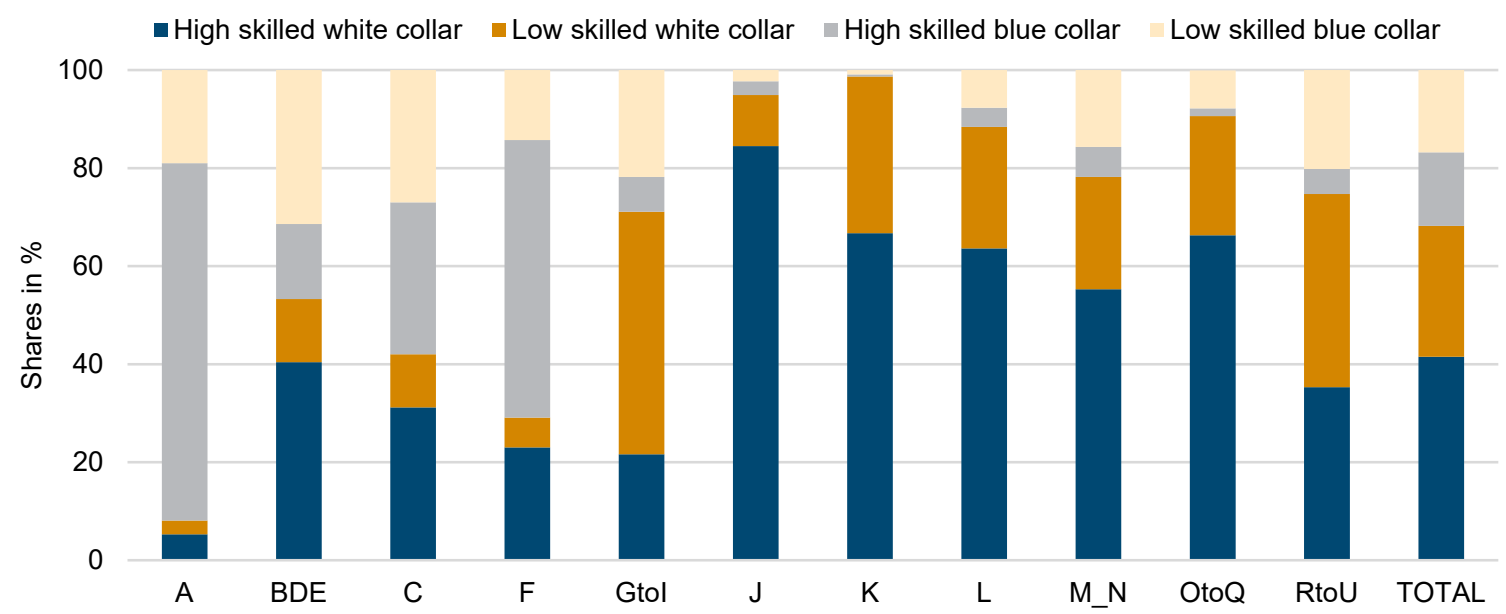

Source: Eurostat; own calculations 
Table 11 / Baseline scenario by age groups, 2019=1

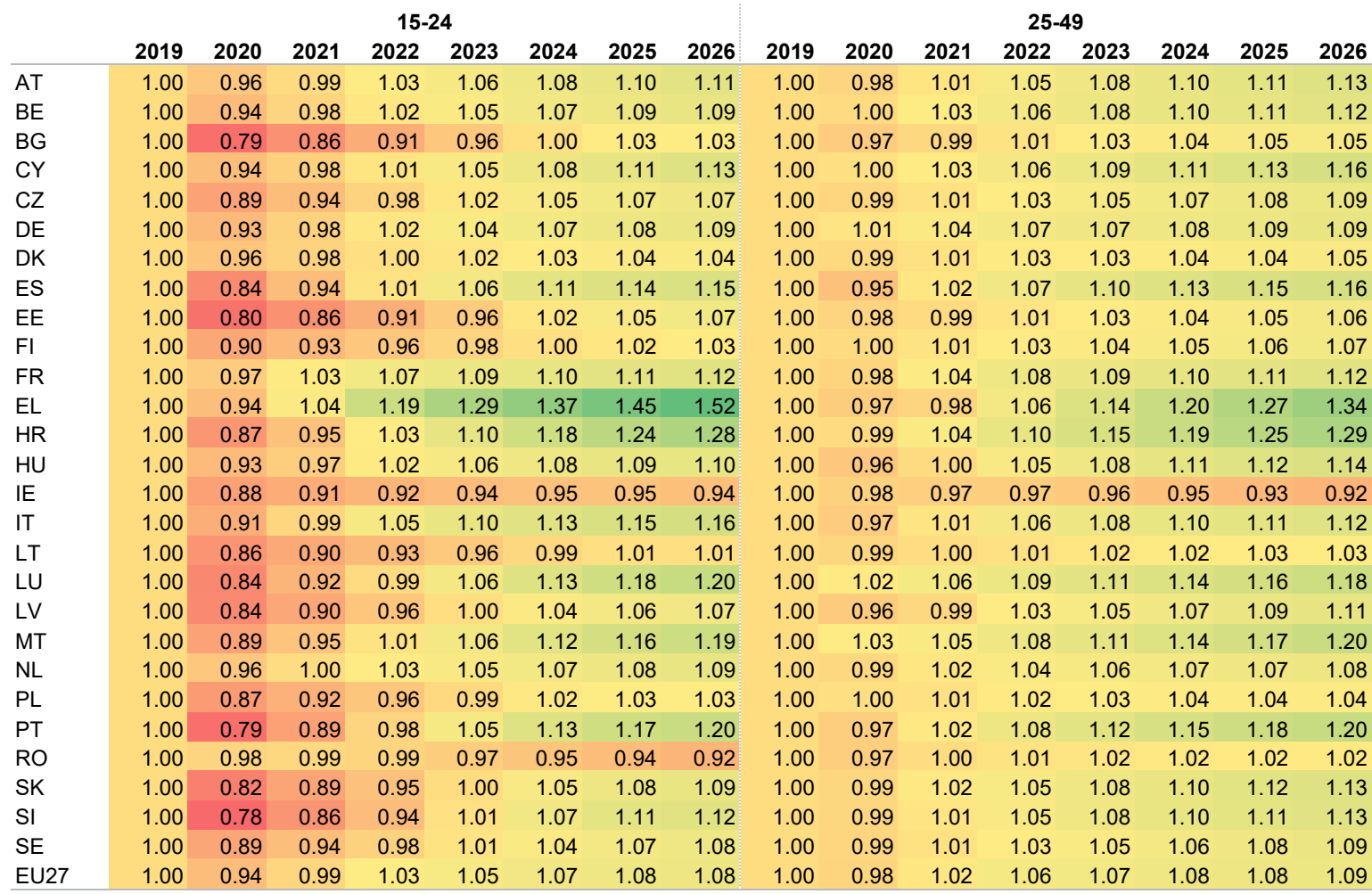

\begin{tabular}{|c|c|c|c|c|c|c|c|c|c|c|c|c|c|c|c|c|}
\hline & & & & 50 & & & & & & & & $>6$ & & & & \\
\hline & 2019 & 2020 & 2021 & 2022 & 2023 & 2024 & 2025 & 2026 & 2019 & 2020 & 2021 & 2022 & 2023 & 2024 & 2025 & 2026 \\
\hline AT & 1.00 & 1.01 & 1.03 & 1.06 & 1.08 & 1.09 & 1.10 & 1.12 & 1.00 & 0.74 & 0.82 & 0.88 & 0.94 & 0.98 & 1.01 & 1.00 \\
\hline BE & 1.00 & 1.02 & 1.05 & 1.07 & 1.08 & 1.09 & 1.10 & 1.10 & 1.00 & 1.03 & 1.05 & 1.06 & 1.08 & 1.09 & 1.10 & 1.11 \\
\hline CY & 1.00 & 1.01 & 1.02 & 1.05 & 1.08 & 1.10 & 1.11 & 1.13 & 1.00 & 0.78 & 0.85 & 0.91 & 0.97 & 1.03 & 1.08 & 1.09 \\
\hline$C Z$ & 1.00 & 1.01 & 1.02 & 1.04 & 1.06 & 1.07 & 1.07 & 1.08 & 1.00 & 0.97 & 1.00 & 1.03 & 1.05 & 1.07 & 1.09 & 1.10 \\
\hline $\mathrm{DE}$ & 1.00 & 1.00 & 1.03 & 1.05 & 1.06 & 1.07 & 1.08 & 1.09 & 1.00 & 0.70 & 0.81 & 0.89 & 0.96 & 1.04 & 1.08 & 1.08 \\
\hline ES & 1.00 & 1.02 & 1.07 & 1.11 & 1.12 & 1.14 & 1.14 & 1.15 & 1.00 & 1.17 & 1.19 & 1.20 & 1.19 & 1.17 & 1.16 & 1.17 \\
\hline EE & 1.00 & 0.99 & 0.99 & 1.00 & 1.01 & 1.01 & 1.02 & 1.03 & 1.00 & 0.90 & 0.93 & 0.96 & 0.99 & 1.01 & 1.03 & 1.04 \\
\hline $\mathrm{FI}$ & 1.00 & 0.99 & 1.01 & 1.02 & 1.03 & 1.04 & 1.05 & 1.06 & 1.00 & 0.99 & 1.00 & 1.01 & 1.02 & 1.02 & 1.03 & 1.03 \\
\hline FR & 1.00 & 1.01 & 1.05 & 1.08 & 1.09 & 1.10 & 1.10 & 1.11 & 1.00 & 1.04 & 1.08 & 1.10 & 1.11 & 1.10 & 1.11 & 1.11 \\
\hline EL & 1.00 & 1.03 & 1.01 & 1.05 & 1.10 & 1.14 & 1.18 & 1.24 & 1.00 & 1.09 & 1.08 & 1.14 & 1.18 & 1.20 & 1.23 & 1.27 \\
\hline HR & 1.00 & 1.01 & 1.05 & 1.10 & 1.14 & 1.17 & 1.21 & 1.25 & 1.00 & 0.73 & 0.79 & 0.81 & 0.84 & 0.85 & 0.85 & 0.83 \\
\hline LU & 1.00 & 1.05 & 1.08 & 1.10 & 1.12 & 1.14 & 1.16 & 1.18 & & & & & & & & \\
\hline LV & 1.00 & 1.00 & 1.01 & 1.04 & 1.05 & 1.06 & 1.06 & 1.07 & 1.00 & 1.25 & 1.20 & 1.18 & 1.15 & 1.11 & 1.09 & 1.10 \\
\hline MT & 1.00 & 1.08 & 1.08 & 1.10 & 1.11 & 1.12 & 1.14 & 1.17 & 1.00 & 0.55 & 0.70 & 0.81 & 0.93 & 1.04 & 1.11 & 1.13 \\
\hline $\mathrm{NL}$ & 1.00 & 1.02 & 1.04 & 1.05 & 1.06 & 1.06 & 1.07 & 1.08 & 1.00 & 1.03 & 1.05 & 1.06 & 1.07 & 1.07 & 1.07 & 1.08 \\
\hline PL & 1.00 & 1.01 & 1.01 & 1.02 & 1.02 & 1.02 & 1.02 & 1.02 & 1.00 & 1.13 & 1.10 & 1.08 & 1.05 & 1.02 & 1.00 & 1.00 \\
\hline PT & 1.00 & 1.04 & 1.06 & 1.10 & 1.11 & 1.12 & 1.13 & 1.14 & 1.00 & 1.02 & 1.01 & 1.01 & 0.99 & 0.97 & 0.95 & 0.93 \\
\hline RO & 1.00 & 1.03 & 1.03 & 1.02 & 1.01 & 0.99 & 0.98 & 0.98 & 1.00 & 0.89 & 0.89 & 0.86 & 0.82 & 0.78 & 0.73 & 0.69 \\
\hline SK & 1.00 & 0.99 & 1.02 & 1.05 & 1.08 & 1.09 & 1.11 & 1.12 & 1.00 & 0.99 & 1.02 & 1.05 & 1.07 & 1.09 & 1.11 & 1.11 \\
\hline SI & 1.00 & 1.04 & 1.05 & 1.07 & 1.08 & 1.09 & 1.10 & 1.11 & 1.00 & 1.00 & 1.00 & 1.01 & 1.01 & 1.00 & 0.99 & 0.98 \\
\hline SE & 1.00 & 1.01 & 1.02 & 1.04 & 1.05 & 1.06 & 1.07 & 1.08 & 1.00 & 1.12 & 1.10 & 1.10 & 1.08 & 1.07 & 1.07 & 1.08 \\
\hline EU27 & 1.00 & 1.01 & 1.03 & 1.07 & 1.07 & 1.07 & 1.08 & 1.08 & 1.00 & 0.92 & 0.97 & 1.01 & 1.03 & 1.05 & 1.06 & 1.07 \\
\hline
\end{tabular}

Notes: IRL introduced a methodological change in the GDP calculation, and is characterised, next to ROU, by a relatively high historic labour productivity growth rate (see Table 23 and 24).

Source: Own calculations. 
Table 12 / Baseline scenario by occupational categories, 2019=1

\begin{tabular}{|c|c|c|c|c|c|c|c|c|c|c|c|c|c|c|c|c|}
\hline & \multicolumn{8}{|c|}{ High-skilled white-collar } & \multicolumn{8}{|c|}{ Low-skilled white-collar } \\
\hline & 2019 & 2020 & 2021 & 2022 & 2023 & 2024 & 2025 & 2026 & 2019 & 2020 & 2021 & 2022 & 2023 & 2024 & 2025 & 2026 \\
\hline $\mathrm{BE}$ & 1.00 & 1.02 & 1.05 & 1.08 & 1.10 & 1.11 & 1.12 & 1.13 & 1.00 & 0.99 & 1.02 & 1.04 & 1.06 & 1.07 & 1.08 & 1.09 \\
\hline $\mathrm{CY}$ & 1.00 & 0.98 & 1.01 & 1.05 & 1.09 & 1.12 & 1.15 & 1.18 & 1.00 & 0.97 & 1.00 & 1.04 & 1.06 & 1.09 & 1.11 & 1.14 \\
\hline $\mathrm{CZ}$ & 1.00 & 1.01 & 1.03 & 1.06 & 1.08 & 1.09 & 1.11 & 1.12 & 1.00 & 0.97 & 1.00 & 1.02 & 1.05 & 1.06 & 1.07 & 1.08 \\
\hline $\mathrm{DE}$ & 1.00 & 0.98 & 1.02 & 1.05 & 1.07 & 1.09 & 1.10 & 1.11 & 1.00 & 1.04 & 1.06 & 1.07 & 1.07 & 1.07 & 1.07 & 1.07 \\
\hline ES & 1.00 & 1.00 & 1.06 & 1.11 & 1.14 & 1.16 & 1.17 & 1.19 & 1.00 & 0.95 & 1.01 & 1.06 & 1.09 & 1.12 & 1.13 & 1.14 \\
\hline EE & 1.00 & 1.01 & 1.02 & 1.04 & 1.05 & 1.06 & 1.08 & 1.09 & 1.00 & 0.92 & 0.94 & 0.97 & 1.00 & 1.02 & 1.04 & 1.06 \\
\hline $\mathrm{FI}$ & 1.00 & 1.03 & 1.04 & 1.06 & 1.07 & 1.07 & 1.08 & 1.10 & 1.00 & 0.94 & 0.96 & 0.98 & 1.00 & 1.01 & 1.03 & 1.04 \\
\hline FR & 1.00 & 1.01 & 1.06 & 1.10 & 1.11 & 1.11 & 1.12 & 1.13 & 1.00 & 0.97 & 1.03 & 1.07 & 1.09 & 1.10 & 1.11 & 1.12 \\
\hline EL & 1.00 & 1.04 & 1.00 & 1.01 & 1.05 & 1.09 & 1.15 & 1.22 & 1.00 & 0.99 & 1.06 & 1.20 & 1.30 & 1.38 & 1.46 & 1.55 \\
\hline HR & 1.00 & 1.02 & 1.06 & 1.12 & & 1.22 & 1.27 & & 1.00 & 0.94 & 1.01 & 1.08 & 1.14 & 1.20 & 1.26 & 1.31 \\
\hline LU & 1.00 & 1.04 & 1.07 & 1.11 & 1.13 & 1.16 & 1.18 & 1.21 & 1.00 & 0.96 & 1.01 & 1.05 & 1.09 & 1.12 & 1.15 & 1.17 \\
\hline LV & 1.00 & 1.05 & 1.06 & 1.08 & 1.09 & 1.10 & 1.11 & 1.13 & 1.00 & 0.91 & 0.94 & 0.99 & 1.03 & 1.06 & 1.08 & 1.09 \\
\hline MT & 1.00 & 1.05 & 1.06 & 1.10 & 1.13 & 1.15 & 1.19 & 1.22 & 1.00 & 1.01 & 1.04 & 1.08 & 1.11 & 1.14 & 1.18 & 1.21 \\
\hline $\mathrm{NL}$ & 1.00 & 1.02 & 1.04 & 1.06 & 1.07 & 1.07 & 1.08 & 1.08 & 1.00 & 0.97 & 1.00 & 1.03 & 1.05 & 1.06 & 1.07 & 1.08 \\
\hline PL & 1.00 & 1.01 & 1.02 & 1.04 & 1.05 & 1.06 & 1.06 & 1.06 & 1.00 & 1.00 & 1.00 & 1.02 & 1.04 & 1.04 & 1.04 & 1.04 \\
\hline PT & 1.00 & 1.06 & 1.09 & 1.14 & 1.16 & 1.18 & 1.20 & 1.23 & 1.00 & 0.97 & 1.02 & 1.09 & 1.12 & 1.16 & 1.18 & 1.21 \\
\hline RO & 1.00 & 0.99 & 1.02 & 1.03 & 1.04 & 1.05 & 1.06 & 1.07 & 1.00 & 1.01 & 1.05 & 1.07 & 1.09 & 1.10 & 1.11 & 1.13 \\
\hline SK & 1.00 & 1.03 & 1.06 & 1.08 & 1.11 & 1.12 & 1.14 & 1.16 & 1.00 & 0.98 & 1.01 & 1.04 & 1.06 & 1.08 & 1.10 & 1.11 \\
\hline SI & 1.00 & 1.03 & 1.05 & 1.07 & 1.09 & 1.10 & 1.12 & 1.13 & 1.00 & 0.93 & 0.97 & 1.02 & 1.06 & 1.10 & 1.12 & 1.13 \\
\hline SE & 1.00 & 1.01 & 1.03 & 1.05 & 1.06 & 1.07 & 1.08 & 1.10 & 1.00 & 0.95 & 0.98 & 1.01 & 1.03 & 1.05 & 1.07 & 1.08 \\
\hline EU27 & 1.00 & 1.00 & 1.04 & 1.08 & 1.08 & 1.09 & 1.10 & 1.11 & 1.00 & 0.98 & 1.02 & 1.05 & 1.07 & 1.08 & 1.08 & 1.09 \\
\hline
\end{tabular}

\begin{tabular}{|c|c|c|c|c|c|c|c|c|c|c|c|c|c|c|c|c|}
\hline & \multicolumn{8}{|c|}{ High-skilled blue-collar } & \multicolumn{8}{|c|}{ Low-skilled blue-collar } \\
\hline & 2019 & 2020 & 2021 & 2022 & 2023 & 2024 & 2025 & 2026 & 2019 & 2020 & 2021 & 2022 & 2023 & 2024 & 2025 & 2026 \\
\hline AT & 1.00 & 0.97 & 1.00 & 1.04 & 1.05 & 1.07 & 1.08 & 1.08 & 1.00 & 0.97 & 1.00 & 1.04 & 1.07 & 1.09 & 1.10 & 1.12 \\
\hline BE & 1.00 & 1.01 & 1.03 & 1.05 & 1.06 & 1.06 & 1.06 & 1.06 & 1.00 & 0.95 & 1.00 & 1.04 & 1.07 & 1.09 & 1.11 & 1.11 \\
\hline $\mathrm{CY}$ & 1.00 & 1.06 & 1.07 & 1.09 & 1.10 & 1.11 & 1.12 & 1.14 & 1.00 & 1.02 & 1.03 & 1.06 & 1.07 & 1.09 & 1.10 & 1.12 \\
\hline$C Z$ & 1.00 & 0.98 & 0.99 & 1.01 & 1.03 & 1.03 & 1.04 & 1.04 & 1.00 & 0.98 & 1.00 & 1.02 & 1.04 & 1.05 & 1.06 & 1.07 \\
\hline $\mathrm{DE}$ & 1.00 & 0.96 & 0.99 & 1.02 & 1.04 & 1.05 & 1.06 & 1.06 & 1.00 & 0.96 & 0.99 & 1.03 & 1.05 & 1.06 & 1.07 & 1.08 \\
\hline ES & 1.00 & 0.97 & 1.03 & 1.07 & 1.09 & 1.11 & 1.11 & 1.12 & 1.00 & 0.93 & 1.01 & 1.06 & 1.10 & 1.12 & 1.13 & 1.14 \\
\hline EE & 1.00 & 0.94 & 0.95 & 0.96 & 0.97 & 0.98 & 0.98 & 0.98 & 1.00 & 0.97 & 0.97 & 0.98 & 0.98 & 0.99 & 0.99 & 0.99 \\
\hline $\mathrm{FI}$ & 1.00 & 0.98 & 0.99 & 1.01 & 1.01 & 1.01 & 1.01 & 1.01 & 1.00 & 0.90 & 0.94 & 0.96 & 0.98 & 1.00 & 1.01 & 1.02 \\
\hline $\mathrm{FR}$ & 1.00 & 0.98 & 1.02 & 1.05 & 1.06 & 1.07 & 1.07 & 1.07 & 1.00 & 0.97 & 1.02 & 1.06 & 1.07 & 1.09 & 1.10 & 1.11 \\
\hline EL & 1.00 & 0.93 & 0.88 & 0.92 & 0.96 & 0.99 & 1.01 & 1.04 & 1.00 & 0.94 & 0.96 & 1.04 & 1.11 & 1.16 & 1.22 & 1.27 \\
\hline HR & 1.00 & 1.05 & 1.05 & 1.07 & 1.08 & 1.09 & 1.11 & 1.12 & 1.00 & 0.96 & 1.01 & 1.07 & 1.12 & 1.17 & 1.22 & 1.25 \\
\hline LU & 1.00 & 1.01 & 1.04 & 1.06 & 1.08 & 1.09 & 1.10 & 1.11 & 1.00 & 0.94 & 0.99 & 1.03 & 1.07 & 1.10 & 1.13 & 1.15 \\
\hline LV & 1.00 & 0.88 & 0.92 & 0.97 & 1.00 & 1.03 & 1.05 & 1.06 & 1.00 & 0.96 & 0.98 & 1.01 & 1.03 & 1.04 & 1.05 & 1.06 \\
\hline MT & 1.00 & 1.00 & 1.01 & 1.03 & 1.04 & 1.05 & 1.05 & 1.06 & 1.00 & 1.00 & 1.01 & 1.03 & 1.05 & 1.07 & 1.10 & 1.12 \\
\hline $\mathrm{NL}$ & 1.00 & 0.99 & 1.02 & 1.04 & 1.05 & 1.05 & 1.06 & 1.06 & 1.00 & 0.96 & 1.00 & 1.03 & 1.05 & 1.06 & 1.08 & 1.09 \\
\hline PL & 1.00 & 1.00 & 0.99 & 0.99 & 0.99 & 0.99 & 0.98 & 0.97 & 1.00 & 0.96 & 0.98 & 1.00 & 1.02 & 1.02 & 1.03 & 1.03 \\
\hline PT & 1.00 & 0.97 & 0.99 & 1.01 & 1.02 & 1.02 & 1.02 & 1.02 & 1.00 & 0.87 & 0.94 & 1.02 & 1.08 & 1.13 & 1.16 & 1.18 \\
\hline RO & 1.00 & 0.97 & 0.97 & 0.95 & 0.93 & 0.90 & 0.87 & 0.85 & 1.00 & 0.98 & 1.00 & 1.02 & 1.02 & 1.02 & 1.03 & 1.03 \\
\hline SK & 1.00 & 0.90 & 0.95 & 1.00 & 1.04 & 1.07 & 1.10 & 1.11 & 1.00 & 0.96 & 1.00 & 1.04 & 1.07 & 1.09 & 1.11 & 1.12 \\
\hline SI & 1.00 & 0.97 & 0.99 & 1.02 & 1.05 & 1.07 & 1.08 & 1.08 & 1.00 & 1.00 & 1.02 & 1.05 & 1.07 & 1.09 & 1.10 & 1.11 \\
\hline SE & 1.00 & 1.01 & 1.02 & 1.04 & 1.05 & 1.05 & 1.06 & 1.07 & 1.00 & 0.93 & 0.96 & 0.99 & 1.01 & 1.03 & 1.04 & 1.05 \\
\hline EU27 & 1.00 & 0.98 & 1.00 & 1.03 & 1.03 & 1.03 & 1.03 & 1.03 & 1.00 & 0.96 & 1.00 & 1.04 & 1.05 & 1.06 & 1.07 & 1.07 \\
\hline
\end{tabular}

Notes: IRL introduced a methodological change in the GDP calculation, and is characterised, next to ROU, by a relatively high historic labour productivity growth rate (see Table 23 and 24).

Source: Own calculations. 
Table 13 / Employment growth by employment groups and scenarios for EU-27, 2019=1

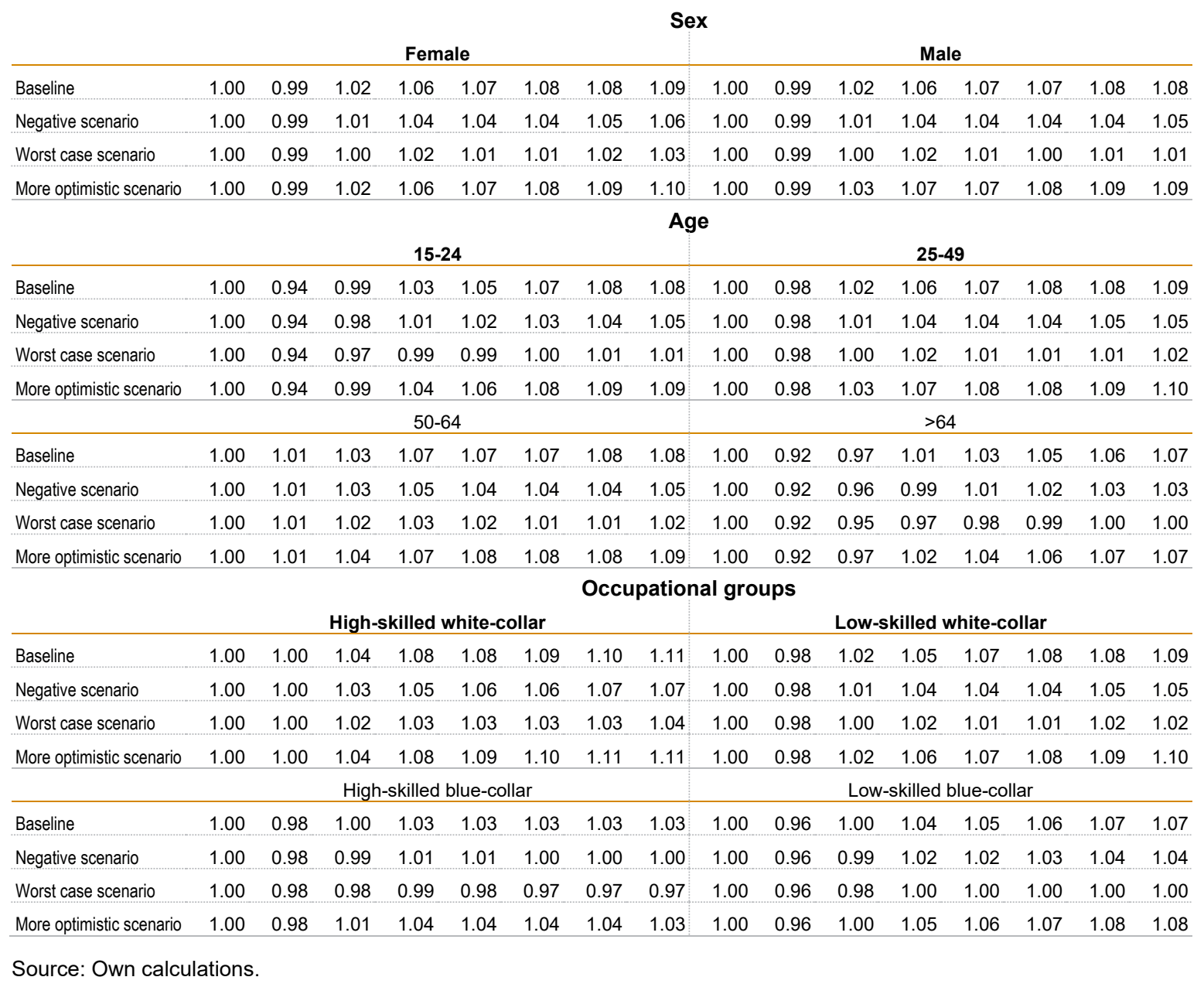

\subsection{SPECIAL FOCUS 1: THE IMPACT OF SLUGGISH RECOVERY IN THE TOURISM INDUSTRY}

In some EU countries, tourism plays an important role for economic development and prosperity. As a result of travel bans and other pandemic-related factors, this industry is likely to take longer to recover, with consequences for countries' growth and employment. Struggles to reach a sufficiently high share of fully vaccinated individuals and the emergence of more resistant mutants may lead to further containment measures, putting even more pressure on the countries that rely on tourism.

In European countries, tourism activities faced a severe contraction in 2020 and early 2021. Even though there was a weak recovery over the summer of 2020 , the second and third virus waves induced the re-implementation of rigorous lockdown measures that primarily hit service industries, most notably the tourism industry. This resulted in a weak performance in tourism in the first months of 2021. However, as governments in European countries once again began to ease lockdown measures, the tourism industry also signalled a slight rebound in April and May 2021. The partial lifting of the international travel ban and the return of cross-border tourism have lent even more momentum to the relaunch of activities in the tourism industry (European Commission, 2021c). 
Wiiw Research Report 457

Despite these positive developments, with a better situation in 2021 than in 2020, tourism demand is nevertheless expected to return only gradually to its pre-pandemic levels (European Commission, 2021b, 2021c).

As data for industry I (tourism) are not yet available from the data used so far (only when aggregated in group G-I), we draw on alternative data from Eurostat (also based on EU-LFS) to show the employment impact of the pandemic crisis in 2020. Table 14 reports the employment growth rates (2019-2020) and shares by sex and age group for this industry in 2019. At the EU27 level, employment in terms of persons employed declined by more than $11 \%$ in 2020 (compared to a decline of around 3-4\% in industries G-I, as a whole, as reported in Figure 9), with the magnitude differing strongly across countries. On average, male workers and (again) younger age groups have been more affected.

\section{Table 14 / Employment growth and structures in tourism (industry I)}

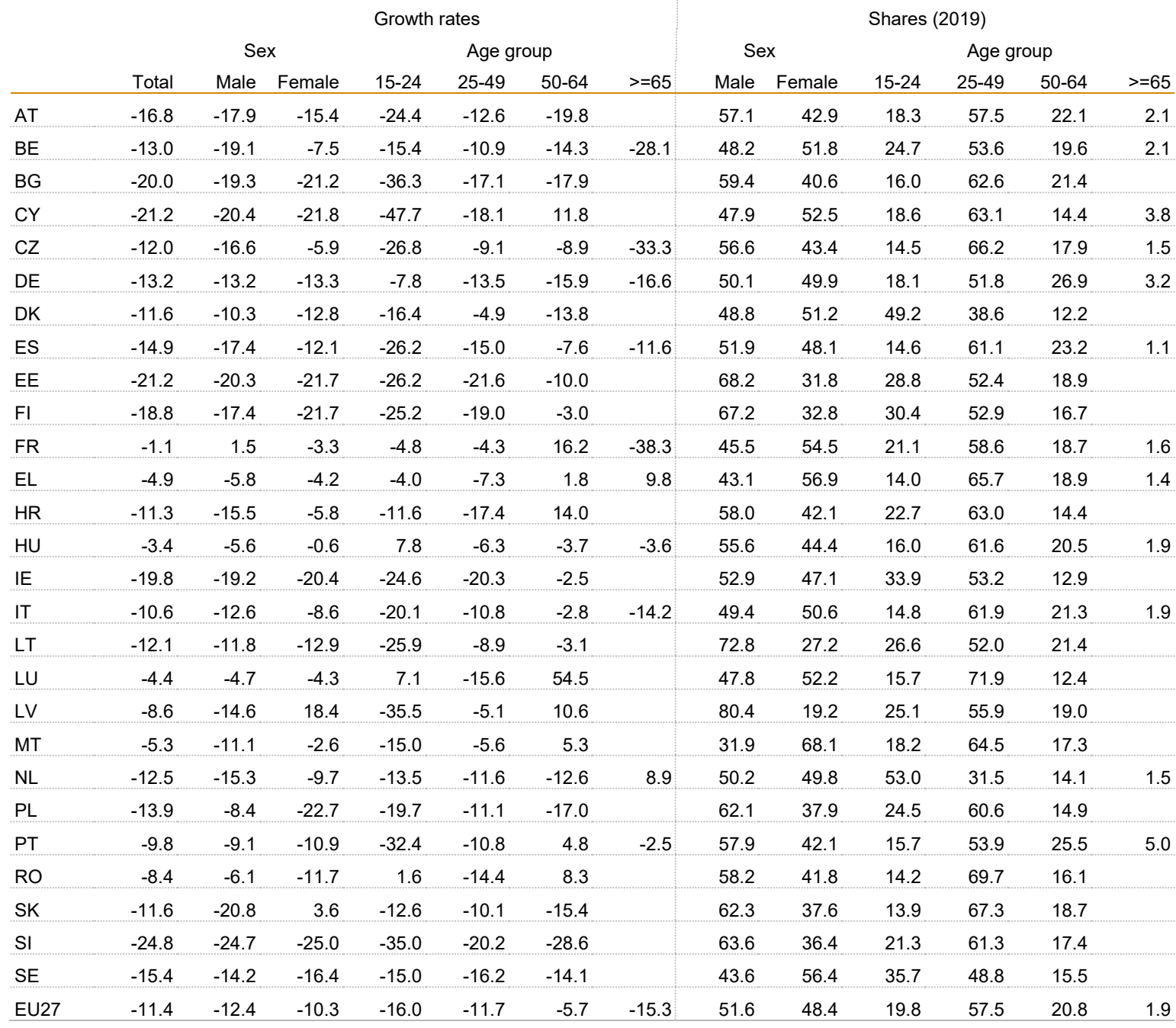

Source: Eurostat LFS; own calculations.

For previous years, more detailed EU-LFS data are available. Appendix Table 15 provides some stylised facts indicating that the industry 'accommodation and foods service activities' (NACE Rev. 2 industry I) 
accounts for about $3 \%$ of value added and $5 \%$ of employment in the EU27 (both for persons employed and hours worked).

Since tourism plays a pivotal role in several EU economies, it is an important question as to what extent recovery paths change when different dynamics for this industry are assumed. For this reason, we run a scenario that assumes - compared to the baseline scenario - the growth rate in industries G-I to be only $50 \%$ in $2021,75 \%$ in 2022 and $90 \%$ in 2023 . Such a weak economic recovery in tourism may reflect the reintroduction of stricter travel bans and the re-emergence of restrained mobility as a result of the pandemic. As we do not adjust the overall growth rates, this results in a slightly lower overall macro-growth rate than assumed in the baseline scenario. The reason for adjusting industry group G-I is that this also includes transport services and retail trade, which might compensate for the lower demand in tourism.

\section{Table 15 / Stylised facts for tourism industry}

\begin{tabular}{|c|c|c|c|c|c|c|c|c|}
\hline \multirow{2}{*}{\multicolumn{2}{|c|}{ Value added }} & \multicolumn{3}{|c|}{ Growth rates 2013-2019 } & \multirow[b]{2}{*}{$\begin{array}{l}\text { Hours } \\
\text { worked }\end{array}$} & \multicolumn{3}{|c|}{ Shares in 2019} \\
\hline & & $\begin{array}{l}\text { Labour productivity } \\
\text { (persons employed) }\end{array}$ & $\begin{array}{c}\text { Labour productivity } \\
\text { (hours worked) }\end{array}$ & $\begin{array}{l}\text { Persons } \\
\text { employed }\end{array}$ & & $\begin{array}{l}\text { Value } \\
\text { added }\end{array}$ & $\begin{array}{l}\text { Persons } \\
\text { employed }\end{array}$ & $\begin{array}{l}\text { Hours } \\
\text { worked }\end{array}$ \\
\hline$B E$ & 1.2 & 0.4 & -0.5 & 0.7 & 1.7 & 1.8 & 3.3 & 3.5 \\
\hline BG & 6.9 & 6.4 & 6.4 & 0.6 & 0.6 & 2.4 & 4.5 & 4.4 \\
\hline$C Z$ & 0.5 & -0.1 & 0.2 & 0.6 & 0.3 & 1.7 & 3.7 & 4.1 \\
\hline DE & 1.8 & 0.5 & 1.4 & 1.3 & 0.4 & 1.6 & 4.2 & 3.8 \\
\hline DK & 1.7 & -2.6 & -2.0 & 4.3 & 3.7 & 1.5 & 4.8 & 3.5 \\
\hline ES & 1.6 & -2.0 & -1.2 & 3.7 & 2.9 & 6.1 & 8.1 & 8.6 \\
\hline EE & 1.7 & -3.2 & -1.9 & 5.2 & 4.1 & 1.7 & 4.2 & 4.0 \\
\hline EL & 4.2 & -2.5 & -1.0 & 7.5 & 5.9 & 7.0 & 12.5 & 13.1 \\
\hline HR & 3.8 & 2.5 & 3.4 & 1.5 & 0.6 & 6.1 & 6.8 & 7.0 \\
\hline $\mathrm{HU}$ & 5.6 & 4.9 & 5.6 & 1.6 & 1.0 & 1.8 & 3.9 & 3.5 \\
\hline IE & 6.4 & 0.9 & 0.4 & 5.5 & 6.1 & 1.8 & 8.7 & 7.5 \\
\hline IT & 1.1 & -1.9 & -1.0 & 3.1 & 2.1 & 3.9 & 6.7 & 6.8 \\
\hline LT & 5.0 & 2.3 & 1.9 & 2.9 & 3.4 & 1.7 & 2.8 & 2.7 \\
\hline LU & 0.1 & -2.7 & -2.6 & 2.8 & 2.8 & 1.6 & 4.7 & 4.5 \\
\hline LV & 6.4 & 3.6 & 4.1 & 2.7 & 2.4 & 2.1 & 3.5 & 3.3 \\
\hline MT & 9.0 & 2.1 & 4.2 & 7.3 & 4.9 & 5.3 & 7.2 & 8.0 \\
\hline SI & 3.8 & 0.1 & 0.8 & 3.6 & 3.0 & 2.3 & 4.1 & 3.9 \\
\hline SE & 3.3 & -0.3 & -0.1 & 3.6 & 3.4 & 1.7 & 4.0 & 3.7 \\
\hline EU27 & 1.9 & -0.8 & -0.3 & 2.7 & 2.2 & 2.8 & 5.1 & 5.2 \\
\hline
\end{tabular}

* calculated from data in chain-linked volumes.

Source: Eurostat; own calculations.

As can be seen in Table 16, despite the relatively large share in value added (around $20 \%$ on average) and high employment shares (of around one quarter), the impact on overall employment is rather 
Wiiw Research Report 457

modest, as the industry is characterised by relatively high labour productivity growth rates (see Figure 5). These offset the effects of value-added growth, resulting in only modest total economy employment effects. Therefore, the assumed changes in value-added growth rates do not have much of an impact on the overall employment dynamics.

Table 16 / Negative impact on tourism, 2019=1

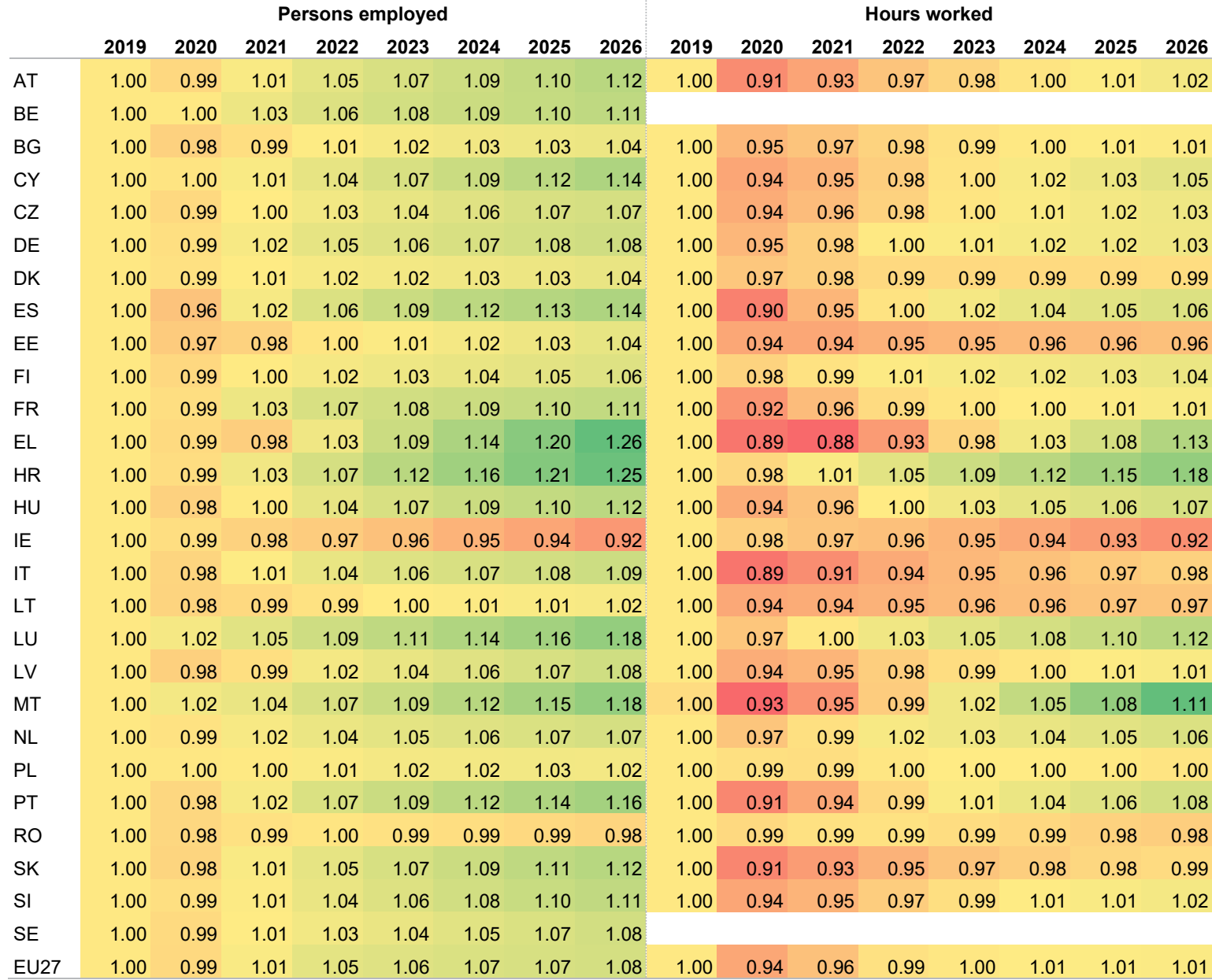

Note: Information on hours worked not available for BEL and SWE. IRL introduced a methodological change in the GDP calculation, and is characterised, next to ROU, by a relatively high historic labour productivity growth rate (see Table 23 and 24).

Source: Own calculations. 


\subsection{SPECIAL FOCUS 2: THE ROLE OF FISCAL MEASURES AND CONSOLIDATION}

For policymakers it is of fundamental importance to know how fiscal stimuli can impact economies' GDP and therefore employment levels. As discussed in Section 2.2, discussions have already evolved around a gradual reduction of government support measures and the introduction of fiscal consolidation measures after the pandemic. Though in 2022 fiscal rules are still officially suspended, it might be worth considering the potential effects of fiscal measures. A simple way to do this is to calculate the economic effects of a $1 \%$ change of fiscal government expenditures using input-output analysis.

We draw on the wiiw multi-country input-output tables (MC IOTs) (see Reiter and Stehrer, 2021) and calculate the effects on value added if all EU Member States were to increase their government expenditure by one percent simultaneously. Using MC IOTs also takes international spillover effects into account, as higher government expenditure leads in part to greater demand for imports, thus also triggering effects on the GDP of other countries. ${ }^{8}$ The results are presented in Figure 17. In most cases, the implied changes in GDP are between 0.15 and $0.2 \%$, and a bit higher in certain countries, such as Sweden, Denmark, the Netherlands and France (depending on the size of government and the international linkages). The average across all countries is $0.2 \%$. Of course, if the fiscal stimuli were higher or, the opposite, were to become fiscal consolidation measures, the results would change accordingly (e.g. fiscal consolidation measures reducing government expenditures by $3 \%$ in all EU countries simultaneously would imply a GDP loss of about $0.6 \%$ on average). One should note that these figures might be lower bounds, as not taking induced effects or so-called Type II multiplier effects (e.g. change in household income and therefore changes in household expenditures) into account. Employment effects (which are not separately presented) are of a similar size to those presented in Figure $17 .^{9}$

A related question applies to the effects of the RFF spending. Drawing on data collected by Bruege ${ }^{10}$, who provide detailed data on the national recovery funds (grants and loans), we perform a similar exercise. Safe assumptions about the allocation of RRF spending across industries could not be made in the data. In our calculations, this spending is thus allocated proportionally to government spending by industry. According to these data, Bulgaria and the Netherlands have not yet submitted their plans, whereas for Denmark, Ireland and Malta no allocation across industries is provided. In these cases, we use the figures on estimated grants and allocate proportionally over government spending by industry. As the time profile of planned recovery spending is only known for some countries, we simply assume that about a fifth is spent per year (even though higher shares of spending are actually expected over the period 2021-2023).

8 Multi-country input-output tables allow the modelling of inter-country linkages via trade in intermediates and final goods. Thus, for example, increasing demand in one country also impacts on value added and employment in other countries due to direct and indirect demand for and production of intermediary products (spillover effects). Formally we calculate $\Delta \mathrm{VA}=\hat{\mathrm{v}} \mathrm{L} \Delta \mathrm{f}$ where $V A$ denotes value-added levels, $\hat{v}$ is the diagonalised value-added coefficient vector (value added relative to gross output), $L$ is the global Leontief inverse and $f$ denotes the final demand vector. We thus calculate the change in value added, given the change in final demand due to changes in government spending, and express it in percent of the original value-added levels. This conforms with the so-called Type I value-added multiplier effects. For the sake of consistency with other results in the report we aggregated the wiiw MC IOTs into the eleven industries considered so far.

9 Here, we implicitly assume that changes in government expenditures do not impact the labour productivity growth rate. $\bar{\varphi}_{i}$ thus remains unchanged.

10 See https://www.bruegel.org/publications/datasets/european-union-countries-recovery-and-resilience-plans/ 
Wiiw Research Report 457

Figure 17 / Effects of simultaneous change of government expenditure by $1 \%$ in all EU27 Member States on value added

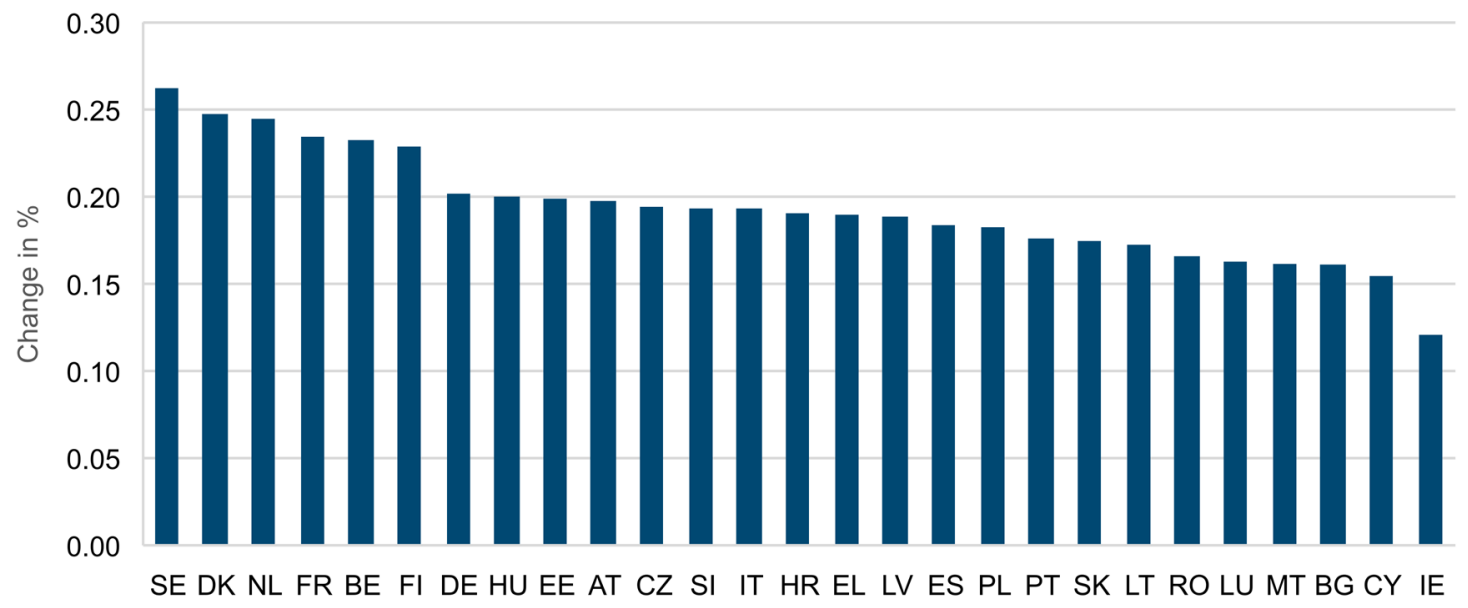

Source: wiiw MC IOD, own calculations

Figure 18 presents the thus calculated average annual RFF spending in percentage of GDP. ${ }^{11}$ These numbers range from more than $2 \%$ in Greece, Italy, Bulgaria, Croatia and Romania, to very small shares in the more advanced economies.

Figure 18 / Share of RFF spending (grants and loans) in \% of value added

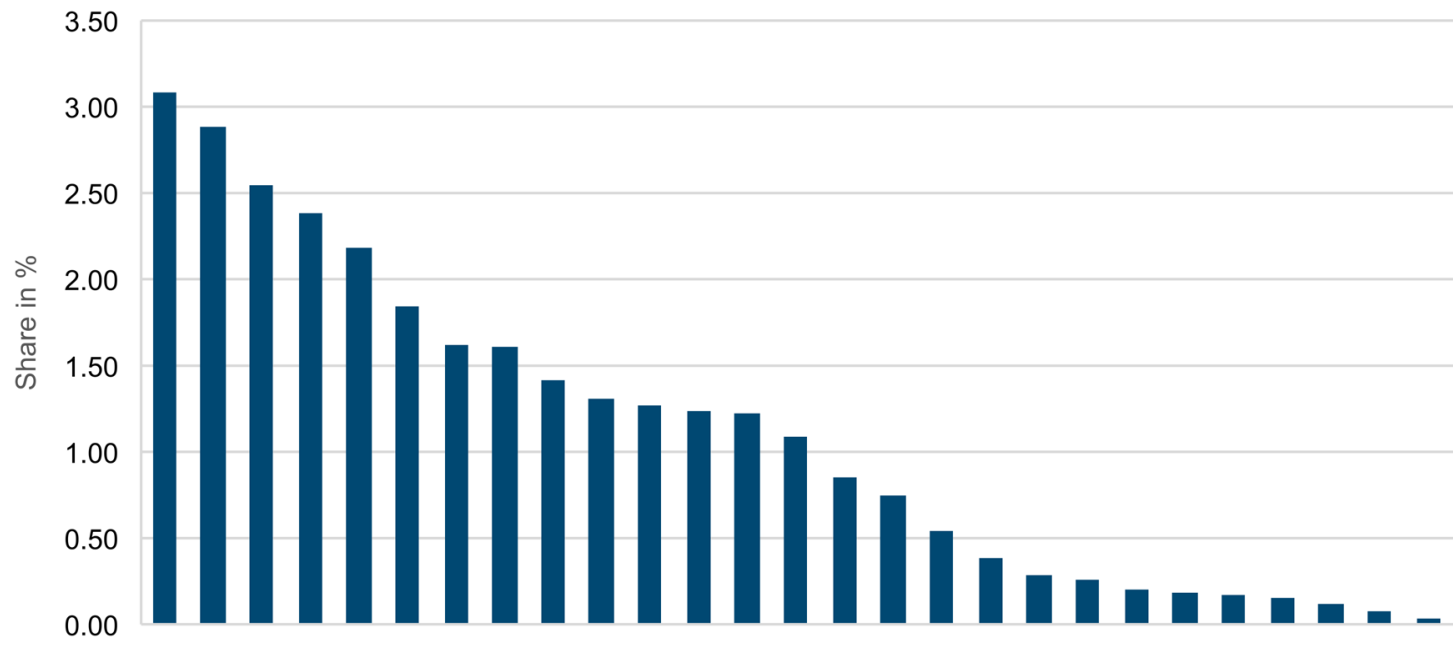

RO HR BG IT EL PT PL SK LV CY ES HU SI LT EE CZ MT FR BE AT FI DE NL SE DK IE LU

Source: Bruegel; wiiw MC IOD, own calculations.

11 Specifically, we converted the RFF data into USD using an exchange rate of 1.2 (average of 2018) and express it as percentage of the value added by country, taken from the wiiw MC IOTs. 
Using the same methodology, we calculate the impacts of this spending from the RFF on value added and present the results in Figure 19. The impact is similar to the shares of the RFF spending in GDP, though slightly lower due to the fact that part of these have to be imported from countries, which is particularly the case for the smaller and less advanced economies. Conversely, the impact is therefore slightly larger in the more advanced economies, although the differences are small. As above, the effects are lower bounds, as they only include Type I multiplier effects.

\section{Figure 19 / Effects of RFF spending per year in all EU27 Member States on value added}

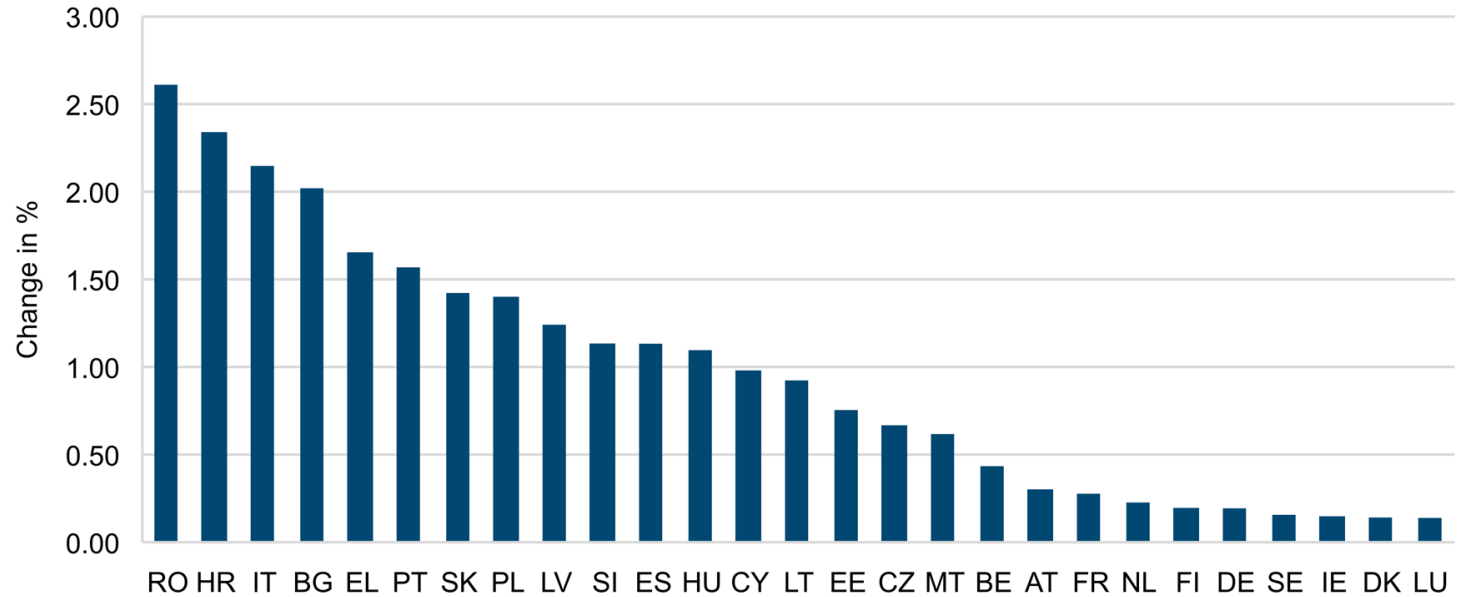

Source: Bruegel; wiiw MC IOD, own calculations.

Figure 20 / Effects of RFF spending per year in all EU27 Member States on employment

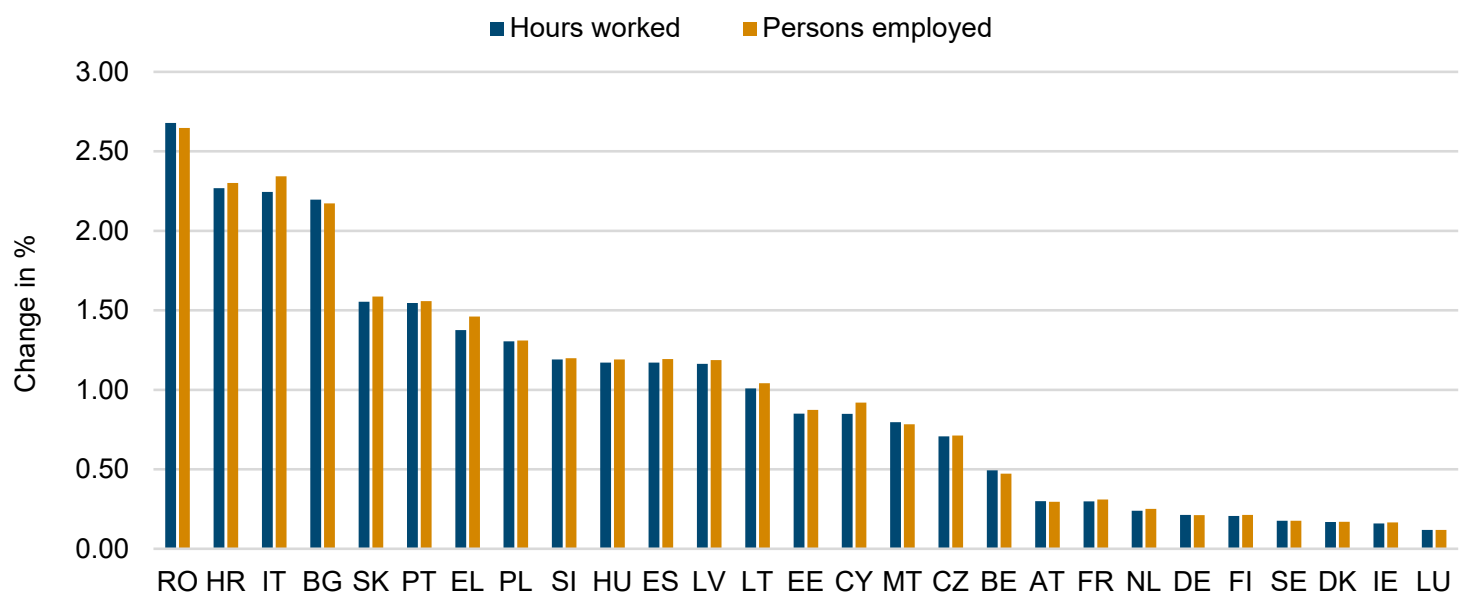

Source: wiiw MC IOT; Eurostat; own calculations.

Table 17 summarises the effects of RRF spending on persons employed in European economies by industry. As can be seen, the results are rather heterogenous across countries and industries, depending on the magnitude of the RFF spending as well as the spending patterns by industry. 
Wiiw Research Report 457

Table 17 / Impact of RFF on persons employed by industry

\begin{tabular}{|c|c|c|c|c|c|c|c|c|c|c|c|}
\hline & A & BDE & C & $\mathrm{F}$ & G-I & $\mathrm{J}$ & K & L & M_N & $O-Q$ & $\mathrm{R}-\mathrm{U}$ \\
\hline AT & 0.24 & 1.24 & 0.18 & 0.31 & 0.29 & 1.18 & 0.19 & 0.11 & 0.31 & 0.26 & 0.14 \\
\hline $\mathrm{BE}$ & 0.51 & 0.36 & 0.35 & 2.78 & 0.26 & 0.21 & 0.24 & 0.12 & 0.51 & 0.30 & 0.11 \\
\hline BG & 0.39 & 0.57 & 0.45 & 0.78 & 0.63 & 0.83 & 0.81 & 0.48 & 1.66 & 9.90 & 2.50 \\
\hline CY & 0.29 & 6.21 & 0.39 & 0.26 & 0.38 & 0.82 & 0.27 & 0.24 & 0.45 & 2.91 & 0.12 \\
\hline$C Z$ & 0.89 & 1.53 & 0.20 & 0.39 & 0.59 & 0.62 & 0.37 & 0.26 & 1.25 & 1.40 & 0.78 \\
\hline $\mathrm{DE}$ & 0.10 & 0.34 & 0.12 & 0.22 & 0.24 & 0.33 & 0.09 & 0.07 & 0.18 & 0.31 & 0.05 \\
\hline DK & 0.11 & 0.12 & 0.12 & 0.04 & 0.06 & 0.10 & 0.04 & 0.03 & 0.11 & 0.37 & 0.13 \\
\hline ES & 1.95 & 5.18 & 0.40 & 0.26 & 1.11 & 0.44 & 0.50 & 0.30 & 1.68 & 1.74 & 0.53 \\
\hline EE & 0.15 & 0.85 & 0.18 & 0.49 & 0.51 & 0.35 & 0.29 & 0.27 & 0.62 & 2.51 & 0.30 \\
\hline $\mathrm{FI}$ & 0.15 & 0.44 & 0.13 & 0.11 & 0.12 & 0.23 & 0.10 & 0.15 & 0.51 & 0.23 & 0.10 \\
\hline FR & 0.15 & 0.17 & 0.14 & 0.03 & 0.29 & 0.70 & 0.14 & 0.07 & 0.19 & 0.51 & 0.27 \\
\hline EL & 0.43 & 7.25 & 0.46 & 1.73 & 0.53 & 7.34 & 0.93 & 0.84 & 1.46 & 2.92 & 1.00 \\
\hline HR & 0.74 & 6.38 & 0.73 & 4.04 & 1.12 & 2.22 & 6.24 & 0.64 & 1.20 & 4.07 & 3.09 \\
\hline $\mathrm{HU}$ & 0.32 & 4.16 & 0.25 & 0.49 & 1.17 & 0.65 & 0.48 & 0.40 & 0.79 & 2.89 & 0.14 \\
\hline $\mathrm{IE}$ & 0.08 & 0.11 & 0.15 & 0.03 & 0.07 & 0.15 & 0.16 & 0.06 & 0.14 & 0.37 & 0.07 \\
\hline IT & 1.80 & 5.46 & 0.63 & 2.47 & 1.92 & 2.43 & 1.24 & 0.52 & 2.72 & 4.64 & 1.41 \\
\hline LT & 0.16 & 2.09 & 0.25 & 0.24 & 0.54 & 0.30 & 0.51 & 1.24 & 1.73 & 2.64 & 0.13 \\
\hline LU & 0.11 & 0.19 & 0.08 & 0.06 & 0.09 & 0.23 & 0.20 & 0.08 & 0.22 & 0.05 & 0.07 \\
\hline LV & 0.18 & 2.41 & 0.25 & 0.27 & 0.76 & 2.79 & 4.24 & 0.54 & 2.01 & 1.71 & 2.96 \\
\hline MT & 0.36 & 0.83 & 0.29 & 0.85 & 0.25 & 0.25 & 0.12 & 0.22 & 0.56 & 2.25 & 0.04 \\
\hline NL & 0.14 & 0.39 & 0.15 & 0.11 & 0.11 & 0.15 & 0.10 & 0.07 & 0.21 & 0.54 & 0.13 \\
\hline $\mathrm{PL}$ & 1.28 & 6.38 & 0.37 & 0.63 & 1.18 & 1.42 & 0.51 & 0.96 & 2.01 & 1.80 & 0.37 \\
\hline PT & 1.64 & 3.10 & 0.38 & 2.08 & 0.76 & 0.90 & 4.96 & 0.24 & 1.99 & 3.04 & 0.57 \\
\hline RO & 2.07 & 6.39 & 0.83 & 2.97 & 3.10 & 1.85 & 4.98 & 0.59 & 3.39 & 4.10 & 1.85 \\
\hline SK & 0.32 & 2.55 & 0.25 & 2.22 & 1.01 & 2.07 & 0.43 & 0.31 & 1.84 & 3.87 & 0.26 \\
\hline SI & 0.88 & 2.20 & 0.34 & 0.84 & 0.78 & 1.22 & 1.80 & 0.38 & 1.05 & 2.71 & 1.95 \\
\hline SE & 0.21 & 0.09 & 0.12 & 0.28 & 0.12 & 0.17 & 0.06 & 0.06 & 0.19 & 0.23 & 0.05 \\
\hline
\end{tabular}

Source: wiiw MC IOT; Eurostat; own calculations.

Beyond that, we also estimate employment effects by employment group. Figure 21 shows the results for women and men. Overall, women can expect to benefit slightly more than men from RRF spending when it comes to persons employed. Figure 22 contrasts the RRF effects on persons employed by age group. Importantly, effects for younger individuals (15-24) appear to lag behind the effects for older individuals in almost all EU economies. Finally, Figure 23 illustrates the RRF effects on persons employed by occupation group. As can be seen, white collar individuals benefit more than blue collar individuals in most countries. Interestingly, lower-skilled white and blue collar workers tend to experience weaker effects than their higher-skilled counterparts. 
Figure 21 / Impact of RFF on persons employed by sex

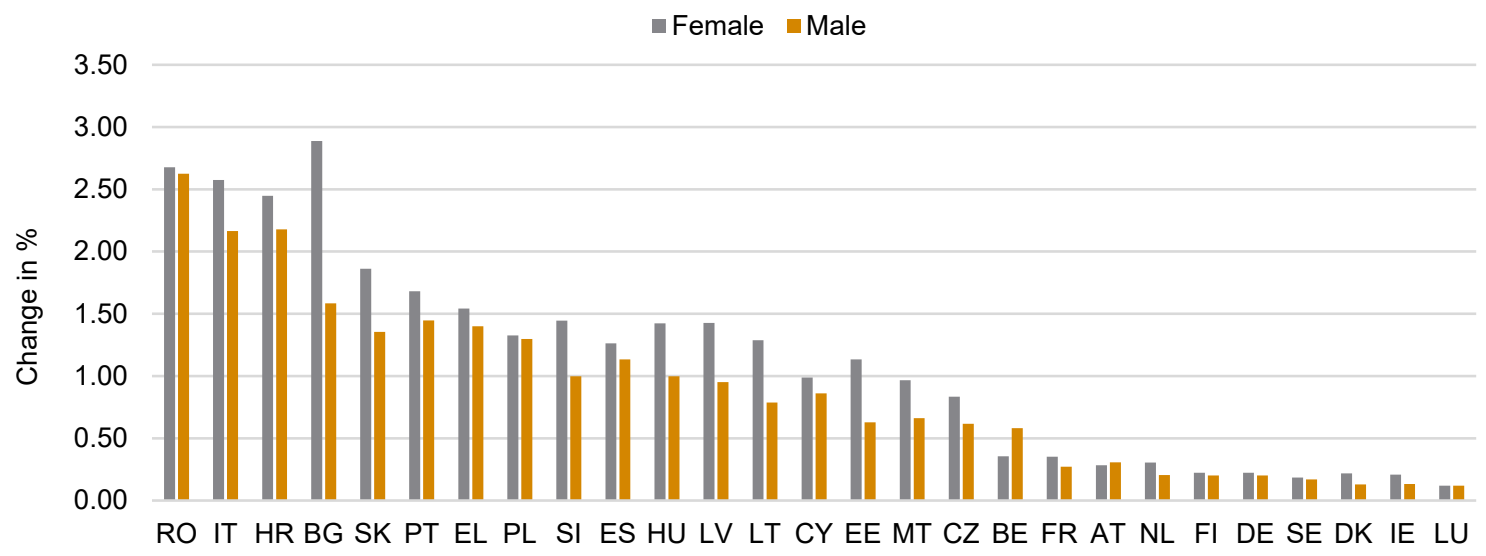

Source: wiiw MC IOT; Eurostat; own calculations.

Figure 22 / Impact of RFF on employment by age group

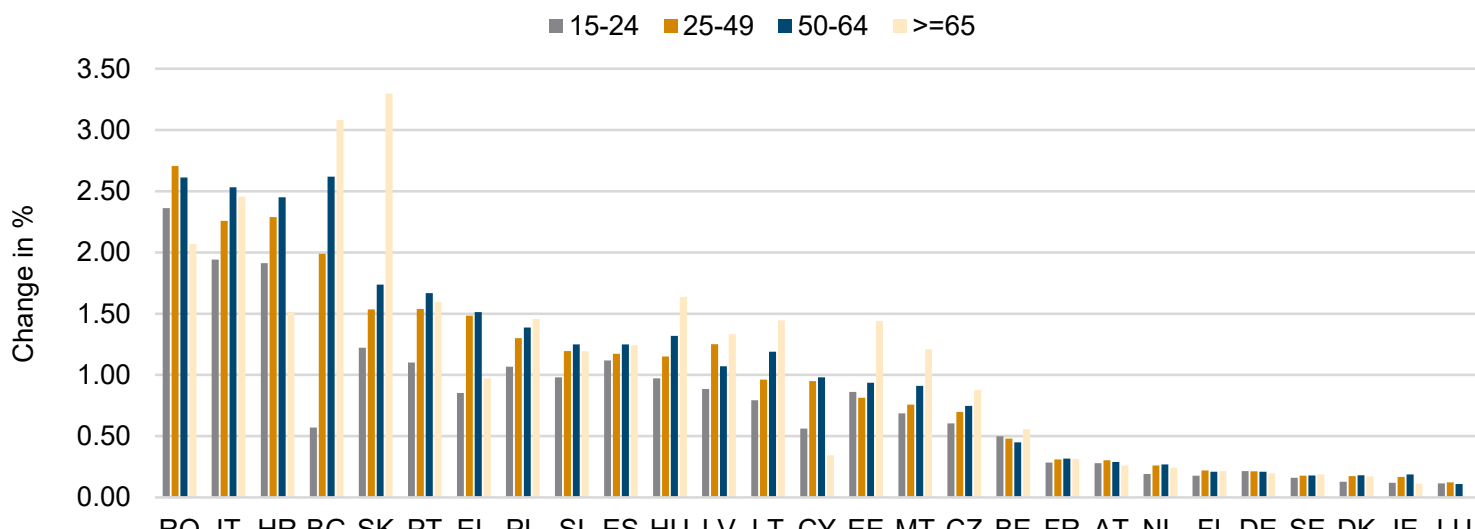

Source: wiiw MC IOT; Eurostat; own calculations.

Figure 23 / Impact of RFF on employment by occupational group

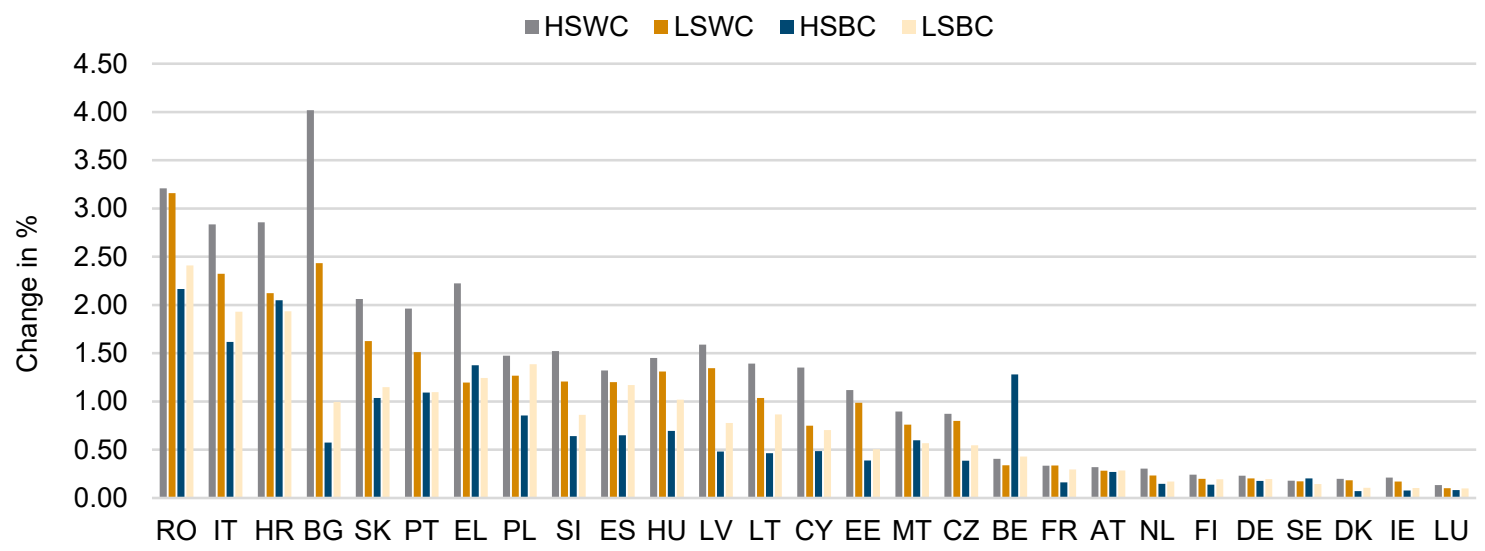




\section{Conclusions}

This study provides detailed insights into the employment dynamics across European countries, industries and employment groups for the period 2021-2026. We have exploited information on past sectoral trends and have drawn upon the latest macroeconomic forecast results taken from the IMF and the European Commission as our baseline. A scenario analysis further accounts for the great uncertainty and risks that are related to the baseline forecasts.

The baseline results indicate that in most countries employment is expected to reach its pre-pandemic level as early as 2021 or 2022 based on high projected GDP growth rates of up to $4 \%$ in 2021 and 2022 , while hours worked will lag behind with a full catching up only in 2022 and 2023 according to these calculations. Even though these predictions suggest a relatively quick recovery from the economic disturbance caused by the pandemic, these numbers are highly uncertain. As indicated by the scenario analysis, the recovery of employment could turn out to be rather sluggish. The more negative scenarios, moreover, predict only a limited recovery for persons employed and an incomplete recovery for hours worked, even by 2026.

The results further suggest that younger and low-skilled workers have been the hardest-hit population subgroups. For these groups the recovery is also expected to take longer than for other age and education groups. A more negative economic development, as is assumed in the negative scenarios, would put even more pressure on these most affected employment groups. Interestingly, the results point to a rather balanced impact and recovery of employment for both gender groups.

These results hint at a number of valuable policy conclusions. First, in order for the labour market recovery to continue and strengthen, including in the most badly affected industries, overall economic growth needs to be strong. This means that fiscal and monetary policies need to be expansionary. On the monetary side, this still seems fairly likely. The ECB retains a dovish stance and has emphasised repeatedly that the current spike in inflation in some parts of the euro area is 'transitory' and will not lead to a tightening of policy. EU fiscal policy has also so far been supportive in response to the pandemic. It is vital that fiscal support be maintained in order to underpin a quick recovery to pre-crisis employment levels in conjunction with sustainable and strong growth. Fiscal support should not be indiscriminate but rather targeted at the most pressing short-term needs, as well as help to prepare EU economies for the most important future challenges, such as the climate crisis and digitalisation. A premature return to fiscal consolidation and harsh austerity - as happened after the global financial crisis in 2009 - would weaken the economic recovery. Our results suggest a pivotal role for RRF investments in the recovery of employment in many European economies.

Second, for the industries that have suffered the most from the pandemic and are still in danger should the Delta variant trigger a fourth wave of the virus, support schemes should remain in place or be quickly reactivated if necessary. This applies in particular to job retention programmes such as short-time work schemes. Limiting the direct impact of future lockdowns on employment will be crucial to making sure that the labour market recovers quickly and sustainably after the pandemic. 
Third, targeted policies are needed for segments of the labour market that have suffered the most and might also lag behind in the recovery phase. This includes, in particular, younger workers who have recently or are about to enter the labour market, and groups such as low-skilled workers and those who have lost jobs in heavily affected industries such as tourism. The RRF is to some extent expected to foster the labour market performance of these groups; however, more help is needed. Failing to address these labour market challenges in the longer term is likely to fuel economic and social inequalities.

Finally, even though employment in terms of persons employed is generally currently recovering in EU countries (albeit less so in terms of hours worked), it might take a long time for it to reach its pre-crisis level. Policymakers need to pay particular attention to the long-term unemployed, as persistent unemployment often results in scarring effects that are harmful for economic development. Again, this will require a particular focus on certain age groups (e.g. older workers), regions (e.g. those most reliant on tourism), and workers lacking skills that are likely to be increasingly important in the post-pandemic world. 


\section{References}

Adams-Prassl A., Boneva T., Golin M. and Rauh C. (2020) Inequality in the impact of the coronavirus shock: evidence from real time surveys, Journal of Public Economics, 189, 104245.

Blanchard O., Leandro A. and Zettelmeyer J. (2021) Redesigning EU fiscal rules: from rules to standards, Working Paper 21.1, Washington, The Peterson Institute for International Economics. https://academic.oup.com/economicpolicy/advancearticle-abstract/doi/10.1093/epolic/eiab003/6122701

Chatterjee P. and Nowak S. (2016) Forecast errors and uncertainty shocks, IMF Working Paper WP/16/228, Washington, International Monetary Fund.

Dingel J.I. and Neiman B. (2020) How many jobs can be done at home? Journal of Public Economics, 189, 104235.

Eurofound (2021) COVID-19: implications for employment and working life, Luxembourg, Publications Office of the European Union.

European Commission (2019) Communication from the Commission to the European Parliament, the European Council, the Council, the European Economic and Social Committee and the Committee of the Regions: The European Green Deal, COM (2019) 640 final, 11 December 2019.

European Commission (2021a) European Economic Forecast Winter 2021 (Interim), Institutional Paper 144, Luxembourg, Publications Office of the European Union.

European Commission (2021b) European Economic Forecast Spring 2021, Institutional Paper 149 Luxembourg, Publications Office of the European Union.

European Commission (2021c) European Economic Forecast Summer 2021, Institutional Paper 156, Luxembourg, Publications Office of the European Union.

Heggeness M. L. (2020) Estimating the immediate impact of the COVID-19 shock on parental attachment to the labor market and the double bind of mothers, Review of Economics of the Household, 18 (4), 1053-1078.

Heimberger P. (2017) Did fiscal consolidation cause the double-dip recession in the euro area? Review of Keynesian Economics, 5 (3), 439-458.

IMF (2021a) World economic outlook - April 2021 - Managing divergent recoveries, Washington DC, International Monetary Fund.

IMF (2021b) World economic outlook update July 2021 - Fault lines widen in the global recovery, Washington DC, International Monetary Fund.

Martin P., Pisani-Ferry J. and Ragot X. (2021) Reforming the European fiscal framework, Les notes du conseil d'analyse économique 63, April 2021

OECD (2021a) OECD economic outlook, interim report. strengthening the recovery: the need for speed, March 2021, Paris, OECD Publishing.

OECD (2021b) OECD employment outlook 2021: navigating the COVID-19 crisis and recovery, Paris, OECD Publishing.

Reiter O. and Stehrer R. (2021) Value chain integration of the Western Balkan countries and policy options for the post-Covid-19 period, wiiw Policy Notes and Reports 48, Vienna, The Vienna Institute for International Economic Studies. 


\section{Appendix A}

\section{CLASSIFICATIONS}

\section{Appendix - Table 18 / EU: List of industries $\left(A^{*} 10\right)$}

\begin{tabular}{rrl} 
Nr & Code & Description \\
\hline 1 & A & Agriculture, forestry and fishing \\
2 & B-E & Manufacturing, mining and quarrying and other industry \\
$2 a$ & $\ldots$ C & ... of which manufacturing \\
3 & F & Construction \\
4 & G-I & Wholesale and retail trade, transportation and storage, accommodation and food service activities \\
5 & J & Information and communication \\
6 & K & Financial and insurance activities \\
7 & L & Real estate activities* \\
8 & M_N & Professional, scientific, technical, administration and support service activities \\
9 & O-Q & Public administration, defence, education, human health and social work activities \\
10 & R-U & Other services
\end{tabular}

*which includes imputed rents of owner-occupied dwellings.

Source: Eurostat (2008). 
Wiiw Research Report 457

\section{Appendix B}

\section{TABLES}

Appendix - Table 19 / EU Commission forecasts (Spring 2021, Summer 2021)

\begin{tabular}{|c|c|c|c|c|c|c|c|c|c|c|c|}
\hline & \multicolumn{3}{|c|}{5 -year averages } & \multirow[b]{2}{*}{2017} & \multirow[b]{2}{*}{2018} & \multirow[b]{2}{*}{2019} & \multirow[b]{2}{*}{2020} & \multicolumn{2}{|c|}{$\begin{array}{c}\text { Spring } 2021 \\
\text { forecast }\end{array}$} & \multicolumn{2}{|c|}{ Summer update } \\
\hline & 2002-2006 & 2007-2011 & 2012-2016 & & & & & 2021 & 2022 & 2021 & 2022 \\
\hline AT & 2.2 & 1.2 & 0.9 & 2.4 & 2.6 & 1.4 & -6.6 & 3.4 & 4.3 & 3.8 & 4.5 \\
\hline $\mathrm{BE}$ & 2.2 & 1.3 & 1.2 & 1.6 & 1.8 & 1.8 & -6.3 & 4.5 & 3.7 & 5.4 & 3.7 \\
\hline BG & 6.3 & 2.4 & 2.1 & 3.5 & 3.1 & 3.7 & -4.2 & 3.5 & 4.7 & 4.6 & 4.1 \\
\hline HR & 5.0 & -0.5 & 0.5 & 3.4 & 2.8 & 2.9 & -8.0 & 5.0 & 6.1 & 5.4 & 5.9 \\
\hline CY & 4.2 & 1.8 & -0.5 & 5.2 & 5.2 & 3.1 & -5.1 & 3.1 & 3.8 & 4.3 & 3.8 \\
\hline$C Z$ & 4.6 & 1.5 & 1.8 & 5.2 & 3.2 & 2.3 & -5.6 & 3.4 & 4.4 & 3.9 & 4.5 \\
\hline DK & 1.9 & -0.3 & 1.7 & 2.8 & 2.2 & 2.8 & -2.7 & 2.9 & 3.5 & 3.0 & 3.4 \\
\hline EE & 8.1 & -0.7 & 2.5 & 5.5 & 4.4 & 5.0 & -2.9 & 2.8 & 5.0 & 4.9 & 3.8 \\
\hline $\mathrm{FI}$ & 2.9 & 0.6 & 0.1 & 3.2 & 1.3 & 1.3 & -2.8 & 2.7 & 2.8 & 2.7 & 2.9 \\
\hline FR & 1.8 & 0.8 & 0.8 & 2.3 & 1.8 & 1.5 & -8.1 & 5.7 & 4.2 & 6.0 & 4.2 \\
\hline DE & 1.0 & 1.2 & 1.4 & 2.6 & 1.3 & 0.6 & -4.9 & 3.4 & 4.1 & 3.6 & 4.6 \\
\hline EL & 4.2 & -3.5 & -2.0 & 1.3 & 1.6 & 1.9 & -8.2 & 4.1 & 6.0 & 4.3 & 6.0 \\
\hline $\mathrm{HU}$ & 4.4 & -0.5 & 2.1 & 4.3 & 5.4 & 4.6 & -5.0 & 5.0 & 5.5 & 6.3 & 5.0 \\
\hline IE & 5.3 & -0.4 & 7.1 & 9.1 & 8.5 & 5.6 & 3.4 & 4.6 & 5.0 & 7.2 & 5.1 \\
\hline IT & 0.9 & -0.5 & -0.6 & 1.7 & 0.9 & 0.3 & -8.9 & 4.2 & 4.4 & 5.0 & 4.2 \\
\hline LV & 9.3 & -1.5 & 2.8 & 3.3 & 4.0 & 2.0 & -3.6 & 3.5 & 6.0 & 3.8 & 6.0 \\
\hline LT & 7.8 & 0.9 & 3.1 & 4.3 & 3.9 & 4.3 & -0.9 & 2.9 & 3.9 & 3.8 & 3.9 \\
\hline LU & 3.5 & 1.9 & 3.3 & 1.8 & 3.1 & 2.3 & -1.3 & 4.5 & 3.3 & 4.8 & 3.3 \\
\hline MT & 2.5 & 2.7 & 6.2 & 8.1 & 5.2 & 5.5 & -7.0 & 4.6 & 6.1 & 5.6 & 5.8 \\
\hline NL & 1.6 & 1.0 & 0.9 & 2.9 & 2.4 & 1.7 & -3.7 & 2.3 & 3.6 & 3.3 & 3.3 \\
\hline PL & 4.0 & 4.5 & 2.6 & 4.8 & 5.4 & 4.7 & -2.7 & 4.0 & 5.4 & 4.8 & 5.2 \\
\hline PT & 0.8 & -0.1 & -0.1 & 3.5 & 2.8 & 2.5 & -7.6 & 3.9 & 5.1 & 3.9 & 5.1 \\
\hline RO & 6.2 & 1.6 & 3.4 & 7.3 & 4.5 & 4.1 & -3.9 & 5.1 & 4.9 & 7.4 & 4.9 \\
\hline SK & 6.1 & 3.8 & 2.4 & 3.0 & 3.7 & 2.5 & -4.8 & 4.8 & 5.2 & 4.9 & 5.3 \\
\hline SI & 4.1 & 0.9 & 0.9 & 4.8 & 4.4 & 3.2 & -5.5 & 4.9 & 5.1 & 5.7 & 5.0 \\
\hline ES & 3.3 & 0.0 & 0.7 & 3.0 & 2.4 & 2.0 & -10.8 & 5.9 & 6.8 & 6.2 & 6.3 \\
\hline SE & 3.3 & 1.5 & 1.9 & 2.6 & 2.0 & 1.4 & -2.8 & 4.4 & 3.3 & 4.6 & 3.6 \\
\hline EU27 & 2.0 & 0.7 & 1.0 & 2.8 & 2.1 & 1.6 & -6.1 & 4.2 & 4.4 & 4.8 & 4.5 \\
\hline
\end{tabular}

Source: EU Commission (2021b). 
Appendix - Table 20 / IMF growth forecasts

\begin{tabular}{|c|c|c|c|c|c|c|c|c|c|c|c|c|c|}
\hline & & year averag & & & & & Sp & ng 202 & foreca & & & & \\
\hline & 2002-2006 & 2007-2011 & 2012-2016 & 2017 & 2018 & 2019 & 2020 & 2021 & 2022 & 2023 & 2024 & 2025 & 2026 \\
\hline AT & 2.2 & 1.2 & 0.9 & 2.4 & 2.6 & 1.4 & -6.6 & 3.5 & 4.0 & 2.3 & 2.0 & 1.8 & 1.8 \\
\hline$B E$ & 2.2 & 1.3 & 1.2 & 1.6 & 1.8 & 1.7 & -6.4 & 4.0 & 3.1 & 2.1 & 1.6 & 1.3 & 1.3 \\
\hline BG & 6.3 & 2.5 & 2.1 & 3.5 & 3.1 & 3.7 & -3.8 & 4.4 & 4.4 & 3.9 & 3.2 & 3.0 & 2.8 \\
\hline $\mathrm{HR}$ & 5.0 & -0.4 & 0.6 & 3.4 & 2.8 & 2.9 & -9.0 & 4.7 & 5.0 & 4.2 & 3.5 & 3.7 & 3.0 \\
\hline CY & 4.2 & 1.8 & -0.4 & 5.2 & 5.2 & 3.1 & -5.1 & 3.0 & 3.9 & 3.1 & 2.8 & 2.6 & 2.5 \\
\hline$C Z$ & 4.7 & 1.6 & 1.9 & 5.2 & 3.2 & 2.3 & -5.6 & 4.2 & 4.3 & 3.7 & 3.2 & 2.9 & 2.5 \\
\hline DK & 2.0 & -0.3 & 1.6 & 2.8 & 2.2 & 2.9 & -3.3 & 2.8 & 2.9 & 1.8 & 1.8 & 1.8 & 1.8 \\
\hline EE & 8.1 & -0.4 & 2.5 & 5.5 & 4.4 & 5.0 & -2.9 & 3.4 & 4.2 & 3.5 & 3.2 & 3.0 & 3.0 \\
\hline $\mathrm{FI}$ & 2.9 & 0.7 & 0.1 & 3.2 & 1.3 & 1.3 & -2.9 & 2.3 & 2.5 & 1.5 & 1.3 & 1.3 & 1.3 \\
\hline FR & 1.8 & 0.8 & 0.8 & 2.3 & 1.9 & 1.5 & -8.2 & 5.8 & 4.2 & 1.7 & 1.5 & 1.4 & 1.2 \\
\hline DE & 1.0 & 1.3 & 1.3 & 2.6 & 1.3 & 0.6 & -4.9 & 3.6 & 3.4 & 1.6 & 1.5 & 1.2 & 1.1 \\
\hline EL & 4.2 & -3.4 & -2.0 & 1.3 & 1.6 & 1.9 & -8.2 & 3.8 & 5.0 & 2.4 & 1.5 & 1.5 & 1.4 \\
\hline $\mathrm{HU}$ & 4.4 & -0.5 & 2.1 & 4.3 & 5.4 & 4.6 & -5.0 & 4.3 & 5.9 & 3.8 & 3.2 & 2.6 & 2.6 \\
\hline IE & 5.3 & -0.4 & 7.5 & 9.4 & 8.9 & 5.9 & 2.5 & 4.2 & 4.8 & 3.7 & 2.8 & 2.7 & 2.6 \\
\hline IT & 0.9 & -0.5 & -0.5 & 1.7 & 0.9 & 0.3 & -8.9 & 4.2 & 3.6 & 1.6 & 0.9 & 0.9 & 0.8 \\
\hline LV & 9.3 & -1.1 & 2.8 & 3.3 & 4.0 & 2.0 & -3.6 & 3.9 & 5.2 & 3.9 & 3.2 & 3.2 & 3.0 \\
\hline LT & 7.8 & 1.3 & 3.1 & 4.3 & 3.9 & 4.3 & -0.8 & 3.2 & 3.2 & 3.1 & 2.7 & 2.6 & 2.3 \\
\hline LU & 3.5 & 2.0 & 3.3 & 1.8 & 3.1 & 2.3 & -1.3 & 4.1 & 3.6 & 3.0 & 2.7 & 2.5 & 2.5 \\
\hline MT & 2.5 & 2.7 & 6.2 & 8.1 & 5.2 & 5.5 & -7.0 & 4.7 & 5.6 & 4.6 & 4.5 & 4.5 & 4.5 \\
\hline $\mathrm{NL}$ & 1.6 & 1.0 & 0.9 & 2.9 & 2.4 & 1.7 & -3.8 & 3.5 & 3.0 & 1.8 & 1.6 & 1.5 & 1.5 \\
\hline PL & 3.9 & 4.5 & 2.6 & 4.8 & 5.4 & 4.5 & -2.7 & 3.5 & 4.5 & 4.0 & 3.0 & 2.9 & 2.6 \\
\hline PT & 0.8 & -0.1 & -0.1 & 3.5 & 2.8 & 2.5 & -7.6 & 3.9 & 4.8 & 2.5 & 2.3 & 1.8 & 1.7 \\
\hline RO & 6.2 & 1.8 & 3.4 & 7.3 & 4.5 & 4.1 & -3.9 & 6.0 & 4.8 & 3.8 & 3.7 & 3.5 & 3.5 \\
\hline SK & 6.1 & 3.9 & 2.4 & 3.0 & 3.8 & 2.3 & -5.2 & 4.7 & 4.4 & 3.8 & 3.1 & 3.0 & 2.5 \\
\hline SI & 4.1 & 1.0 & 0.9 & 4.8 & 4.4 & 3.2 & -5.5 & 3.7 & 4.5 & 3.6 & 3.1 & 2.7 & 2.5 \\
\hline ES & 3.3 & 0.0 & 0.8 & 3.0 & 2.4 & 2.0 & -11.0 & 6.4 & 4.7 & 2.8 & 2.4 & 1.4 & 1.4 \\
\hline SE & 3.3 & 1.6 & 2.0 & 2.6 & 2.0 & 1.4 & -2.8 & 3.1 & 3.0 & 2.3 & 2.1 & 2.0 & 2.0 \\
\hline
\end{tabular}

Source: IMF (2021). 
Wiiw Research Report 457

Appendix - Table 21 / Sectoral average annual value-added growth rates 2013-2019, in \%

\begin{tabular}{|c|c|c|c|c|c|c|c|c|c|c|c|c|}
\hline & A & BDE & C & $\mathbf{F}$ & G-I & $\mathbf{J}$ & $\mathrm{K}$ & L & M_N & $O-Q$ & R-U & Total \\
\hline AT & 1.7 & 1.6 & 2.5 & 0.2 & 1.0 & 3.8 & 1.4 & 1.0 & 2.7 & 0.8 & 0.4 & 1.5 \\
\hline $\mathrm{BE}$ & -2.1 & -0.2 & 1.2 & 2.2 & 0.5 & 4.1 & -0.5 & 2.2 & 4.2 & 0.8 & 0.9 & 1.5 \\
\hline BG & 3.0 & 0.1 & 3.2 & 0.5 & 3.2 & 7.3 & 0.7 & 4.6 & 5.5 & 1.0 & 3.1 & 2.8 \\
\hline CY & -1.5 & -2.4 & 5.7 & 4.7 & 2.9 & 12.7 & -4.1 & 2.1 & 4.4 & 0.7 & 0.4 & 2.1 \\
\hline$C Z$ & 3.3 & -2.9 & 4.0 & 0.5 & 3.8 & 6.6 & 6.4 & 1.6 & 4.5 & 1.1 & 3.2 & 3.0 \\
\hline DE & -2.5 & 2.1 & 1.5 & 1.2 & 1.7 & 4.5 & -0.1 & 0.9 & 2.4 & 1.3 & 0.1 & 1.5 \\
\hline DK & 2.3 & -4.7 & 3.9 & 5.1 & 2.7 & 5.7 & -0.4 & 1.6 & 5.1 & 0.9 & 1.1 & 2.3 \\
\hline EE & 3.4 & 0.0 & 2.1 & 1.2 & 2.4 & 5.1 & -1.8 & 1.5 & 4.6 & 0.9 & 2.4 & 1.9 \\
\hline ES & 1.8 & 1.5 & 4.3 & 2.3 & 4.5 & 11.3 & 1.7 & 1.8 & 5.2 & 1.0 & 3.0 & 3.5 \\
\hline $\mathrm{FI}$ & 3.4 & 0.2 & 1.8 & 0.3 & 0.2 & 3.5 & 0.7 & 1.7 & 2.5 & 0.1 & 0.6 & 1.1 \\
\hline FR & 1.8 & -0.6 & 0.8 & 0.3 & 1.6 & 3.5 & 1.8 & 1.0 & 2.4 & 0.9 & 0.3 & 1.3 \\
\hline EL & 0.7 & -3.0 & 0.3 & -5.4 & 0.8 & -1.8 & 6.0 & 1.0 & -1.6 & -0.6 & 2.2 & 0.2 \\
\hline HR & 0.7 & 0.7 & 2.1 & 2.6 & 3.2 & 2.5 & 0.2 & 0.3 & 2.3 & 1.2 & 2.5 & 1.9 \\
\hline HU & 5.6 & 3.1 & 3.3 & 7.9 & 4.9 & 6.6 & 2.9 & 1.8 & 7.1 & 1.4 & 4.8 & 3.9 \\
\hline IE & 9.5 & 2.3 & 16.3 & 9.4 & 4.6 & 17.2 & 1.4 & 1.7 & 10.1 & 2.4 & 5.0 & 8.4 \\
\hline IT & -0.1 & -0.8 & 1.3 & -1.8 & 1.3 & 1.3 & -0.8 & 0.8 & 1.2 & -0.6 & 0.3 & 0.5 \\
\hline LT & 0.1 & -0.6 & 4.1 & 5.4 & 4.4 & 6.3 & 2.0 & 2.4 & 6.4 & 0.6 & 2.8 & 3.5 \\
\hline LU & -3.0 & 4.7 & 5.0 & 4.7 & 1.4 & 9.3 & 2.3 & 2.9 & 5.3 & 3.5 & 1.1 & 3.4 \\
\hline LV & 2.9 & -2.3 & 2.6 & 2.8 & 3.1 & 4.2 & -2.2 & 1.6 & 2.5 & 3.3 & 3.3 & 2.4 \\
\hline MT & 3.0 & 84.0 & 2.4 & 8.2 & 7.5 & 16.4 & 3.7 & 6.3 & 15.1 & 4.0 & 3.4 & 7.1 \\
\hline NL & 1.5 & -3.3 & 2.2 & 4.3 & 2.4 & 4.5 & -1.1 & 3.1 & 2.9 & 0.8 & 0.6 & 1.8 \\
\hline PL & -1.1 & -0.2 & 4.8 & 3.0 & 3.7 & 8.1 & 10.0 & 4.1 & 6.2 & 2.0 & 2.2 & 3.8 \\
\hline PT & 1.6 & -0.6 & 2.6 & 0.2 & 2.8 & 2.0 & -2.8 & 1.2 & 5.2 & 0.5 & 2.0 & 1.6 \\
\hline RO & 7.2 & 0.7 & 5.0 & 1.8 & 5.3 & 11.6 & 0.2 & 6.5 & 9.1 & -0.6 & 0.7 & 4.4 \\
\hline SK & 8.0 & 0.2 & 5.8 & -1.4 & 1.0 & 2.3 & 4.0 & 2.7 & 4.0 & 3.1 & 0.3 & 2.5 \\
\hline SI & 4.0 & 0.5 & 4.3 & 2.4 & 4.6 & 3.9 & 0.0 & 0.9 & 4.2 & 1.1 & 1.7 & 3.0 \\
\hline SE & 0.8 & -1.6 & 1.2 & 3.0 & 3.0 & 5.5 & 4.1 & 2.5 & 3.8 & 0.9 & 1.8 & 2.3 \\
\hline EU27 & 1.2 & -0.2 & 2.2 & 1.0 & 2.0 & 4.9 & 0.6 & 1.3 & 3.0 & 0.8 & 0.8 & 1.7 \\
\hline
\end{tabular}

Source: Eurostat, own calculations. 
Appendix - Table 22 / Sectoral value-added shares 2019, in \%

\begin{tabular}{|c|c|c|c|c|c|c|c|c|c|c|c|}
\hline & A & BDE & C & $\mathbf{F}$ & G-I & $\mathbf{J}$ & K & $\mathbf{L}$ & M_N & $O-Q$ & $R-U$ \\
\hline AT & 1.2 & 3.2 & 18.6 & 6.8 & 22.3 & 3.8 & 4.1 & 9.9 & 9.9 & 17.4 & 2.8 \\
\hline $\mathrm{BE}$ & 0.7 & 2.4 & 13.6 & 5.4 & 19.1 & 4.3 & 6.5 & 9.2 & 15.5 & 21.3 & 2.1 \\
\hline$B G$ & 3.7 & 5.2 & 15.4 & 4.5 & 23.6 & 7.6 & 5.8 & 10.4 & 7.1 & 14.4 & 2.4 \\
\hline CY & 2.0 & 2.0 & 6.2 & 6.4 & 25.3 & 6.7 & 7.8 & 10.1 & 10.6 & 18.7 & 4.2 \\
\hline$C Z$ & 2.1 & 4.4 & 24.8 & 5.6 & 18.6 & 5.9 & 4.2 & 9.3 & 7.5 & 15.4 & 2.1 \\
\hline DE & 0.8 & 3.1 & 21.2 & 5.4 & 16.1 & 4.9 & 3.8 & 10.5 & 11.6 & 18.7 & 3.8 \\
\hline DK & 1.5 & 3.1 & 15.2 & 6.0 & 19.7 & 4.7 & 5.4 & 10.4 & 10.0 & 20.8 & 3.4 \\
\hline ES & 2.9 & 3.8 & 12.3 & 6.4 & 23.5 & 3.8 & 3.8 & 11.5 & 9.1 & 18.0 & 4.8 \\
\hline EE & 2.9 & 4.2 & 14.7 & 6.4 & 22.2 & 7.6 & 4.5 & 9.7 & 9.5 & 15.9 & 2.5 \\
\hline $\mathrm{FI}$ & 2.8 & 3.5 & 16.7 & 7.4 & 15.4 & 6.0 & 2.9 & 12.8 & 9.2 & 20.1 & 3.1 \\
\hline FR & 1.8 & 2.5 & 11.0 & 5.8 & 17.7 & 5.4 & 4.0 & 12.9 & 14.2 & 21.9 & 2.8 \\
\hline EL & 4.4 & 4.6 & 8.9 & 1.4 & 27.6 & 3.3 & 5.2 & 16.2 & 5.1 & 19.9 & 3.5 \\
\hline HR & 3.6 & 4.4 & 14.6 & 5.7 & 23.9 & 5.0 & 5.9 & 9.0 & 8.2 & 15.8 & 3.9 \\
\hline HU & 3.9 & 2.9 & 20.9 & 5.7 & 18.2 & 4.9 & 3.7 & 10.0 & 10.1 & 16.7 & 3.0 \\
\hline IE & 1.0 & 1.5 & 33.5 & 2.6 & 11.3 & 14.9 & 5.8 & 6.9 & 10.9 & 10.3 & 1.3 \\
\hline IT & 2.1 & 3.0 & 16.6 & 4.3 & 21.5 & 3.7 & 4.9 & 13.5 & 10.0 & 16.4 & 4.0 \\
\hline LT & 3.6 & 2.8 & 17.9 & 7.3 & 31.4 & 3.8 & 2.3 & 6.4 & 7.3 & 14.8 & 2.3 \\
\hline LU & 0.2 & 1.4 & 5.0 & 6.0 & 15.3 & 7.0 & 26.8 & 7.2 & 12.5 & 16.8 & 1.7 \\
\hline LV & 4.3 & 2.9 & 12.0 & 6.5 & 24.8 & 5.6 & 2.9 & 12.5 & 8.3 & 16.9 & 3.4 \\
\hline MT & 0.8 & 1.7 & 8.2 & 4.2 & 20.1 & 7.9 & 7.9 & 6.2 & 17.7 & 16.7 & 8.5 \\
\hline $\mathrm{NL}$ & 1.8 & 2.7 & 12.3 & 5.0 & 20.6 & 5.0 & 6.4 & 7.3 & 15.5 & 21.1 & 2.3 \\
\hline PL & 2.6 & 5.6 & 18.8 & 7.4 & 25.9 & 4.3 & 4.1 & 5.6 & 8.8 & 14.5 & 2.3 \\
\hline PT & 2.4 & 3.7 & 13.8 & 4.3 & 24.5 & 3.6 & 4.9 & 12.4 & 8.2 & 19.2 & 3.0 \\
\hline RO & 4.6 & 4.5 & 18.9 & 6.7 & 20.2 & 6.4 & 2.6 & 8.6 & 8.4 & 15.6 & 3.5 \\
\hline SK & 2.8 & 4.3 & 20.3 & 7.2 & 18.8 & 5.0 & 3.3 & 10.4 & 9.3 & 15.5 & 3.2 \\
\hline SI & 2.3 & 3.5 & 23.6 & 6.0 & 20.8 & 4.1 & 3.8 & 7.3 & 9.9 & 16.3 & 2.5 \\
\hline SE & 1.6 & 3.5 & 14.7 & 6.8 & 17.5 & 7.7 & 3.9 & 8.7 & 11.6 & 21.3 & 2.9 \\
\hline EU27 & 1.8 & 3.1 & 16.6 & 5.5 & 19.2 & 5.1 & 4.5 & 10.8 & 11.4 & 18.7 & 3.3 \\
\hline
\end{tabular}

Source: Eurostat, own calculations. 
Wiiw Research Report 457

Appendix - Table 23 / Average annual labour productivity growth rates based on persons employed 2013-2019, in \%

\begin{tabular}{|c|c|c|c|c|c|c|c|c|c|c|c|c|}
\hline & A & BDE & C & $F$ & G-I & $\mathbf{J}$ & K & $\mathbf{L}$ & M_N & $\mathbf{O}-\mathbf{Q}$ & R-U & Total \\
\hline AT & 4.9 & 0.9 & 1.6 & -1.0 & 0.0 & 0.8 & 2.5 & 0.4 & 0.3 & -0.7 & -0.9 & 0.4 \\
\hline $\mathrm{BE}$ & -1.9 & -0.3 & 2.0 & 1.8 & 0.3 & 1.9 & 1.1 & -0.6 & 1.3 & -0.5 & -0.1 & 0.5 \\
\hline BG & 4.2 & 0.6 & 2.9 & -0.3 & 2.4 & 2.1 & -0.1 & 5.0 & 4.3 & 0.7 & 0.9 & 2.4 \\
\hline CY & -0.8 & -2.5 & 4.2 & 2.5 & 0.6 & 8.1 & -4.2 & -3.4 & -1.4 & -0.2 & -0.2 & 0.3 \\
\hline$C Z$ & 3.7 & -3.2 & 2.8 & 1.5 & 3.3 & 2.8 & 7.1 & 1.2 & 2.0 & -0.7 & 1.9 & 2.0 \\
\hline DE & -1.4 & 1.5 & 0.9 & 0.3 & 0.9 & 2.4 & 1.2 & 0.4 & 0.7 & -0.5 & -0.5 & 0.4 \\
\hline DK & 1.9 & -3.9 & 3.0 & 2.8 & 1.1 & 3.8 & -0.4 & 0.6 & 1.9 & 0.4 & 0.6 & 1.1 \\
\hline ES & 2.8 & -0.8 & 1.3 & -0.2 & 1.0 & 1.7 & -0.9 & -2.2 & 1.6 & -0.7 & 1.4 & 0.4 \\
\hline EE & 6.0 & 5.5 & 3.5 & 1.7 & 2.6 & 2.9 & 0.3 & 1.3 & 1.6 & 0.3 & -1.2 & 2.0 \\
\hline $\mathrm{FI}$ & 6.5 & -0.3 & 2.8 & -1.2 & 0.2 & 1.1 & 1.4 & 0.4 & -0.3 & -0.9 & -0.6 & 0.5 \\
\hline FR & 1.9 & -1.0 & 1.4 & 0.6 & 0.8 & 1.5 & 1.8 & 0.5 & -0.1 & 0.4 & 0.0 & 0.6 \\
\hline EL & 1.6 & -4.3 & 0.4 & -4.5 & -1.1 & -2.5 & 9.2 & -3.9 & -2.2 & -1.5 & 2.2 & -0.6 \\
\hline HR & 10.2 & 1.0 & 0.7 & 0.1 & 1.8 & -3.7 & 0.2 & -7.4 & -1.1 & -2.6 & 1.4 & 0.5 \\
\hline HU & 6.3 & 3.7 & 1.7 & 3.5 & 3.3 & 0.8 & 4.7 & -0.1 & -0.6 & -0.3 & 0.2 & 1.5 \\
\hline IE & 10.5 & -1.5 & 13.1 & 1.0 & 1.6 & 12.8 & -0.2 & 2.7 & 5.4 & -0.5 & 2.7 & 5.1 \\
\hline IT & -0.4 & -1.1 & 1.7 & 0.2 & 0.4 & 0.2 & 0.3 & 0.3 & -0.8 & -1.1 & 0.1 & 0.1 \\
\hline LT & 3.7 & -0.4 & 2.8 & 2.8 & 3.4 & 2.8 & 0.6 & 2.1 & 2.7 & -0.6 & 0.5 & 2.3 \\
\hline LU & -2.2 & 2.9 & 4.8 & 2.2 & -0.8 & 4.4 & -0.3 & -2.4 & 0.2 & -0.1 & -1.1 & 0.4 \\
\hline LV & 3.5 & -1.8 & 3.2 & 0.3 & 3.0 & -2.9 & -1.1 & 0.5 & 0.9 & 3.3 & 3.1 & 1.9 \\
\hline MT & 2.6 & 96.8 & 1.2 & 3.9 & 2.4 & 8.3 & -0.1 & -4.9 & 1.8 & -0.1 & -5.0 & 1.6 \\
\hline NL & 1.3 & -3.9 & 1.7 & 4.2 & 1.0 & 1.6 & 1.3 & 3.1 & 0.2 & 0.3 & -0.7 & 0.6 \\
\hline PL & 2.7 & -0.5 & 2.6 & 2.5 & 2.7 & 3.6 & 9.6 & 2.7 & 4.8 & 1.1 & -1.4 & 2.9 \\
\hline PT & 6.5 & -0.9 & 0.8 & 0.5 & 0.4 & -3.6 & -1.6 & -5.3 & 1.1 & -0.2 & 1.6 & 0.5 \\
\hline RO & 12.0 & 0.5 & 4.2 & 0.0 & 2.5 & 8.8 & 1.9 & 3.3 & 5.2 & -1.1 & -1.6 & 4.4 \\
\hline SK & 7.7 & 0.1 & 4.0 & -2.2 & 0.1 & -1.9 & 2.2 & 0.5 & 1.3 & 1.9 & -2.4 & 1.0 \\
\hline SI & 4.9 & 0.8 & 2.3 & 1.0 & 2.7 & 0.5 & 1.9 & -2.7 & 1.7 & -0.2 & -1.9 & 1.4 \\
\hline SE & 1.9 & -2.9 & 1.6 & 0.2 & 1.7 & 3.3 & 4.4 & -0.2 & 1.0 & -0.7 & -0.1 & 0.8 \\
\hline EU27 & 3.5 & -0.6 & 1.6 & 0.5 & 0.9 & 2.1 & 1.3 & 0.0 & 0.6 & -0.3 & -0.1 & 0.8 \\
\hline
\end{tabular}

Source: Eurostat, own calculations. 
Appendix - Table 24 / Average annual labour productivity growth rates based on hours worked 2013-2019, in \%

\begin{tabular}{|c|c|c|c|c|c|c|c|c|c|c|c|c|}
\hline & A & BDE & C & $F$ & G-I & $\mathbf{J}$ & $\mathrm{K}$ & $\mathbf{L}$ & M_N & O-Q & R-U & Total \\
\hline AT & 4.3 & 1.4 & 2.0 & -0.8 & 0.3 & 0.2 & 2.8 & 0.9 & 0.5 & -0.6 & -0.9 & 0.6 \\
\hline $\mathrm{BE}$ & -3.6 & -0.1 & 1.9 & 1.3 & 0.3 & 1.6 & 1.2 & -0.8 & 2.0 & -0.2 & -0.2 & 0.6 \\
\hline BG & 4.3 & 0.6 & 2.8 & -0.2 & 2.5 & 2.1 & -0.1 & 5.4 & 4.2 & 0.7 & 0.8 & 2.4 \\
\hline CY & -0.6 & -3.0 & 4.1 & 2.6 & 1.2 & 8.0 & -4.3 & -2.5 & -1.3 & -0.2 & 0.6 & 0.6 \\
\hline$C Z$ & 3.5 & -3.3 & 2.8 & 1.7 & 3.4 & 2.7 & 6.9 & 0.8 & 1.9 & -1.1 & 1.3 & 1.9 \\
\hline $\mathrm{DE}$ & -0.3 & 1.6 & 0.9 & 0.9 & 1.2 & 2.1 & 1.4 & 0.6 & 0.8 & -0.3 & 0.2 & 0.7 \\
\hline DK & 3.0 & -3.4 & 3.5 & 3.2 & 1.7 & 4.4 & -0.1 & 1.4 & 2.1 & 0.8 & 1.4 & 1.5 \\
\hline ES & 3.0 & 0.0 & 1.4 & -0.9 & 1.3 & 1.4 & -0.7 & -2.5 & 1.4 & -0.5 & 1.3 & 0.5 \\
\hline EE & 7.4 & 6.6 & 3.8 & 3.0 & 3.6 & 4.1 & 0.6 & 0.9 & 2.1 & 0.9 & -0.4 & 2.7 \\
\hline $\mathrm{FI}$ & 6.4 & -0.1 & 3.1 & -0.6 & 0.3 & 1.4 & 1.4 & 0.5 & 0.0 & -0.7 & 0.1 & 0.7 \\
\hline FR & 3.1 & -0.6 & 1.6 & 0.8 & 1.0 & 1.6 & 1.9 & 0.9 & 0.0 & 0.8 & 0.5 & 0.9 \\
\hline EL & 3.3 & -2.9 & 0.4 & -5.4 & -0.3 & -1.5 & 8.0 & -2.9 & -1.5 & -1.5 & 3.0 & -0.1 \\
\hline HR & 8.2 & 2.3 & 1.8 & 0.0 & 2.7 & -3.4 & 2.1 & -4.0 & -0.3 & -1.3 & 2.3 & 1.2 \\
\hline $\mathrm{HU}$ & 8.2 & 3.8 & 1.6 & 3.4 & 3.2 & 0.7 & 5.1 & -0.4 & -0.8 & -0.3 & 0.6 & 1.6 \\
\hline IE & 9.4 & -1.0 & 12.5 & -0.4 & 1.8 & 12.3 & -0.5 & 3.5 & 4.6 & -0.7 & 2.5 & 4.8 \\
\hline IT & -0.9 & -1.3 & 1.4 & 0.1 & 1.0 & 0.4 & 0.5 & 0.9 & -0.4 & -0.9 & 0.0 & 0.2 \\
\hline LT & 3.7 & 0.1 & 3.0 & 3.1 & 3.3 & 3.0 & 0.0 & 3.0 & 2.7 & -0.6 & 1.0 & 2.4 \\
\hline LU & -2.8 & 2.8 & 4.8 & 2.0 & -0.7 & 4.4 & -0.1 & -3.1 & 0.1 & 0.0 & -1.7 & 0.4 \\
\hline LV & 3.3 & -1.6 & 3.5 & 1.0 & 3.6 & -3.2 & 0.5 & 1.3 & 0.9 & 4.2 & 4.8 & 2.5 \\
\hline MT & 2.9 & 97.2 & 0.7 & 3.3 & 2.9 & & & & 3.9 & -0.5 & -3.7 & 1.7 \\
\hline NL & 0.5 & -4.3 & 1.5 & 3.5 & 1.1 & 1.7 & 1.0 & 2.7 & -0.4 & -0.1 & -1.3 & 0.3 \\
\hline PL & 2.3 & -0.2 & 3.0 & 3.3 & 3.4 & 4.0 & 9.9 & 3.3 & 5.4 & 0.9 & -1.0 & 3.3 \\
\hline PT & 5.3 & -0.7 & 1.1 & 0.2 & 0.5 & -3.6 & -1.7 & -6.1 & 1.0 & -0.4 & 1.1 & 0.2 \\
\hline RO & 12.9 & 0.6 & 4.8 & 0.1 & 2.8 & 9.0 & 2.2 & 2.6 & 5.3 & -0.8 & -1.4 & 4.6 \\
\hline SK & 8.1 & 0.8 & 4.7 & -1.9 & 1.1 & -0.7 & 2.8 & 1.4 & 2.8 & 2.4 & -1.4 & 1.9 \\
\hline SI & 4.4 & 1.0 & 2.6 & 2.0 & 3.3 & 0.9 & 2.0 & -2.1 & 2.3 & -0.2 & -0.9 & 1.8 \\
\hline $\mathrm{SE}$ & 1.7 & -2.5 & 2.1 & 0.6 & 1.9 & 3.4 & 5.0 & 0.0 & 1.0 & -0.7 & 0.2 & 1.0 \\
\hline EU27 & 3.4 & -0.4 & 1.7 & 0.6 & 1.2 & 2.1 & 1.4 & 0.1 & 0.7 & -0.2 & 0.1 & 1.0 \\
\hline
\end{tabular}

Source: Eurostat, own calculations. 
Wiiw Research Report 457

Appendix - Table 25 / Average annual growth rates of persons employed 2013-2019, in \%

\begin{tabular}{|c|c|c|c|c|c|c|c|c|c|c|c|c|}
\hline & A & BDE & C & $F$ & G-I & $\mathbf{J}$ & K & L & M_N & $O-Q$ & R-U & Total \\
\hline AT & -2.9 & 0.6 & 0.8 & 1.3 & 1.0 & 2.9 & -1.1 & 0.6 & 2.3 & 1.5 & 1.3 & 1.1 \\
\hline $\mathrm{BE}$ & -0.3 & 0.1 & -0.7 & 0.4 & 0.2 & 2.2 & -1.6 & 2.9 & 2.8 & 1.3 & 1.0 & 1.0 \\
\hline BG & -1.1 & -0.5 & 0.2 & 0.8 & 0.8 & 5.1 & 0.8 & -0.4 & 1.3 & 0.4 & 2.3 & 0.4 \\
\hline$C Y$ & -0.9 & 0.2 & 1.2 & 1.9 & 2.3 & 4.4 & 0.1 & 6.4 & 5.8 & 0.9 & 0.5 & 1.8 \\
\hline$C Z$ & -0.3 & 0.4 & 1.2 & -0.9 & 0.4 & 3.8 & -0.7 & 0.3 & 2.4 & 1.8 & 1.2 & 1.0 \\
\hline DE & -1.1 & 0.6 & 0.7 & 0.9 & 0.8 & 2.1 & -1.3 & 0.5 & 1.7 & 1.8 & 0.5 & 1.1 \\
\hline DK & 0.3 & -0.8 & 0.9 & 2.2 & 1.5 & 1.8 & 0.0 & 1.1 & 3.1 & 0.4 & 0.6 & 1.2 \\
\hline ES & 0.6 & 0.7 & 0.9 & 1.5 & 1.4 & 3.4 & -0.9 & 3.9 & 3.0 & 1.6 & 1.0 & 1.5 \\
\hline EE & -3.4 & -3.2 & 0.9 & 1.2 & 1.8 & 8.7 & 2.6 & 1.8 & 3.9 & 0.8 & 4.5 & 1.5 \\
\hline $\mathrm{FI}$ & -2.9 & 0.5 & -1.0 & 1.5 & 0.0 & 2.3 & -0.6 & 1.3 & 2.8 & 1.0 & 1.2 & 0.6 \\
\hline FR & -0.2 & 0.4 & -0.6 & -0.3 & 0.7 & 2.0 & 0.0 & 0.6 & 2.4 & 0.5 & 0.3 & 0.7 \\
\hline EL & -0.9 & 1.6 & -0.1 & -1.0 & 2.0 & 0.9 & -2.7 & 5.3 & 0.8 & 0.9 & 0.0 & 0.8 \\
\hline HR & -8.1 & 0.2 & 1.5 & 2.6 & 1.5 & 7.8 & 0.6 & 11.0 & 3.8 & 4.1 & 1.6 & 1.3 \\
\hline $\mathrm{HU}$ & -0.3 & -0.5 & 1.5 & 4.4 & 1.7 & 5.8 & -1.7 & 2.0 & 8.2 & 1.7 & 4.6 & 2.4 \\
\hline $\mathrm{IE}$ & -0.7 & 4.4 & 2.7 & 8.5 & 3.0 & 3.9 & 1.7 & 0.2 & 4.5 & 3.0 & 2.2 & 3.1 \\
\hline IT & 0.3 & 0.4 & -0.4 & -2.1 & 1.0 & 1.1 & -1.1 & 0.5 & 2.0 & 0.5 & 0.2 & 0.4 \\
\hline LT & -3.1 & 0.3 & 1.3 & 2.7 & 1.0 & 4.4 & 1.7 & 0.9 & 3.7 & 1.2 & 2.5 & 1.2 \\
\hline LU & -0.9 & 1.9 & 0.1 & 2.4 & 2.2 & 4.7 & 2.6 & 5.5 & 5.2 & 3.6 & 2.3 & 3.0 \\
\hline LV & -0.4 & -0.6 & -0.6 & 2.4 & 0.2 & 7.4 & -1.1 & 1.1 & 1.8 & 0.0 & 0.5 & 0.5 \\
\hline MT & 0.5 & -3.8 & 1.2 & 4.2 & 5.0 & 7.5 & 3.9 & 13.2 & 13.0 & 4.1 & 9.2 & 5.5 \\
\hline NL & 0.2 & 0.6 & 0.5 & 0.1 & 1.4 & 2.8 & -2.4 & 0.0 & 2.7 & 0.5 & 1.3 & 1.2 \\
\hline PL & -3.5 & 0.9 & 2.2 & 0.4 & 0.9 & 4.5 & 0.4 & 1.7 & 1.5 & 0.9 & 3.7 & 0.8 \\
\hline PT & -4.5 & 0.3 & 1.8 & -0.4 & 2.4 & 5.9 & -1.3 & 7.1 & 4.0 & 0.8 & 0.4 & 1.1 \\
\hline RO & -4.4 & 0.3 & 0.8 & 1.8 & 2.7 & 3.1 & -1.2 & 5.1 & 3.7 & 0.9 & 2.4 & 0.0 \\
\hline SK & 0.4 & 0.1 & 1.8 & 0.9 & 1.0 & 4.2 & 1.7 & 2.4 & 2.6 & 1.1 & 2.9 & 1.5 \\
\hline SI & -0.9 & -0.2 & 2.0 & 1.4 & 1.8 & 3.3 & -1.9 & 3.7 & 2.4 & 1.3 & 3.6 & 1.6 \\
\hline SE & -1.1 & 1.3 & -0.4 & 2.8 & 1.2 & 2.2 & -0.3 & 2.7 & 2.8 & 1.7 & 1.9 & 1.5 \\
\hline EU27 & -2.2 & 0.4 & 0.6 & 0.5 & 1.1 & 2.7 & -0.7 & 1.3 & 2.4 & 1.2 & 0.9 & 1.0 \\
\hline
\end{tabular}

Source: Eurostat, own calculations. 
Appendix - Table 26 / Average annual growth rates of hours worked 2013-2019, in \%

\begin{tabular}{|c|c|c|c|c|c|c|c|c|c|c|c|c|}
\hline & A & BDE & C & $\mathbf{F}$ & G-I & $\mathbf{J}$ & $\mathrm{K}$ & L & M_N & O-Q & R-U & Total \\
\hline AT & -2.5 & 0.2 & 0.5 & 1.1 & 0.7 & 3.6 & -1.2 & 0.3 & 2.2 & 1.4 & 1.3 & 0.9 \\
\hline $\mathrm{BE}$ & 1.6 & -0.1 & -0.6 & 0.8 & 0.2 & 2.5 & -1.7 & 3.1 & 2.1 & 1.0 & 1.2 & 0.9 \\
\hline$B G$ & -1.2 & -0.5 & 0.3 & 0.7 & 0.7 & 5.1 & 0.9 & -0.7 & 1.3 & 0.3 & 2.3 & 0.4 \\
\hline CY & -0.9 & 0.7 & 1.3 & 2.6 & 1.6 & 4.5 & 0.2 & 5.9 & 5.7 & 0.9 & -0.3 & 1.5 \\
\hline$C Z$ & 0.0 & 0.5 & 1.2 & -1.1 & 0.4 & 3.9 & -0.4 & 0.8 & 2.6 & 2.2 & 1.9 & 1.1 \\
\hline DE & -2.2 & 0.5 & 0.6 & 0.3 & 0.5 & 2.3 & -1.5 & 0.3 & 1.6 & 1.6 & -0.1 & 0.8 \\
\hline DK & -0.8 & -1.4 & 0.4 & 1.9 & 1.0 & 1.2 & -0.3 & 0.3 & 2.9 & 0.1 & -0.2 & 0.7 \\
\hline ES & 0.4 & -0.1 & 0.8 & 2.2 & 1.1 & 3.7 & -1.1 & 4.3 & 3.1 & 1.5 & 1.1 & 1.4 \\
\hline EE & -4.2 & -4.2 & 0.6 & 0.1 & 0.9 & 8.2 & 2.8 & 2.0 & 3.2 & 0.2 & 3.7 & 0.8 \\
\hline $\mathrm{FI}$ & -2.8 & 0.3 & -1.2 & 0.9 & -0.1 & 2.0 & -0.6 & 1.2 & 2.5 & 0.8 & 0.5 & 0.4 \\
\hline FR & -1.3 & 0.0 & -0.8 & -0.5 & 0.6 & 1.9 & -0.1 & 0.2 & 2.4 & 0.1 & -0.2 & 0.4 \\
\hline EL & -2.2 & 0.3 & 0.1 & -0.1 & 1.3 & 0.0 & -1.2 & 5.6 & 0.1 & 0.9 & -0.7 & 0.3 \\
\hline HR & -6.5 & -0.8 & 0.5 & 2.8 & 0.6 & 7.4 & -0.7 & 17.1 & 3.0 & 2.8 & 1.0 & 0.7 \\
\hline HU & -2.4 & -0.5 & 1.7 & 4.5 & 1.8 & 5.9 & -2.1 & 2.3 & 8.5 & 1.8 & 4.2 & 2.3 \\
\hline IE & 0.3 & 3.7 & 3.1 & 10.2 & 2.8 & 4.3 & 2.0 & -0.2 & 5.3 & 3.1 & 2.4 & 3.4 \\
\hline IT & 0.9 & 0.6 & -0.1 & -1.9 & 0.4 & 1.0 & -1.3 & -0.1 & 1.6 & 0.4 & 0.2 & 0.3 \\
\hline LT & -3.2 & -0.1 & 1.2 & 2.5 & 1.1 & 4.5 & 2.8 & 0.0 & 3.8 & 1.2 & 1.9 & 1.1 \\
\hline LU & -0.3 & 1.9 & 0.2 & 2.6 & 2.1 & 4.6 & 2.5 & 6.3 & 5.2 & 3.5 & 2.9 & 2.9 \\
\hline LV & -0.3 & -0.8 & -0.9 & 1.8 & -0.4 & 7.7 & -2.5 & 0.4 & 1.7 & -0.8 & 0.1 & 0.0 \\
\hline MT & 13.8 & -3.5 & 1.7 & 5.1 & 4.6 & & & & 10.8 & 4.3 & 8.3 & 5.4 \\
\hline $\mathrm{NL}$ & 1.0 & 1.1 & 0.6 & 0.7 & 1.3 & 2.8 & -2.0 & 0.4 & 3.3 & 0.8 & 1.9 & 1.5 \\
\hline PL & -3.2 & 0.7 & 1.8 & -0.3 & 0.3 & 4.1 & 0.1 & 1.3 & 0.9 & 1.1 & 3.2 & 0.5 \\
\hline PT & -3.5 & 0.1 & 1.4 & -0.1 & 2.3 & 5.8 & -1.2 & 8.0 & 4.1 & 1.0 & 0.9 & 1.4 \\
\hline RO & -5.2 & 0.2 & 0.2 & 1.8 & 2.4 & 2.9 & -1.6 & 5.6 & 3.6 & 0.5 & 2.2 & -0.2 \\
\hline SK & -0.1 & -0.4 & 1.0 & 0.6 & 0.0 & 3.0 & 1.1 & 1.5 & 1.2 & 0.7 & 1.8 & 0.7 \\
\hline SI & -0.4 & -0.3 & 1.7 & 0.4 & 1.3 & 2.9 & -2.0 & 3.1 & 1.8 & 1.3 & 2.7 & 1.2 \\
\hline SE & -0.6 & 0.9 & -0.9 & 2.4 & 1.1 & 2.0 & -0.8 & 2.5 & 2.8 & 1.7 & 1.6 & 1.3 \\
\hline EU27 & -2.2 & 0.2 & 0.5 & 0.4 & 0.8 & 2.7 & -0.9 & 1.3 & 2.3 & 1.0 & 0.7 & 0.8 \\
\hline
\end{tabular}

Source: Eurostat, own calculations. 
Wiiw Research Report 457

Appendix - Table 27 / Sectoral value-added growth rates 2020, in \%

\begin{tabular}{|c|c|c|c|c|c|c|c|c|c|c|c|c|}
\hline & A & BDE & C & $\mathbf{F}$ & G-I & $\mathbf{J}$ & K & $\mathbf{L}$ & M_N & $O-Q$ & R-U & Total \\
\hline AT & -2.9 & -5.1 & -7.2 & -2.3 & -15.2 & 1.8 & 2.5 & 1.9 & -11.6 & 0.3 & -19.6 & -6.4 \\
\hline $\mathrm{BE}$ & 9.9 & -5.9 & -3.8 & -4.7 & -13.5 & -1.6 & -2.6 & 1.2 & -5.9 & -4.6 & -22.1 & -5.9 \\
\hline$B G$ & -5.3 & -1.1 & -6.9 & -1.0 & -11.9 & 0.6 & 2.5 & -3.5 & -6.6 & 5.9 & -15.6 & -4.3 \\
\hline$C Y$ & -0.4 & -10.3 & -6.3 & -6.4 & -15.0 & 1.4 & -0.5 & 1.0 & -2.6 & 1.0 & -9.3 & -5.1 \\
\hline$C Z$ & 4.8 & -8.5 & -6.9 & -3.5 & -11.6 & 1.5 & -2.8 & -3.1 & -9.2 & 1.3 & -12.1 & -5.4 \\
\hline $\mathrm{DE}$ & -0.7 & -4.3 & -10.5 & 2.8 & -6.1 & -0.9 & -0.2 & -0.5 & -8.1 & -3.0 & -11.4 & -5.2 \\
\hline DK & 1.3 & -8.9 & -1.9 & -1.1 & -9.5 & 1.9 & 3.0 & 1.3 & 2.6 & -2.3 & -20.6 & -3.0 \\
\hline EE & 5.3 & -5.9 & -10.7 & -14.5 & -24.4 & -7.6 & 3.3 & -2.0 & -13.7 & 1.5 & -24.9 & -10.6 \\
\hline ES & -13.5 & -3.1 & -6.9 & 6.8 & -7.6 & 7.9 & 8.6 & -4.2 & -5.5 & 1.8 & -7.8 & -2.6 \\
\hline $\mathrm{FI}$ & -2.5 & -1.8 & -2.2 & -1.3 & -8.1 & 2.3 & 0.4 & 0.6 & -3.6 & -2.0 & -11.8 & -2.7 \\
\hline FR & -2.3 & -7.5 & -11.6 & -14.7 & -14.1 & -3.0 & -4.1 & -0.4 & -9.0 & -4.0 & -24.0 & -8.1 \\
\hline EL & -0.3 & -9.2 & -1.3 & 10.4 & -22.8 & 0.1 & -7.6 & -0.6 & -10.7 & 2.5 & -25.4 & -8.1 \\
\hline HR & 3.7 & -0.7 & -3.5 & 4.1 & -21.0 & 3.9 & -4.3 & -0.5 & -6.8 & 1.2 & -15.3 & -6.3 \\
\hline HU & -6.8 & -2.0 & -5.3 & -9.4 & -8.1 & 6.1 & 3.4 & -5.2 & -7.2 & -3.5 & -9.4 & -5.1 \\
\hline IE & -1.6 & 4.7 & 15.7 & -12.7 & -16.7 & 14.3 & -1.2 & -1.7 & -15.5 & -1.1 & -54.4 & 2.5 \\
\hline IT & -6.0 & -9.5 & -11.4 & -6.3 & -16.0 & 1.9 & -2.6 & -3.0 & -10.4 & -3.0 & -14.6 & -8.6 \\
\hline LT & 5.4 & 3.6 & 0.7 & -0.8 & -3.2 & 6.0 & 0.2 & 0.6 & -3.9 & 0.2 & -11.3 & -0.9 \\
\hline LU & 0.3 & -2.8 & -7.5 & -2.9 & -9.6 & 17.0 & -1.9 & 2.2 & -2.1 & 4.5 & -0.3 & -0.7 \\
\hline LV & 1.8 & -1.8 & -0.9 & 2.6 & -9.5 & -6.2 & -5.7 & -0.4 & -2.2 & 1.5 & -20.9 & -3.5 \\
\hline MT & -10.7 & -4.9 & -0.1 & 2.9 & -32.9 & 13.6 & 3.9 & -4.8 & -5.7 & 0.9 & 7.9 & -5.8 \\
\hline NL & 1.0 & -5.2 & -2.0 & -0.8 & -7.6 & -0.4 & 0.4 & 2.0 & -6.3 & -2.3 & -24.5 & -3.9 \\
\hline PL & -3.0 & -0.7 & -0.1 & -3.7 & -6.4 & 2.6 & -7.7 & 1.2 & -0.6 & 3.2 & -44.9 & -2.8 \\
\hline PT & -9.0 & -7.3 & -7.7 & 3.2 & -12.6 & 3.9 & -2.1 & 0.7 & -12.8 & -1.4 & -20.3 & -6.4 \\
\hline RO & -16.2 & -5.5 & -9.9 & 10.0 & -5.2 & 10.4 & -1.4 & 0.3 & -0.6 & 0.8 & -24.4 & -3.3 \\
\hline SK & -14.3 & -12.9 & -14.1 & -8.3 & 8.1 & -7.8 & -15.3 & -5.5 & -4.0 & 2.4 & -12.1 & -4.7 \\
\hline SI & -2.8 & -7.4 & -4.5 & -0.5 & -11.3 & -0.5 & 5.7 & 0.8 & -8.7 & -0.3 & -19.8 & -4.9 \\
\hline SE & 0.9 & 1.0 & -5.8 & 1.1 & -8.4 & 2.5 & 2.8 & 0.5 & -5.1 & -2.1 & -4.8 & -3.1 \\
\hline EU27 & -1.6 & -5.4 & -7.3 & -4.8 & -12.5 & 0.8 & -1.1 & -0.7 & -8.2 & -2.1 & -18.2 & -6.1 \\
\hline
\end{tabular}

Source: Eurostat, own calculations. 
Appendix - Table 28 / Sectoral nominal value-added shares 2020, in \%

\begin{tabular}{|c|c|c|c|c|c|c|c|c|c|c|c|}
\hline & A & BDE & C & $F$ & G-I & $\mathrm{J}$ & $\mathrm{K}$ & $\mathrm{L}$ & M_N & $\mathrm{O}-\mathrm{Q}$ & $\mathrm{R}-\mathrm{U}$ \\
\hline AT & 1.3 & 3.5 & 17.7 & 7.3 & 20.4 & 4.1 & 4.2 & 10.9 & 9.4 & 18.7 & 2.6 \\
\hline $\mathrm{BE}$ & 0.8 & 2.3 & 13.7 & 5.5 & 17.7 & 4.5 & 6.7 & 10.0 & 15.3 & 21.9 & 1.8 \\
\hline BG & 3.9 & 5.8 & 15.9 & 4.9 & 19.0 & 8.0 & 6.2 & 10.2 & 6.8 & 17.1 & 2.1 \\
\hline CY & 2.1 & 1.8 & 6.1 & 6.3 & 22.4 & 7.1 & 8.1 & 11.0 & 10.8 & 20.2 & 4.1 \\
\hline$C Z$ & 2.1 & 4.6 & 24.0 & 6.0 & 17.4 & 6.2 & 4.1 & 9.6 & 7.0 & 16.8 & 2.0 \\
\hline $\mathrm{DE}$ & 0.7 & 3.2 & 19.7 & 6.1 & 15.7 & 5.2 & 3.9 & 11.1 & 11.2 & 19.6 & 3.6 \\
\hline DK & 1.6 & 2.4 & 15.4 & 6.0 & 18.9 & 4.8 & 5.4 & 10.7 & 10.6 & 21.4 & 2.8 \\
\hline ES & 3.5 & 4.1 & 12.2 & 6.3 & 19.8 & 3.8 & 4.5 & 12.6 & 8.8 & 20.5 & 4.0 \\
\hline EE & 2.2 & 4.2 & 14.4 & 6.4 & 20.7 & 8.6 & 4.9 & 9.2 & 9.5 & 17.3 & 2.5 \\
\hline $\mathrm{FI}$ & 2.8 & 3.3 & 16.0 & 8.0 & 14.6 & 6.2 & 3.2 & 13.4 & 9.1 & 20.6 & 2.9 \\
\hline FR & 1.9 & 2.5 & 10.4 & 5.3 & 16.3 & 5.6 & 4.1 & 13.8 & 14.1 & 23.5 & 2.6 \\
\hline EL & 4.7 & 4.7 & 9.5 & 1.7 & 23.1 & 3.6 & 5.2 & 17.5 & 4.8 & 22.3 & 2.9 \\
\hline HR & 3.9 & 4.7 & 14.7 & 6.3 & 20.0 & 5.6 & 6.1 & 9.6 & 8.1 & 17.5 & 3.5 \\
\hline $\mathrm{HU}$ & 4.1 & 2.9 & 21.3 & 5.7 & 17.2 & 5.3 & 3.9 & 9.8 & 9.7 & 17.4 & 2.8 \\
\hline IE & 1.0 & 0.4 & 38.8 & 2.2 & 9.1 & 16.4 & 5.6 & 6.8 & 8.9 & 10.2 & 0.6 \\
\hline IT & 2.2 & 3.0 & 16.5 & 4.3 & 19.8 & 4.0 & 5.0 & 14.3 & 9.6 & 17.6 & 3.7 \\
\hline LT & 3.7 & 3.0 & 17.4 & 7.4 & 30.2 & 4.1 & 2.3 & 6.6 & 7.2 & 16.2 & 2.1 \\
\hline LU & 0.2 & 1.5 & 4.1 & 6.2 & 14.6 & 8.4 & 25.7 & 7.4 & 12.5 & 17.7 & 1.7 \\
\hline LV & 4.3 & 2.9 & 12.2 & 7.0 & 23.2 & 5.6 & 2.8 & 12.8 & 8.4 & 18.0 & 2.8 \\
\hline MT & 0.7 & 1.7 & 8.6 & 4.6 & 14.1 & 9.6 & 8.7 & 6.5 & 17.7 & 18.2 & 9.7 \\
\hline NL & 1.8 & 2.4 & 12.3 & 5.4 & 20.0 & 5.2 & 6.4 & 7.9 & 15.0 & 21.7 & 1.9 \\
\hline PL & 2.7 & 5.7 & 18.9 & 7.4 & 24.9 & 4.5 & 3.9 & 6.1 & 9.3 & 15.3 & 1.3 \\
\hline PT & 2.3 & 3.7 & 13.6 & 4.7 & 22.5 & 4.0 & 4.9 & 13.5 & 7.7 & 20.5 & 2.5 \\
\hline RO & 4.2 & 4.7 & 16.9 & 7.3 & 19.7 & 7.5 & 2.7 & 8.8 & 8.9 & 16.5 & 2.8 \\
\hline SK & 2.4 & 4.1 & 18.5 & 6.9 & 21.0 & 4.7 & 2.9 & 10.5 & 9.3 & 16.7 & 3.0 \\
\hline SI & 2.3 & 3.5 & 23.2 & 6.3 & 19.2 & 4.3 & 4.0 & 7.4 & 9.6 & 18.0 & 2.1 \\
\hline SE & 1.5 & 3.2 & 14.1 & 7.1 & 16.5 & 8.0 & 4.4 & 8.9 & 11.4 & 21.9 & 2.9 \\
\hline EU27 & 1.9 & 3.2 & 16.2 & 5.7 & 17.8 & 5.4 & 4.6 & 11.4 & 11.1 & 19.8 & 3.0 \\
\hline
\end{tabular}

Source: Eurostat, own calculations. 
Wiiw Research Report 457

Appendix - Table 29 / Labour productivity growth rates (based on persons employed) in 2020 , in \%

\begin{tabular}{|c|c|c|c|c|c|c|c|c|c|c|c|c|}
\hline & A & BDE & C & $\mathbf{F}$ & G-I & $\mathbf{J}$ & K & L & M_N & $\mathbf{O}-\mathbf{Q}$ & R-U & Total \\
\hline AT & -4.7 & -5.1 & -6.1 & -2.3 & -10.7 & -0.5 & 2.9 & -2.9 & -9.3 & -0.2 & -16.6 & -4.8 \\
\hline $\mathrm{BE}$ & 9.1 & -7.5 & -3.2 & -5.6 & -12.4 & -2.2 & -0.8 & -0.5 & -5.4 & -5.6 & -22.4 & -5.9 \\
\hline$B G$ & -5.1 & -0.4 & -2.2 & 0.7 & -5.7 & -5.0 & 2.1 & -2.0 & -6.5 & 4.6 & -15.1 & -2.0 \\
\hline CY & 0.0 & -11.3 & -7.1 & -8.9 & -11.5 & -0.1 & -0.3 & 0.7 & -3.7 & -0.4 & -9.1 & -4.6 \\
\hline$C Z$ & 6.1 & -6.5 & -3.7 & -4.9 & -8.9 & -1.9 & -0.8 & -3.5 & -4.9 & -0.7 & -11.8 & -4.0 \\
\hline $\mathrm{DE}$ & 2.6 & -5.2 & -8.1 & 2.0 & -4.1 & -2.2 & 0.7 & -0.3 & -5.8 & -4.4 & -9.3 & -4.3 \\
\hline DK & 1.6 & -10.1 & 1.1 & -2.6 & -7.4 & 0.1 & 0.9 & 0.4 & 3.5 & -3.1 & -17.4 & -2.3 \\
\hline ES & 14.0 & -1.3 & -5.3 & -13.7 & -17.7 & -9.5 & 5.7 & -1.0 & -12.2 & 1.3 & -19.1 & -6.7 \\
\hline EE & -5.2 & 2.4 & -4.5 & 5.2 & 0.9 & 12.5 & 15.2 & 3.7 & -4.1 & 0.5 & -13.9 & 0.1 \\
\hline $\mathrm{FI}$ & 2.9 & -3.7 & -2.1 & -0.6 & -0.9 & -0.8 & 0.4 & -3.4 & -5.1 & -2.1 & -8.3 & -1.3 \\
\hline FR & -2.0 & -7.2 & -10.7 & -15.9 & -13.2 & -3.4 & -3.3 & -0.4 & -6.0 & -3.5 & -22.3 & -7.1 \\
\hline EL & 9.8 & -4.5 & 0.1 & 14.3 & -21.4 & 2.4 & -7.9 & 3.2 & -10.6 & -0.8 & -24.8 & -6.9 \\
\hline HR & 5.0 & -4.4 & -2.3 & -1.3 & -19.8 & 5.7 & -4.3 & -10.3 & -4.9 & 2.9 & -3.5 & -5.1 \\
\hline $\mathrm{HU}$ & -6.1 & 0.4 & -1.8 & -12.4 & -4.4 & 0.1 & 7.7 & -4.8 & -4.1 & -1.6 & -6.9 & -3.0 \\
\hline IE & -1.5 & 13.4 & 12.1 & -6.6 & -11.1 & 6.3 & -8.5 & -24.5 & -11.4 & -3.8 & -47.8 & 4.1 \\
\hline IT & -6.0 & -9.9 & -10.9 & -7.6 & -11.8 & 2.4 & 0.0 & -1.4 & -8.8 & -2.7 & -10.7 & -6.7 \\
\hline LT & 19.4 & 2.7 & 2.0 & 4.4 & 1.3 & 0.2 & -21.5 & 20.6 & -10.3 & -0.2 & -10.1 & 0.6 \\
\hline LU & 1.4 & -5.9 & -6.6 & -6.2 & -10.0 & 13.9 & -3.6 & -1.5 & -2.7 & -0.5 & -1.6 & -2.7 \\
\hline LV & 1.3 & -1.4 & 2.6 & 7.5 & -5.0 & -8.9 & -2.3 & 0.7 & 0.6 & 0.8 & -17.0 & -1.2 \\
\hline MT & -10.0 & -11.7 & -0.3 & -7.0 & -33.9 & 15.5 & 3.5 & -10.7 & -10.5 & -0.6 & 4.2 & -8.2 \\
\hline NL & 3.0 & -5.2 & -1.6 & -1.6 & -6.2 & -4.3 & -1.5 & 0.7 & -1.5 & -4.7 & -24.9 & -3.3 \\
\hline PL & -5.8 & 4.4 & 2.9 & -5.6 & -4.6 & -3.6 & -9.9 & 14.6 & -6.1 & 2.5 & -48.1 & -2.9 \\
\hline PT & -7.7 & -10.4 & -5.5 & 2.7 & -8.4 & -1.8 & -2.3 & 6.2 & -9.4 & -2.7 & -19.8 & -4.7 \\
\hline RO & -11.3 & -6.2 & -4.1 & 5.8 & -6.5 & 2.9 & 7.6 & 2.9 & 1.1 & 0.5 & -20.9 & -1.6 \\
\hline SK & -11.5 & -10.8 & -10.2 & -8.1 & 11.0 & -8.7 & -13.1 & -5.1 & -3.6 & 2.0 & -9.2 & -2.9 \\
\hline SI & -1.0 & -7.3 & -2.3 & -1.5 & -9.9 & -3.0 & 8.0 & -2.2 & -4.9 & -2.4 & -19.6 & -4.0 \\
\hline SE & -1.8 & -3.0 & -3.7 & 1.9 & -4.6 & -2.2 & 0.6 & -0.9 & -3.7 & -1.4 & -1.7 & -1.8 \\
\hline EU27 & 0.7 & -4.1 & -5.0 & -5.6 & -9.5 & -1.4 & -0.5 & 0.3 & -6.3 & -2.7 & -15.7 & -4.7 \\
\hline
\end{tabular}

Source: Eurostat, own calculations. 
Appendix - Table 30 / Labour productivity growth rates (based on hours worked) in 2020

\begin{tabular}{|c|c|c|c|c|c|c|c|c|c|c|c|c|}
\hline & A & BDE & C & $\mathbf{F}$ & G-I & $\mathbf{J}$ & K & $\mathbf{L}$ & M_N & $O-Q$ & R-U & Total \\
\hline AT & -7.5 & -3.1 & -1.0 & 2.1 & 1.4 & 8.5 & 6.2 & 8.2 & -1.1 & 5.3 & -2.1 & 2.7 \\
\hline \multicolumn{13}{|l|}{ BE } \\
\hline BG & -3.8 & 0.8 & 0.6 & 4.2 & -2.4 & -4.3 & 3.8 & 2.3 & -5.1 & 5.9 & -9.4 & 0.5 \\
\hline $\mathrm{CY}$ & 1.7 & -10.8 & -2.1 & -2.4 & 0.5 & -0.8 & 0.8 & 8.2 & 0.1 & 0.1 & -4.1 & 1.4 \\
\hline$C Z$ & 6.4 & -4.8 & 0.5 & -2.1 & -1.5 & -1.8 & 3.7 & -0.9 & -1.7 & 1.9 & 1.0 & 0.5 \\
\hline $\mathrm{DE}$ & 4.2 & -4.3 & -4.3 & 3.6 & 1.6 & 0.2 & 3.1 & 4.1 & -1.1 & -2.2 & -2.8 & -0.5 \\
\hline DK & 3.0 & -9.9 & 2.2 & -2.6 & -1.9 & 1.1 & -0.3 & 3.1 & 3.9 & -0.4 & -13.2 & 0.3 \\
\hline ES & 11.2 & -1.7 & -0.2 & -3.2 & -6.3 & -6.8 & 5.4 & 3.2 & -7.2 & 1.0 & -9.2 & -0.2 \\
\hline EE & -3.7 & 1.4 & -0.8 & 8.0 & 5.9 & 11.6 & 18.9 & 18.5 & 4.1 & 0.0 & -6.8 & 3.5 \\
\hline $\mathrm{FI}$ & 1.3 & -5.8 & -0.3 & -1.3 & 1.3 & -1.6 & -0.4 & -3.2 & -4.8 & -2.8 & -6.2 & -0.8 \\
\hline FR & -1.5 & -5.3 & -3.4 & -9.3 & -1.2 & 1.1 & -1.2 & 5.1 & -0.9 & 0.8 & -6.2 & 0.1 \\
\hline EL & 9.6 & -1.9 & 5.4 & 22.1 & -7.3 & 5.6 & -2.9 & 20.1 & -0.5 & 6.1 & -4.6 & 3.5 \\
\hline HR & 1.3 & -4.6 & -1.3 & 4.0 & -21.5 & 19.2 & 6.4 & 8.6 & -6.4 & 3.8 & -9.7 & -4.9 \\
\hline $\mathrm{HU}$ & -2.8 & -0.3 & 4.4 & -9.4 & 0.8 & 1.1 & 9.6 & 3.6 & -0.8 & -1.3 & -0.5 & 0.6 \\
\hline IE & 3.3 & 14.3 & 14.1 & -5.4 & -8.9 & 8.3 & -8.1 & -27.1 & -9.2 & -4.7 & -44.8 & 5.6 \\
\hline IT & -3.4 & -7.4 & 0.3 & 2.9 & 1.1 & 5.9 & 5.8 & 16.4 & 0.6 & 1.2 & -1.5 & 2.7 \\
\hline LT & 19.6 & 6.8 & 5.7 & 9.5 & 7.0 & 1.7 & -16.5 & 15.8 & -4.6 & 3.1 & -2.0 & 5.1 \\
\hline LU & 5.0 & -3.0 & 0.0 & 1.4 & 0.2 & 17.5 & -2.6 & 3.3 & 1.8 & 0.5 & 4.0 & 2.7 \\
\hline LV & 3.5 & -0.9 & 7.1 & 9.7 & -2.0 & -3.7 & 4.4 & 4.7 & 1.9 & 3.7 & -5.8 & 2.2 \\
\hline MT & & & & & -19.0 & & & & & & & 1.6 \\
\hline $\mathrm{NL}$ & 2.4 & -3.1 & 2.4 & 2.7 & -0.7 & -4.3 & -1.4 & 1.4 & -0.9 & -3.0 & -19.9 & -0.5 \\
\hline PL & -5.6 & 5.9 & 3.5 & -3.9 & -3.6 & -3.9 & -9.7 & 15.8 & -4.9 & 2.5 & -47.7 & -2.2 \\
\hline PT & -6.8 & -8.3 & 0.5 & 12.2 & 5.7 & 4.2 & 1.3 & 10.0 & -3.3 & 2.3 & -14.9 & 3.0 \\
\hline RO & -11.1 & -5.8 & -4.1 & 5.8 & -6.6 & 3.0 & 7.7 & 2.5 & 1.1 & 0.5 & -20.6 & -1.8 \\
\hline SK & -8.4 & -7.8 & -3.6 & -1.0 & 22.7 & -6.7 & -7.4 & 0.7 & 4.2 & 7.4 & 1.3 & 4.5 \\
\hline SI & -1.0 & -5.7 & 3.9 & 2.2 & -0.9 & 0.1 & 8.2 & 1.9 & 0.7 & 1.6 & -9.2 & 1.5 \\
\hline \multicolumn{13}{|l|}{ SE } \\
\hline EU27 & 1.0 & -3.0 & -0.1 & -0.6 & -1.3 & 0.9 & 1.7 & 6.1 & -1.6 & -0.5 & -7.5 & 0.3 \\
\hline
\end{tabular}


Wiiw Research Report 457

Appendix - Table 31 / Average annual growth rates of persons employed 2020, in \%

\begin{tabular}{|c|c|c|c|c|c|c|c|c|c|c|c|c|}
\hline & A & BDE & C & $F$ & G-I & $\mathbf{J}$ & $\mathbf{K}$ & L & M_N & $O-Q$ & R-U & Total \\
\hline AT & 1.9 & 0.1 & -1.2 & 0.0 & -5.0 & 2.3 & -0.4 & 4.9 & -2.5 & 0.5 & -3.6 & -1.7 \\
\hline $\mathrm{BE}$ & 0.7 & 1.7 & -0.6 & 0.9 & -1.2 & 0.7 & -1.8 & 1.7 & -0.6 & 1.1 & 0.4 & 0.0 \\
\hline BG & -0.2 & -0.6 & -4.8 & -1.7 & -6.5 & 6.0 & 0.4 & -1.5 & -0.1 & 1.2 & -0.7 & -2.3 \\
\hline$C Y$ & -0.4 & 1.1 & 0.9 & 2.8 & -3.9 & 1.6 & -0.2 & 0.3 & 1.1 & 1.4 & -0.3 & -0.6 \\
\hline$C Z$ & -1.3 & -2.2 & -3.3 & 1.5 & -3.0 & 3.5 & -1.9 & 0.3 & -4.6 & 2.1 & -0.3 & -1.5 \\
\hline DE & -3.2 & 1.0 & -2.5 & 0.8 & -2.1 & 1.3 & -0.8 & -0.2 & -2.4 & 1.5 & -2.3 & -1.0 \\
\hline DK & -0.3 & 1.3 & -2.9 & 1.5 & -2.3 & 1.7 & 2.1 & 0.9 & -0.8 & 0.8 & -3.8 & -0.7 \\
\hline ES & -7.7 & -4.7 & -5.7 & -1.0 & -8.1 & 2.1 & -2.3 & -1.1 & -1.7 & 0.1 & -7.1 & -4.2 \\
\hline EE & -8.7 & -5.4 & -2.5 & 1.6 & -8.5 & -4.0 & -5.8 & -7.7 & -1.5 & 1.3 & 7.0 & -2.7 \\
\hline $\mathrm{FI}$ & -5.2 & 2.0 & -0.2 & -0.7 & -7.2 & 3.1 & 0.0 & 4.2 & 1.5 & 0.1 & -3.8 & -1.5 \\
\hline FR & -0.3 & -0.3 & -1.0 & 1.4 & -1.1 & 0.4 & -0.9 & 0.0 & -3.1 & -0.5 & -2.2 & -1.1 \\
\hline EL & -9.2 & -4.9 & -1.4 & -3.4 & -1.8 & -2.3 & 0.3 & -3.7 & -0.2 & 3.3 & -0.7 & -1.3 \\
\hline HR & -1.3 & 3.9 & -1.3 & 5.5 & -1.5 & -1.7 & 0.0 & 10.9 & -2.0 & -1.7 & -12.2 & -1.2 \\
\hline $\mathrm{HU}$ & -0.8 & -2.4 & -3.6 & 3.5 & -3.9 & 6.0 & -3.9 & -0.4 & -3.3 & -1.9 & -2.7 & -2.2 \\
\hline $\mathrm{IE}$ & -0.1 & -7.7 & 3.2 & -6.5 & -6.3 & 7.5 & 8.1 & 30.3 & -4.6 & 2.8 & -12.7 & -1.5 \\
\hline IT & 0.0 & 0.5 & -0.6 & 1.4 & -4.7 & -0.5 & -2.6 & -1.6 & -1.8 & -0.4 & -4.3 & -2.1 \\
\hline LT & -11.7 & 0.8 & -1.3 & -5.0 & -4.5 & 5.9 & 27.6 & -16.6 & 7.2 & 0.4 & -1.3 & -1.5 \\
\hline LU & -1.1 & 3.3 & -0.9 & 3.6 & 0.4 & 2.8 & 1.7 & 3.8 & 0.6 & 5.1 & 1.4 & 2.0 \\
\hline LV & 0.4 & -0.5 & -3.4 & -4.5 & -4.7 & 2.9 & -3.5 & -1.1 & -2.8 & 0.7 & -4.7 & -2.3 \\
\hline MT & -0.8 & 7.8 & 0.3 & 10.7 & 1.6 & -1.6 & 0.5 & 6.7 & 5.3 & 1.5 & 3.5 & 2.6 \\
\hline NL & -2.0 & 0.0 & -0.4 & 0.8 & -1.5 & 4.1 & 1.9 & 1.3 & -4.9 & 2.5 & 0.5 & -0.6 \\
\hline PL & 3.0 & -4.9 & -2.8 & 2.1 & -1.9 & 6.4 & 2.5 & -11.7 & 5.8 & 0.7 & 6.2 & 0.1 \\
\hline PT & -1.5 & 3.4 & -2.4 & 0.5 & -4.6 & 5.8 & 0.2 & -5.1 & -3.8 & 1.3 & -0.6 & -1.7 \\
\hline RO & -5.6 & 0.7 & -6.0 & 3.9 & 1.5 & 7.3 & -8.3 & -2.5 & -1.7 & 0.3 & -4.4 & -1.8 \\
\hline SK & -3.2 & -2.4 & -4.3 & -0.2 & -2.6 & 1.0 & -2.5 & -0.5 & -0.5 & 0.4 & -3.2 & -1.9 \\
\hline SI & -1.8 & -0.1 & -2.3 & 0.9 & -1.6 & 2.6 & -2.1 & 3.1 & -4.0 & 2.1 & -0.2 & -1.0 \\
\hline SE & 2.8 & 4.1 & -2.2 & -0.8 & -4.0 & 4.8 & 2.2 & 1.4 & -1.4 & -0.7 & -3.2 & -1.3 \\
\hline EU27 & -2.3 & -1.3 & -2.5 & 0.9 & -3.3 & 2.2 & -0.6 & -1.0 & -2.1 & 0.6 & -3.0 & -1.5 \\
\hline
\end{tabular}

Source: Eurostat, own calculations. 
Appendix - Table 32 / Average annual growth rates of hours worked 2020, in \%

\begin{tabular}{|c|c|c|c|c|c|c|c|c|c|c|c|c|}
\hline & A & BDE & C & $\mathbf{F}$ & G-I & $\mathbf{J}$ & $\mathbf{K}$ & L & M_N & $\mathbf{O}-\mathbf{Q}$ & R-U & Total \\
\hline AT & 5.0 & -2.1 & -6.3 & -4.3 & -16.4 & -6.2 & -3.5 & -5.8 & -10.6 & -4.7 & -17.9 & -8.8 \\
\hline \multicolumn{13}{|l|}{$\mathrm{BE}$} \\
\hline$B G$ & -1.6 & -1.9 & -7.5 & -5.0 & -9.7 & 5.2 & -1.3 & -5.6 & -1.6 & 0.0 & -6.9 & -4.7 \\
\hline CY & -2.0 & 0.5 & -4.3 & -4.0 & -15.4 & 2.3 & -1.2 & -6.6 & -2.6 & 0.9 & -5.4 & -6.4 \\
\hline$C Z$ & -1.5 & -3.9 & -7.3 & -1.4 & -10.2 & 3.4 & -6.2 & -2.3 & -7.7 & -0.5 & -13.0 & -5.8 \\
\hline $\mathrm{DE}$ & -4.7 & 0.1 & -6.4 & -0.8 & -7.6 & -1.1 & -3.2 & -4.4 & -7.0 & -0.8 & -8.8 & -4.7 \\
\hline DK & -1.7 & 1.0 & -4.0 & 1.5 & -7.8 & 0.8 & 3.3 & -1.7 & -1.3 & -1.9 & -8.5 & -3.2 \\
\hline ES & -5.3 & -4.3 & -10.6 & -11.7 & -19.2 & -0.9 & -2.0 & -5.1 & -7.0 & 0.5 & -17.3 & -10.4 \\
\hline EE & -10.2 & -4.4 & -6.1 & -1.1 & -12.8 & -3.3 & -8.7 & -19.2 & -9.2 & 1.8 & -1.1 & -6.0 \\
\hline $\mathrm{FI}$ & -3.8 & 4.3 & -2.0 & 0.0 & -9.2 & 4.0 & 0.9 & 4.0 & 1.3 & 0.8 & -5.9 & -2.0 \\
\hline FR & -0.8 & -2.3 & -8.5 & -5.9 & -13.1 & -4.0 & -2.9 & -5.3 & -8.1 & -4.8 & -19.0 & -8.2 \\
\hline EL & -9.1 & -7.4 & -6.4 & -9.6 & -16.7 & -5.3 & -4.9 & -17.2 & -10.2 & -3.5 & -21.8 & -11.2 \\
\hline HR & 2.3 & 4.1 & -2.2 & 0.1 & 0.7 & -12.8 & -10.1 & -8.4 & -0.4 & -2.6 & -6.2 & -1.4 \\
\hline HU & -4.2 & -1.7 & -9.3 & 0.0 & -8.9 & 4.9 & -5.6 & -8.5 & -6.5 & -2.2 & -9.0 & -5.7 \\
\hline $\mathrm{IE}$ & -4.8 & -8.4 & 1.4 & -7.7 & -8.6 & 5.5 & 7.5 & 34.9 & -7.0 & 3.8 & -17.5 & -2.9 \\
\hline IT & -2.6 & -2.2 & -11.7 & -9.0 & -16.9 & -3.7 & -8.0 & -16.7 & -10.9 & -4.1 & -13.2 & -11.0 \\
\hline LT & -11.9 & -3.0 & -4.7 & -9.4 & -9.5 & 4.2 & 19.9 & -13.2 & 0.8 & -2.8 & -9.5 & -5.7 \\
\hline LU & -4.5 & 0.2 & -7.5 & -4.2 & -9.8 & -0.4 & 0.6 & -1.0 & -3.8 & 3.9 & -4.1 & -3.3 \\
\hline LV & -1.6 & -1.0 & -7.5 & -6.4 & -7.6 & -2.6 & -9.7 & -4.9 & -4.0 & -2.1 & -16.0 & -5.6 \\
\hline MT & & & & & -17.2 & & & & & & & -7.3 \\
\hline NL & -1.4 & -2.2 & -4.3 & -3.4 & -7.0 & 4.1 & 1.9 & 0.7 & -5.5 & 0.7 & -5.7 & -3.4 \\
\hline PL & 2.8 & -6.3 & -3.5 & 0.3 & -3.0 & 6.7 & 2.2 & -12.6 & 4.5 & 0.7 & 5.2 & -0.7 \\
\hline PT & -2.5 & 1.1 & -8.2 & -8.0 & -17.3 & -0.3 & -3.4 & -8.5 & -9.9 & -3.6 & -6.4 & -9.2 \\
\hline RO & -5.7 & 0.3 & -6.0 & 4.0 & 1.5 & 7.2 & -8.4 & -2.1 & -1.7 & 0.3 & -4.7 & -1.6 \\
\hline SK & -6.4 & -5.6 & -10.9 & -7.4 & -11.9 & -1.1 & -8.5 & -6.2 & -7.9 & -4.7 & -13.2 & -8.8 \\
\hline SI & -1.8 & -1.8 & -8.1 & -2.7 & -10.5 & -0.5 & -2.3 & -1.1 & -9.4 & -1.9 & -11.7 & -6.3 \\
\hline \multicolumn{13}{|l|}{ SE } \\
\hline EU27 & -2.6 & -2.4 & -7.2 & -4.2 & -11.4 & -0.1 & -2.8 & -6.5 & -6.7 & -1.6 & -11.6 & -6.4 \\
\hline
\end{tabular}


Wiiw Research Report 457

Appendix - Table 33 / Sectoral shares of persons employed 2019, in \%

\begin{tabular}{|c|c|c|c|c|c|c|c|c|c|c|c|}
\hline & A & BDE & C & $F$ & G-I & $\mathbf{J}$ & K & L & M_N & $O-Q$ & R-U \\
\hline AT & 3.3 & 1.3 & 14.6 & 6.8 & 26.6 & 2.8 & 2.7 & 1.4 & 12.3 & 23.6 & 4.5 \\
\hline $\mathrm{BE}$ & 1.2 & 1.1 & 10.4 & 5.9 & 20.8 & 2.6 & 2.4 & 0.6 & 20.1 & 30.6 & 4.3 \\
\hline BG & 16.9 & 2.6 & 17.4 & 5.5 & 25.7 & 3.0 & 1.9 & 0.7 & 7.1 & 15.8 & 3.2 \\
\hline CY & 3.4 & 1.3 & 8.1 & 8.3 & 32.0 & 3.0 & 4.4 & 0.6 & 10.2 & 19.2 & 9.3 \\
\hline$C Z$ & 3.0 & 2.4 & 26.3 & 7.5 & 23.2 & 3.0 & 1.7 & 1.8 & 9.0 & 18.6 & 3.6 \\
\hline DE & 1.3 & 1.3 & 17.1 & 5.6 & 22.7 & 3.0 & 2.4 & 1.1 & 13.7 & 25.0 & 6.7 \\
\hline DK & 2.4 & 0.9 & 10.0 & 6.4 & 26.0 & 3.6 & 2.7 & 1.6 & 11.0 & 30.2 & 5.3 \\
\hline ES & 3.8 & 1.3 & 10.0 & 6.3 & 29.6 & 2.7 & 1.8 & 1.1 & 12.6 & 22.2 & 8.6 \\
\hline EE & 3.1 & 2.0 & 18.2 & 7.7 & 24.7 & 4.9 & 1.8 & 1.8 & 8.3 & 22.3 & 5.2 \\
\hline $\mathrm{FI}$ & 3.3 & 1.3 & 12.8 & 8.0 & 20.1 & 4.2 & 1.7 & 1.0 & 13.3 & 29.1 & 5.2 \\
\hline FR & 2.6 & 1.1 & 9.1 & 6.3 & 23.1 & 3.2 & 2.8 & 1.4 & 15.8 & 29.3 & 5.3 \\
\hline EL & 10.9 & 1.5 & 7.6 & 4.2 & 35.2 & 2.1 & 1.7 & 0.4 & 8.8 & 22.5 & 5.0 \\
\hline HR & 6.2 & 3.1 & 17.5 & 7.5 & 26.7 & 3.4 & 2.4 & 0.4 & 6.9 & 21.9 & 4.2 \\
\hline $\mathrm{HU}$ & 4.0 & 1.9 & 19.0 & 7.6 & 24.0 & 3.3 & 1.9 & 1.7 & 11.2 & 21.0 & 4.6 \\
\hline $\mathrm{IE}$ & 4.5 & 1.1 & 10.0 & 6.9 & 28.1 & 4.0 & 4.1 & 0.6 & 11.1 & 25.6 & 4.0 \\
\hline IT & 3.7 & 1.3 & 15.5 & 6.0 & 26.1 & 2.5 & 2.4 & 0.7 & 12.6 & 18.9 & 10.3 \\
\hline LT & 6.4 & 2.2 & 15.8 & 7.7 & 27.1 & 2.7 & 1.5 & 1.0 & 8.2 & 22.9 & 4.5 \\
\hline LU & 0.8 & 1.1 & 7.1 & 10.3 & 22.6 & 4.5 & 10.8 & 1.0 & 17.1 & 20.7 & 4.1 \\
\hline LV & 7.3 & 2.3 & 13.5 & 7.9 & 27.0 & 4.0 & 1.7 & 2.4 & 8.8 & 20.6 & 4.5 \\
\hline MT & 1.1 & 0.9 & 9.4 & 6.0 & 26.4 & 3.9 & 5.1 & 1.1 & 16.6 & 22.9 & 6.7 \\
\hline NL & 2.1 & 0.7 & 8.4 & 5.2 & 24.9 & 3.3 & 2.2 & 0.8 & 21.7 & 26.4 & 4.4 \\
\hline PL & 9.2 & 3.7 & 20.5 & 7.6 & 22.8 & 2.6 & 2.5 & 1.0 & 6.3 & 20.3 & 3.6 \\
\hline PT & 7.9 & 1.3 & 15.7 & 6.2 & 26.2 & 2.2 & 1.7 & 0.8 & 11.9 & 20.6 & 5.7 \\
\hline RO & 22.2 & 3.1 & 18.3 & 8.3 & 23.1 & 2.0 & 1.3 & 0.4 & 4.7 & 13.6 & 3.0 \\
\hline SK & 3.0 & 2.0 & 22.0 & 7.5 & 26.0 & 3.0 & 1.9 & 1.2 & 10.5 & 19.9 & 3.2 \\
\hline SI & 7.0 & 2.0 & 21.1 & 7.0 & 21.7 & 3.1 & 2.0 & 0.7 & 12.9 & 18.5 & 4.0 \\
\hline SE & 1.9 & 1.3 & 11.1 & 7.6 & 20.1 & 4.0 & 1.8 & 1.7 & 12.1 & 33.6 & 4.7 \\
\hline EU27 & 4.6 & 1.6 & 14.5 & 6.4 & 24.6 & 2.9 & 2.3 & 1.0 & 12.6 & 23.5 & 6.1 \\
\hline
\end{tabular}

Source: Eurostat, own calculations. 
Appendix - Table 34 / Sectoral shares of persons employed 2020, in \%

\begin{tabular}{|c|c|c|c|c|c|c|c|c|c|c|c|}
\hline & A & BDE & C & $F$ & G-I & $\mathbf{J}$ & K & $\mathbf{L}$ & M_N & $O-Q$ & $R-U$ \\
\hline AT & 3.4 & 1.3 & 14.7 & 6.9 & 25.7 & 2.9 & 2.8 & 1.5 & 12.2 & 24.1 & 4.4 \\
\hline $\mathrm{BE}$ & 1.2 & 1.1 & 10.4 & 5.9 & 20.5 & 2.6 & 2.3 & 0.6 & 20.0 & 30.9 & 4.3 \\
\hline BG & 17.3 & 2.7 & 16.9 & 5.6 & 24.6 & 3.3 & 2.0 & 0.8 & 7.3 & 16.4 & 3.3 \\
\hline CY & 3.4 & 1.3 & 8.2 & 8.6 & 30.9 & 3.1 & 4.5 & 0.7 & 10.4 & 19.6 & 9.3 \\
\hline$C Z$ & 3.0 & 2.4 & 25.8 & 7.7 & 22.8 & 3.2 & 1.7 & 1.8 & 8.7 & 19.2 & 3.7 \\
\hline $\mathrm{DE}$ & 1.3 & 1.4 & 16.9 & 5.7 & 22.4 & 3.1 & 2.4 & 1.1 & 13.5 & 25.6 & 6.6 \\
\hline DK & 2.4 & 0.9 & 9.8 & 6.6 & 25.6 & 3.7 & 2.7 & 1.6 & 11.0 & 30.7 & 5.1 \\
\hline ES & 3.7 & 1.3 & 9.8 & 6.5 & 28.4 & 2.8 & 1.8 & 1.1 & 12.9 & 23.2 & 8.3 \\
\hline EE & 2.9 & 1.9 & 18.2 & 8.0 & 23.3 & 4.8 & 1.8 & 1.7 & 8.5 & 23.2 & 5.7 \\
\hline $\mathrm{FI}$ & 3.2 & 1.3 & 13.0 & 8.0 & 18.9 & 4.4 & 1.7 & 1.0 & 13.7 & 29.6 & 5.1 \\
\hline FR & 2.6 & 1.1 & 9.1 & 6.4 & 23.1 & 3.3 & 2.8 & 1.4 & 15.5 & 29.4 & 5.3 \\
\hline EL & 10.0 & 1.5 & 7.6 & 4.1 & 35.1 & 2.1 & 1.8 & 0.4 & 8.9 & 23.6 & 5.0 \\
\hline HR & 6.2 & 3.3 & 17.5 & 8.0 & 26.6 & 3.3 & 2.4 & 0.4 & 6.8 & 21.8 & 3.7 \\
\hline $\mathrm{HU}$ & 4.0 & 1.9 & 18.7 & 8.1 & 23.5 & 3.6 & 1.8 & 1.7 & 11.0 & 21.0 & 4.6 \\
\hline IE & 4.6 & 1.0 & 10.4 & 6.6 & 26.8 & 4.4 & 4.5 & 0.8 & 10.8 & 26.7 & 3.5 \\
\hline IT & 3.8 & 1.3 & 15.7 & 6.2 & 25.4 & 2.5 & 2.4 & 0.7 & 12.6 & 19.2 & 10.0 \\
\hline LT & 5.7 & 2.2 & 15.9 & 7.4 & 26.3 & 2.9 & 1.9 & 0.8 & 9.0 & 23.4 & 4.5 \\
\hline LU & 0.8 & 1.1 & 6.9 & 10.4 & 22.3 & 4.5 & 10.8 & 1.0 & 16.9 & 21.4 & 4.1 \\
\hline LV & 7.5 & 2.4 & 13.3 & 7.7 & 26.3 & 4.2 & 1.7 & 2.5 & 8.8 & 21.2 & 4.3 \\
\hline MT & 1.0 & 1.0 & 9.2 & 6.4 & 26.2 & 3.7 & 5.0 & 1.1 & 17.0 & 22.6 & 6.8 \\
\hline NL & 2.1 & 0.7 & 8.4 & 5.3 & 24.6 & 3.5 & 2.2 & 0.8 & 20.8 & 27.2 & 4.4 \\
\hline PL & 9.5 & 3.5 & 19.9 & 7.8 & 22.3 & 2.8 & 2.5 & 0.9 & 6.7 & 20.4 & 3.8 \\
\hline PT & 7.9 & 1.3 & 15.5 & 6.3 & 25.4 & 2.4 & 1.7 & 0.8 & 11.6 & 21.3 & 5.7 \\
\hline RO & 21.4 & 3.2 & 17.6 & 8.7 & 23.9 & 2.2 & 1.2 & 0.4 & 4.7 & 13.9 & 2.9 \\
\hline SK & 2.9 & 2.0 & 21.5 & 7.6 & 25.8 & 3.1 & 1.9 & 1.2 & 10.6 & 20.4 & 3.1 \\
\hline SI & 6.9 & 2.0 & 20.8 & 7.2 & 21.6 & 3.2 & 2.0 & 0.7 & 12.5 & 19.1 & 4.0 \\
\hline SE & 2.0 & 1.4 & 11.0 & 7.6 & 19.5 & 4.3 & 1.9 & 1.7 & 12.0 & 33.8 & 4.6 \\
\hline EU27 & 4.5 & 1.6 & 14.4 & 6.5 & 24.1 & 3.0 & 2.3 & 1.0 & 12.5 & 24.0 & 6.0 \\
\hline
\end{tabular}

Source: Eurostat, own calculations. 
wiiw Research Report 457

Appendix - Table 35 / Sectoral shares of hours worked 2019, in \%

\begin{tabular}{|c|c|c|c|c|c|c|c|c|c|c|c|}
\hline & A & BDE & C & $\mathbf{F}$ & G-I & $\mathbf{J}$ & K & L & M_N & $O-Q$ & R-U \\
\hline AT & 5.2 & 1.3 & 14.5 & 7.1 & 26.7 & 3.1 & 2.7 & 1.5 & 12.5 & 21.3 & 4.2 \\
\hline $\mathrm{BE}$ & 2.0 & 1.1 & 10.5 & 6.4 & 21.0 & 2.9 & 2.2 & 0.6 & 22.6 & 26.5 & 4.2 \\
\hline BG & 15.2 & 2.7 & 17.8 & 5.9 & 26.6 & 3.1 & 1.9 & 0.7 & 6.9 & 16.1 & 3.2 \\
\hline CY & 5.6 & 1.3 & 8.3 & 8.2 & 32.2 & 3.0 & 4.1 & 0.6 & 10.1 & 16.6 & 10.0 \\
\hline$C Z$ & 3.3 & 2.3 & 25.3 & 8.1 & 24.0 & 3.1 & 1.7 & 2.0 & 8.8 & 17.9 & 3.6 \\
\hline DE & 1.6 & 1.5 & 18.0 & 6.4 & 22.1 & 3.3 & 2.6 & 1.0 & 13.6 & 24.6 & 5.4 \\
\hline DK & 2.4 & 1.0 & 11.0 & 7.4 & 24.0 & 3.9 & 2.8 & 1.6 & 11.6 & 29.5 & 4.6 \\
\hline ES & 4.4 & 1.2 & 10.3 & 7.5 & 31.0 & 2.8 & 1.7 & 1.2 & 12.5 & 19.8 & 7.7 \\
\hline EE & 3.3 & 2.0 & 18.9 & 7.8 & 25.2 & 5.0 & 1.9 & 1.5 & 8.3 & 21.2 & 4.8 \\
\hline $\mathrm{FI}$ & 4.3 & 1.3 & 12.5 & 9.8 & 20.6 & 4.2 & 1.7 & 1.0 & 12.0 & 27.6 & 4.9 \\
\hline FR & 3.9 & 1.1 & 9.4 & 7.2 & 23.9 & 3.5 & 2.9 & 1.4 & 16.2 & 25.7 & 4.9 \\
\hline EL & 11.5 & 1.5 & 7.8 & 4.1 & 37.6 & 2.0 & 1.9 & 0.4 & 8.9 & 19.4 & 4.7 \\
\hline HR & 6.5 & 3.1 & 17.5 & 8.0 & 27.3 & 3.5 & 2.2 & 0.3 & 6.9 & 20.7 & 4.0 \\
\hline $\mathrm{HU}$ & 5.8 & 1.9 & 18.9 & 7.7 & 23.4 & 3.4 & 1.8 & 1.6 & 10.9 & 20.4 & 4.4 \\
\hline $\mathrm{IE}$ & 6.4 & 1.2 & 11.3 & 7.9 & 26.4 & 4.4 & 4.2 & 0.5 & 11.4 & 22.8 & 3.5 \\
\hline IT & 5.6 & 1.3 & 15.7 & 6.5 & 27.8 & 2.6 & 2.5 & 0.9 & 12.3 & 15.3 & 9.4 \\
\hline LT & 6.8 & 2.2 & 16.3 & 8.1 & 27.7 & 2.7 & 1.5 & 0.9 & 8.1 & 21.6 & 4.1 \\
\hline LU & 0.4 & 1.1 & 7.5 & 11.4 & 22.8 & 4.8 & 10.9 & 1.0 & 16.8 & 19.3 & 4.1 \\
\hline LV & 8.1 & 2.4 & 13.8 & 8.0 & 27.1 & 4.1 & 1.6 & 2.4 & 8.8 & 19.7 & 4.1 \\
\hline MT & & 1.0 & 10.2 & 6.6 & 31.5 & & & & 19.0 & 22.8 & 8.9 \\
\hline NL & 2.9 & 0.9 & 9.6 & 6.7 & 23.9 & 3.9 & 2.4 & 0.8 & 20.7 & 23.4 & 4.7 \\
\hline PL & 9.4 & 3.7 & 20.8 & 8.1 & 23.1 & 2.6 & 2.4 & 0.9 & 6.2 & 19.5 & 3.3 \\
\hline PT & 6.3 & 1.2 & 14.9 & 6.4 & 27.9 & 2.3 & 1.7 & 1.3 & 12.3 & 20.3 & 5.3 \\
\hline RO & 18.1 & 3.3 & 19.1 & 9.0 & 24.7 & 2.1 & 1.3 & 0.4 & 5.0 & 13.9 & 3.1 \\
\hline SK & 3.2 & 2.0 & 21.8 & 8.5 & 26.4 & 3.1 & 1.9 & 1.1 & 10.6 & 18.3 & 3.1 \\
\hline SI & 8.8 & 2.0 & 20.8 & 6.9 & 21.1 & 3.1 & 1.9 & 0.6 & 12.6 & 18.2 & 3.8 \\
\hline SE & 2.6 & 1.4 & 11.6 & 7.8 & 21.0 & 3.9 & 1.6 & 1.8 & 11.1 & 32.6 & 4.4 \\
\hline EU27 & 5.4 & 1.7 & 15.0 & 7.1 & 25.3 & 3.1 & 2.3 & 1.1 & 12.2 & 21.3 & 5.4 \\
\hline
\end{tabular}

Source: Eurostat, own calculations. 
Appendix - Table 36 / Sectoral shares of hours worked 2020, in \%

\begin{tabular}{|c|c|c|c|c|c|c|c|c|c|c|c|}
\hline & A & BDE & C & $\mathbf{F}$ & G-I & $\mathbf{J}$ & K & L & M_N & $O-Q$ & $R-U$ \\
\hline AT & 5.9 & 1.4 & 14.9 & 7.4 & 24.5 & 3.2 & 2.8 & 1.6 & 12.2 & 22.3 & 3.8 \\
\hline \multicolumn{12}{|l|}{$\mathrm{BE}$} \\
\hline BG & 15.7 & 2.7 & 17.3 & 5.8 & 25.2 & 3.4 & 2.0 & 0.7 & 7.1 & 16.9 & 3.1 \\
\hline CY & 5.8 & 1.4 & 8.5 & 8.5 & 29.2 & 3.3 & 4.4 & 0.6 & 10.5 & 17.9 & 10.1 \\
\hline $\mathrm{CZ}$ & 3.4 & 2.3 & 24.9 & 8.5 & 22.9 & 3.4 & 1.7 & 2.0 & 8.6 & 18.9 & 3.4 \\
\hline $\mathrm{DE}$ & 1.6 & 1.5 & 17.6 & 6.7 & 21.4 & 3.5 & 2.6 & 1.0 & 13.3 & 25.6 & 5.1 \\
\hline DK & 2.5 & 1.0 & 11.0 & 7.8 & 22.9 & 4.1 & 3.0 & 1.7 & 11.8 & 29.9 & 4.4 \\
\hline ES & 4.6 & 1.3 & 10.3 & 7.4 & 27.9 & 3.1 & 1.9 & 1.3 & 13.0 & 22.2 & 7.1 \\
\hline EE & 3.2 & 2.1 & 18.9 & 8.2 & 23.4 & 5.1 & 1.8 & 1.3 & 8.0 & 22.9 & 5.1 \\
\hline $\mathrm{FI}$ & 4.2 & 1.4 & 12.5 & 10.0 & 19.1 & 4.5 & 1.7 & 1.1 & 12.4 & 28.4 & 4.7 \\
\hline FR & 4.2 & 1.2 & 9.3 & 7.4 & 22.6 & 3.7 & 3.0 & 1.4 & 16.2 & 26.7 & 4.3 \\
\hline EL & 11.8 & 1.5 & 8.3 & 4.2 & 35.3 & 2.2 & 2.0 & 0.4 & 9.0 & 21.1 & 4.2 \\
\hline HR & 6.7 & 3.3 & 17.4 & 8.2 & 27.9 & 3.1 & 2.0 & 0.3 & 7.0 & 20.4 & 3.8 \\
\hline HU & 5.9 & 1.9 & 18.1 & 8.1 & 22.6 & 3.8 & 1.8 & 1.6 & 10.8 & 21.2 & 4.2 \\
\hline IE & 6.3 & 1.2 & 11.8 & 7.5 & 24.8 & 4.8 & 4.7 & 0.7 & 10.9 & 24.4 & 3.0 \\
\hline IT & 6.2 & 1.5 & 15.6 & 6.6 & 26.0 & 2.8 & 2.6 & 0.8 & 12.3 & 16.5 & 9.1 \\
\hline LT & 6.4 & 2.3 & 16.5 & 7.7 & 26.5 & 3.0 & 1.9 & 0.9 & 8.7 & 22.2 & 3.9 \\
\hline LU & 0.4 & 1.1 & 7.2 & 11.3 & 21.3 & 4.9 & 11.3 & 1.0 & 16.8 & 20.7 & 4.1 \\
\hline LV & 8.4 & 2.5 & 13.6 & 7.9 & 26.5 & 4.2 & 1.6 & 2.4 & 8.9 & 20.4 & 3.6 \\
\hline MT & & & & & 100.0 & & & & & & \\
\hline $\mathrm{NL}$ & 3.0 & 0.9 & 9.5 & 6.7 & 23.0 & 4.2 & 2.5 & 0.9 & 20.3 & 24.4 & 4.6 \\
\hline PL & 9.7 & 3.5 & 20.2 & 8.2 & 22.6 & 2.8 & 2.5 & 0.8 & 6.5 & 19.7 & 3.5 \\
\hline PT & 6.8 & 1.3 & 15.1 & 6.5 & 25.4 & 2.5 & 1.8 & 1.3 & 12.3 & 21.6 & 5.5 \\
\hline RO & 17.3 & 3.4 & 18.3 & 9.5 & 25.5 & 2.3 & 1.2 & 0.4 & 5.0 & 14.2 & 3.0 \\
\hline SK & 3.3 & 2.0 & 21.3 & 8.6 & 25.5 & 3.3 & 1.9 & 1.2 & 10.8 & 19.1 & 3.0 \\
\hline SI & 9.3 & 2.1 & 20.4 & 7.2 & 20.2 & 3.3 & 2.0 & 0.7 & 12.2 & 19.1 & 3.6 \\
\hline \multicolumn{12}{|l|}{ SE } \\
\hline EU27 & 5.7 & 1.8 & 14.9 & 7.3 & 23.9 & 3.3 & 2.4 & 1.1 & 12.2 & 22.4 & 5.1 \\
\hline
\end{tabular}



IMPRESSUM

Herausgeber, Verleger, Eigentümer und Hersteller:

Verein "Wiener Institut für Internationale Wirtschaftsvergleiche“ (wiiw),

Wien 6, Rahlgasse 3

ZVR-Zahl: 329995655

Postanschrift: A 1060 Wien, Rahlgasse 3, Tel: [+431] 53366 10, Telefax: [+431] 533661050 Internet Homepage: www.wiiw.ac.at

Nachdruck nur auszugsweise und mit genauer Quellenangabe gestattet.

Offenlegung nach $\S 25$ Mediengesetz: Medieninhaber (Verleger): Verein "Wiener Institut für Internationale Wirtschaftsvergleiche", A 1060 Wien, Rahlgasse 3. Vereinszweck: Analyse der wirtschaftlichen Entwicklung der zentral- und osteuropäischen Länder sowie anderer Transformationswirtschaften sowohl mittels empirischer als auch theoretischer Studien und ihre Veröffentlichung; Erbringung von Beratungsleistungen für Regierungs- und Verwaltungsstellen, Firmen und Institutionen. 


\section{wiiw}
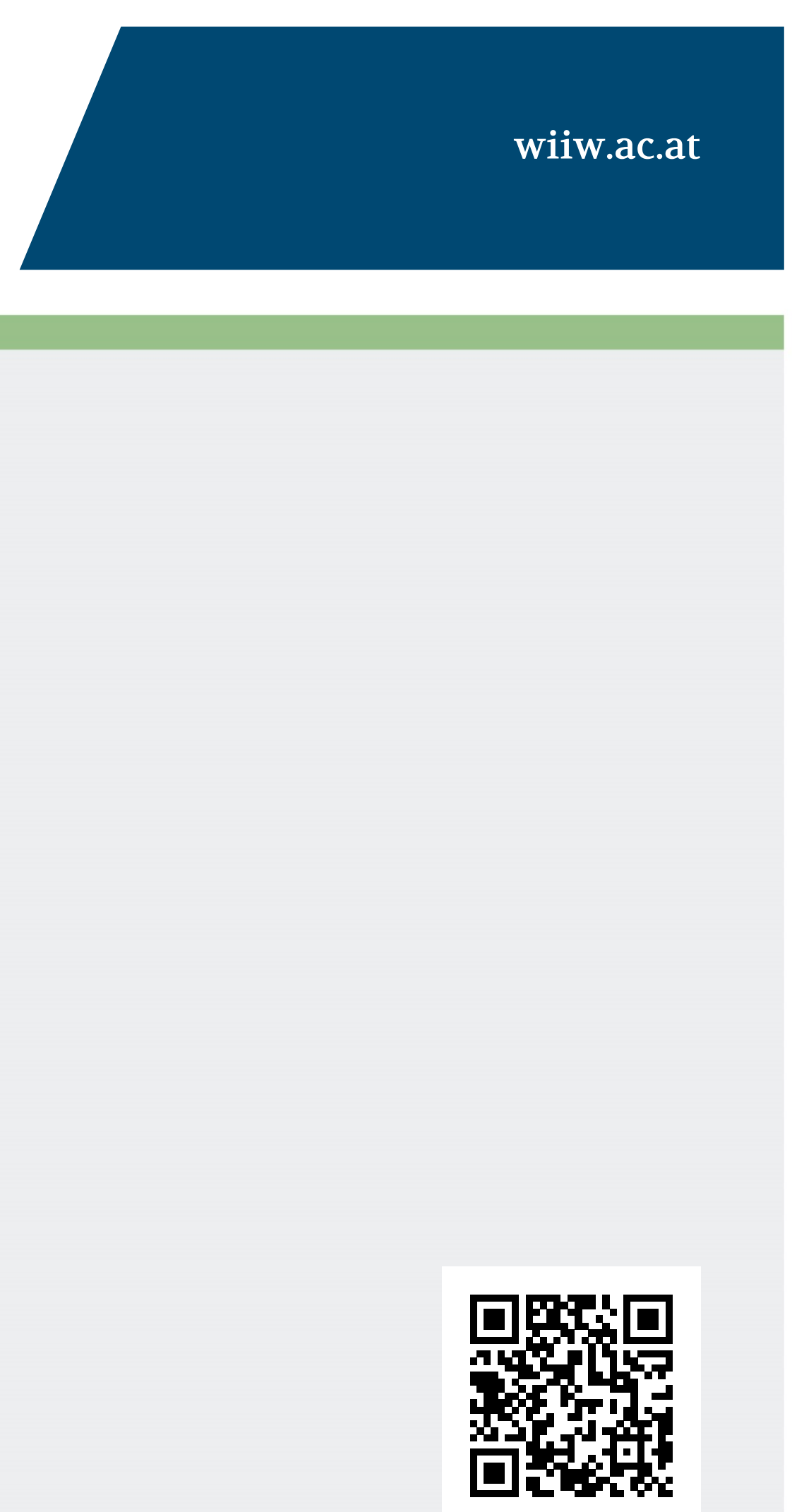

https://wiiw.ac.at/p-5975.html 